\title{
FATORES ASSOCIADOS A PRESBIACUSIA EM IDOSOS
}

\author{
ANDRÉA VIUDE
}

Tese de doutorado apresentada ao Departamento de Epidemiologia da Faculdade de Saúde Pública da Universidade de São Paulo para obtenção do Título de Doutor.

Área de concentração: Epidemiologia

ORIENTADORA: Profa. Associada Maria do Rosário Dias de Oliveira Latorre.

São Paulo 


$$
426121200+(\alpha x)
$$

Autorizo, exclusivamente para fins acadêmicos e científicos, a reprodução total ou parcial desta tese, por processos fotocopiadores.

Assinatura:

Data: 


\title{
EU QUERO TE OUVIR
}

Iêda Pacheco-Russo

Euquerote ouvir,

poistués a história

Viva na memória

Do que hei de sentir.

\author{
Ewquerote ouvir \\ Sorrindo ow chorando, \\ Emoçöes cantando \\ Jamais desistir.
}

Euquerote ouvir,

Pois tua deficiência

Nega tua vivência

Tew jeito de agir

Euquerote ouvir,

Pois teu isolamento

Impede orescimento

Imenso que há de vir.

E assim procedendo,

Valorizo a vida,

Contigo aprendendo

Que não tem guarida

Quem de tuduvida;

Julgando te um velho

Surdoe abandonado,

Quando no tew peito

Bate um coração

Jovem e apaixonado.

In: Ribeiro, JC. (org.) Caleidoscópio 2000. Säopaulo, olhod'Água, 2000. 


\section{AGRADECIMENTOS}

A Profa. Maria do Rosário de Oliveira Latorre pela orientação neste trabalho e por ser capaz de dividir conhecimentos de forma clara e objetiva. A você, Rosário, minha gratidão e admiração.

Ao Prof. Dr. Wilson Jacob Filho pelo apoio e incentivo constantes na realização deste trabalho.

Ao Dr. Sérgio Garbi pela competência exemplar em tudo que realiza e pelo apoio desde a fase de elaboração deste trabalho.

Ao Sr. Ronaldo Soares por me ensinar que a parceria entre pesquisa e apoio privado pode ser ético e meus sinceros agradecimentos pelo apoio logístico na realização dos exames audiométricos.

A equipe do Serviço de Geriatria do Hospital das Clínicas da FMUSP pelo apoio durante a coleta de dados, em especial ao Dr. Omar Jaluul pelo auxilio constante e incondicional, minha gratidão e profunda amizade.

A equipe e funcionários do Serviço de Otorrinolaringologia do Hospital das Clínicas da FMUSP pela acolhida aos pacientes encaminhados para avaliação, 
agradeço a atenção dispensada a cada um deles bem como a minha pessoa em todos os momentos. Agradeço especialmente a Dra Sulene Pirana pela dedicação e carinho, minha profunda gratidão pelas horas dedicadas a esta pesquisa.

Ao Sr. Valdevir Pessoa, da Audibel, que apoiou a realização dos exames audiométricos recebendo com carinho cada um dos idosos encaminhados a sua empresa. Minha gratidão e meu respeito por sua conduta ética na condução dos atendimentos.

As fonoaudiólogas Priscila Pasculli e Juliana Alves Mota, da Audibel, pelo carinho e competência ao receberem os idosos para realização dos exames audiométricos.

Aos meus alunos e estagiários que souberam compreender minha atenção dividida e em especial às fonoaudiólogas Adriana Augusta Di Nardo e Rita de Cássia Frade pelo carinho e apoio.

Ao querido Weverton de Souza Castanho pelo companheirismo e apoio logístico na resolução dos mais variados problemas relacionados à informática, minha profunda gratidão e carinho. 
Aos idosos do GAMIA do Serviço de Geriatria que permitiram a concretização deste trabalho meus sinceros agradecimentos, todo meu respeito e admiração.

A todos os colaboradores diretos e indiretos deste trabalho meus sinceros agradecimentos. 


\section{RESUMO}

Viude, A. Fatores associados a presbiacusia em idosos. São Paulo; 2002. [Tese de Doutorado- Faculdade de Saúde Pública da Universidade de São Paulo].

A presbiacusia caracteriza-se pela perda auditiva em função do processo de envelhecimento. As pessoas com presbiacusia apresentam diminuição da sensibilidade auditiva e redução na inteligibilidade da fala comprometendo a comunicação verbal. O objetivo deste estudo foi descrever os sinais e sintomas auditivos e sua associação com presbiacusia além de determinar os fatores associados à presença de presbiacusia em idosos. Foi conduzido estudo transversal observacional junto aos participantes do Grupo de Atendimento Multidisciplinar ao Idoso Ambulatorial (GAMIA) do Hospital das Clínicas da Faculdade de Medicina da Universidade de São Paulo. Foram aplicados protocolos sócio-demográfico e auditivo, de avaliação clínica em geriatria, de avaliação otorrinolaringológica e de avaliação audiológica. Para avaliar a relação entre a presença de presbiacusia e as variáveis foi feito o teste de associação pelo qui-quadrado e a análise conjunta dos fatores associados por meio da regressão logística múltipla. Participaram deste estudo 85 idosos, com idade entre 61 e 89 anos, sendo 14 homens e 71 mulheres. A presbiacusia esteve presente em $71,8 \%$ dos idosos. Foi encontrada associação estatisticamente significativa entre presbiacusia e ver 
a face com quem conversa e pensou em fazer exame da audição. Dos fatores de risco foi encontrada associação estatisticamente significativa entre presbiacusia e idade na análise univariada e na múltipla. Não foi encontrada associação estatisticamente significativa entre presbiacusia e demais variáveis sócio-demográficas, hábito de beber e tabagismo, presença de outras doenças e exames laboratoriais. A presbiacusia é uma questão de saúde pública com necessidades específicas quanto à promoção de saúde e reabilitação auditiva.

Descritores: Presbiacusia. Audição. Envelhecimento. Epidemiologia. 


\section{SUMMARY}

Viude, A. Fatores associados a presbiacusia em idosos. [Associated factors to presbyacusis in the elderly]. São Paulo; 2002. [Tese de Doutorado - Faculdade de Saúde Pública da Universidade de São Paulo].

Presbyacusis is characterized by the hearing loss due to the aging process. People with presbyacusis present reduction of auditive sensitivity and speech intelligibility, compromising thus, verbal communication. The aim of this study was to describe the signs and auditive symptoms and their association with presbyacusis as well as to determine the associated factors with the presence of presbyacusis in the elderly. A transversal observational study was carried out with participants of the Aged Clinical Multidisciplinary Attendance Group (GAMIA) of the Hospital of the Clinics, School of Medicine, University of Sao Paulo. The people answered socio-demographic and hearing protocols, of clinical evaluation in geriatrics, otolaryngological and audiologic evaluation. The relationship between the presence of presbyacusis and the variables was evaluated using the chi-square test and the adjusted analysis was done using the multiple logistic regression model. 85 elderly participated, ages ranging from 61 to 89,14 men and 71 women. Presbyacusis was present in $71,8 \%$ of the participants. A statistically significant association was found between presbyacusis and looking at the face of the talker and thinking of undergoing hearing exams. In the risk 
factors, a statistically significant association was found between the presbyacusis and the age in the univaried analysis as well as in the multiple one. No statistically significant association was found between presbyacusis and the other socio-demographic variables, habit of drinking and tobacco addiction, presence of others illnesses and laboratory exams. Presbyacusis is a public health matter with specific needs that concerns the promotion of health and hearing rehabilitation.

Descriptors: Presbyacusis. Hearing. Aging. Epidemiology. 


\section{Lista de abreviaturas, siglas e símbolos}

\section{A: altura}

AASI: aparelho de amplificação sonora individual

ant.: anterior

ASHA: American Speech and Hearing Association

EUA: Estados Unidos da América

$\mathrm{dB}$ : decibel

desquit.: desquitado

desv.: desvio

div.: divorciado

Dr.: Doutor

GAMIA: Grupo de Atendimento ao Idoso Ambulatorial

$H$ : homens

HC-FMUSP: Hospital das Clínicas da Faculdade de Medicina da Universidade de São Paulo

HDL: lipoproteína de alta densidade

HgB: hemoglobulina

$\mathrm{Hz}$ : Herts

IMC: Índice de massa corporal

K: potássio

LDL: lipoproteína de baixa densidade

M: mulheres

$\mathrm{mEq} / \mathrm{L}$ : miliequivalente por litro

$\mathrm{mg} / \mathrm{L}$ : miligramas por litro

$\mathrm{mm}^{3}$ : milimetro cúbico

Na: sódio

OD: orelha direita

OE: orelha esquerda

OMS: Organização Mundial de Saúde

ONU: Organização das Nações Unidas

OR: odds ratio

IRF: limiar de reconhecimento de fala

p: nível de significância estatística

P: peso

PAIR: perda auditiva induzida por ruído

Prof.: Professor

sep.: separado

SPSS: Statistical Package for Social Sciences

VLDL: lipoproteína de densidade muito baixa. 


\section{ÍNDICE}

\section{AGRADECIMENTOS}

RESUMO

SUMMARY

Lista de abreviaturas, siglas e símbolos

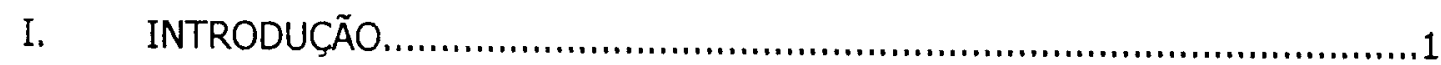

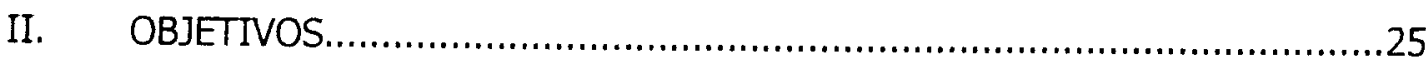

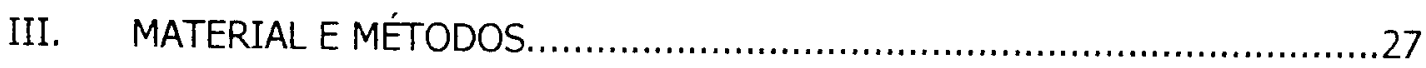

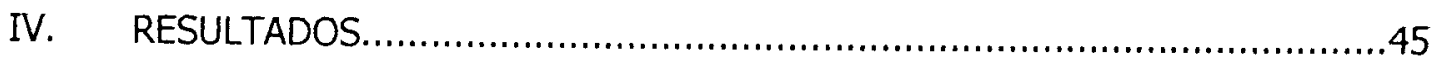

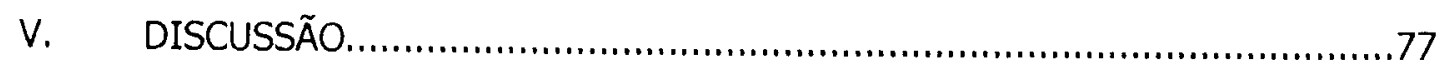

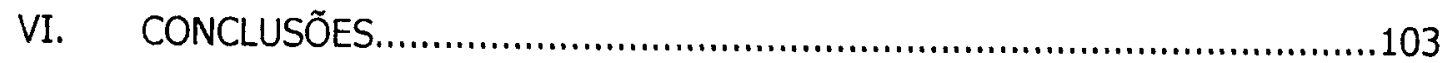

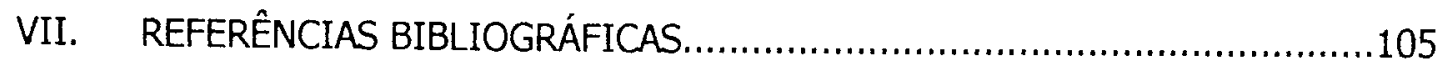

\section{ANEXOS}

Anexo 1: Termo de consentimento livre e esclarecido.............................II

Anexo 2: Protocolo sócio-demográfico e auditivo....................................

Anexo 3: Protocolo de avaliação clínica em Geriatria e de saúde................IX

Anexo 4: Protocolo de pedido de consulta e encaminhamento

do HC-FMUSP........................................................ XII

Anexo 5: Protocolo de avaliação otorrinolaringológica............................XV

Anexo 6: Protocolo de avaliação audiológica.....................................XIX

Anexo 7: Termo de aprovação do Comitê de Ética

em Pesquisa. 


\section{INTRODUÇÃO}

A presbiacusia foi descrita, pela primeira vez, pelo pesquisador H. Zwaademaker em 1891 (LOWELL e PAPARELLA ${ }^{61}$ 1977, ARNESEN ${ }^{6}$ 1982, RUSSO $^{83}$ 1988). Seu estudo consistiu em comparar a audição de tons puros entre crianças e idosos. Os resultados mostraram a dificuldade dos idosos ouvirem tons altos e ele concluiu que a audição para tons altos diminuía com - avançar da idade (JENNINGS e JONES ${ }^{48}$ 2001); mais tarde empregou o termo presbiacusia para se referir a esse tipo de perda auditiva (RUSSO ${ }^{83}$ 1988).

A presbiacusia é uma palavra de origem grega e significa "presby" = velho e "akousis" = audição, significando perda da audição no velho. Zwaademaker empregou tal termo em analogia à presbiopia utilizada muito antes pela oftalmologia $\left(\mathrm{COHN}^{16} 1999\right)$.

Ao se empregar o termo idoso neste momento utiliza-se o limite de idade iniciando aos 60 anos estabelecido pela Organização das Nações Unidas (ONU), em 1980 (OMS ${ }^{74}$ 1989).

O estudo científico da presbiacusia iniciou cerca de 50 anos antes de Zwaademaker descrevê-la, com Toynbee. Ao dissecar ossos temporais em idosos, ele focou seu estudo na orelha média, concluindo que 
a membrana timpânica estava envolvida na perda auditiva (JENNINGS e JONES ${ }^{48}$ 2001).

Com o avançar dos estudos na área de deficiência auditiva em idosos, outros pesquisadores acrescentaram novos conhecimentos a esse vocábulo e presbiacusia passou a agregar, em sua definição, conceitos relacionados à especificidade da perda auditiva (CORSO ${ }^{17}$ 1977, BUTLER e GASTEL $^{11}$ 1979, JERGER, CHMIEL, WILSON E LUCHI ${ }^{47}$ 1995, JENNINGS e JONES ${ }^{48}$ 2001).

O avanço dos estudos decorreu da acurácia diagnóstica em audiologia com a utilização de audiômetros cada vez mais modernos capazes de medir limiares auditivos em diferentes tons puros (JENNINGS e JONES ${ }^{48}$ 2001).

Hoje em dia, a presbiacusia é definida como sendo a perda auditiva para frequêencias altas em função do processo de envelhecimento (CORSO ${ }^{17}$ 1997). As pessoas com presbiacusia apresentam diminuição da sensibilidade auditiva e redução na inteligibilidade da fala, comprometendo a comunicação verbal (BESS, LICHTENSTEIN, LOGAN, BURGER e NELSON ${ }^{9}$ 1989, JERGER, CHMIEL, WILSON E LUCHI ${ }^{47}$ 1995, JENNINGS e JONES ${ }^{48}$ 2001). 
Cabe salientar neste momento que 0 uso da expressão freqüências altas utilizada na descrição de presbiacusia precisa ser explicada.

A audição humana, em um ouvinte normal, encontra-se variando de 20 a $20.000 \mathrm{~Hz}$ (HUMES ${ }^{41}$ 1999), isso quer dizer que abaixo e acima desses limites o ser humano não ouve. Esse limite estabelecido permite sua divisão em baixa, média e alta freqüência. Considerando-se essa faixa de audibilidade normal em um ser humano pode-se dividir, grosso modo, as freqüências como baixa no limite abaixo de $500 \mathrm{~Hz}$, alta freqüência acima de $8000 \mathrm{~Hz}$, sendo as freqüências intermediárias a esses valores consideradas como de média freqüência (HUMES ${ }^{41} 1999$, YANTIS ${ }^{97} 1999$ ).

A avaliação da audição realizada pela audiometria compreende as freqüências entre 250 e $8.000 \mathrm{~Hz}$, testagens acima de $8.000 \mathrm{~Hz}$ são conhecidas como audiometria de alta freqüência e necessitam de equipamento especializado além de calibração com procedimentos específicos a essa testagem (YANTIS ${ }^{97}$ 1999).

Como a audiometria para tons puros realizada freqüentemente varia de 250 a $8.000 \mathrm{~Hz}$ tornou-se habitual o uso de altas freqüências para designar as freqüências acima de $4.000 \mathrm{~Hz}$ e essa designação vem sendo utilizada na literatura quando relacionada à presbiacusia (BERGMAN ${ }^{8} 1971$, GATES $^{28}$ 1999). 
Nesse sentido, quando se lê "perda auditiva em altas freqüências" deve-se compreender que não foi realizada audiometria para altas freqüências, mas utiliza-se nesse momento o termo alta freqüência para designar as freqüências altas testadas dentro de uma audiometria normalmente realizada.

A perda auditiva em altas freqüências implica a diminuição da percepção de sons consonantais (SACIA e BECK ${ }^{85}$ 1926, JERGER, CHMIEL, WILSON E LUCHI ${ }^{47}$ 1995) em especial, em ambientes ruidosos (FRISINA e FRISINA ${ }^{24}$ 1997) gerando respostas inadequadas por parte dos idosos (KATSARKAS e AYUKAWA ${ }^{56}$ 1986). A diminuição da percepção de sons consonantais, consoantes, tem papel importante na diminuição da habilidade do idoso em discriminar a mensagem. A queixa mais comum entre eles é que são capazes de ouvir, mas não entendem o que lhes é dito (JONES, VICTOR e VETTER ${ }^{49} 1984$ RUSSO $^{83} 1988$ ). 
Etiologia

O envelhecimento atinge as orelhas externa, média e interna; contudo, a importância das alterações da orelha interna são decisivas para caracterizar a presbiacusia (CORSO ${ }^{17}$ 1977). A perda da audição para altas freqüências foi identificada como associada às alterações precoces da orelha interna. Além disso, conhece-se o efeito da idade não somente no sistema auditivo periférico como no central (HINCHCLFFE ${ }^{37}$ 1962). Desse modo os componentes centrais da audição encontram-se igualmente envolvidos na fisiopatologia da presbiacusia (GULYA ${ }^{31}$ 1990, STACH, SPRETNJAK e JERGER $^{90} 1990$, FRISINA e FRISINA ${ }^{24}$ 1997).

A presbiacusia é resultante da somatória de fatores genéticos e fatores extrínsecos, que se acumulam ao longo da vida (GILAD e GLORIG ${ }^{29}$ 1979), pode-se dizer que ela é multifatorial (BHATT, LIBERMAN e NADOL ${ }^{10}$ 2001).

A compreensão do envelhecimento na orelha interna e nas estruturas neurais permitiu a classificação dos tipos de presbiacusia por Schuknecht, em 1964, que é utilizada até os dias de hoje. A presbiacusia pode ser classificada em quatro categorias (RUPP ${ }^{82}$ 1970, ARNESEN ${ }^{6} 1982$, RUSSO $^{83} 1988$, COHN $^{16} 1999$, BHATT, LIBERMAN E NADOL ${ }^{10} 2001$ ): 
A presbiacusia sensorial que é caracterizada pela diminuição auditiva abrupta nas freqüências altas. Tal fato deve-se à atrofia do órgão de Corti, na porção basal da cóclea. A perda auditiva nesses casos inicia-se aos 2000 $\mathrm{Hz}$, com quedas variando de $35 \mathrm{a} 40 \mathrm{~dB}$, nas freqüências mais altas; a perda auditiva varia de severa a profunda.

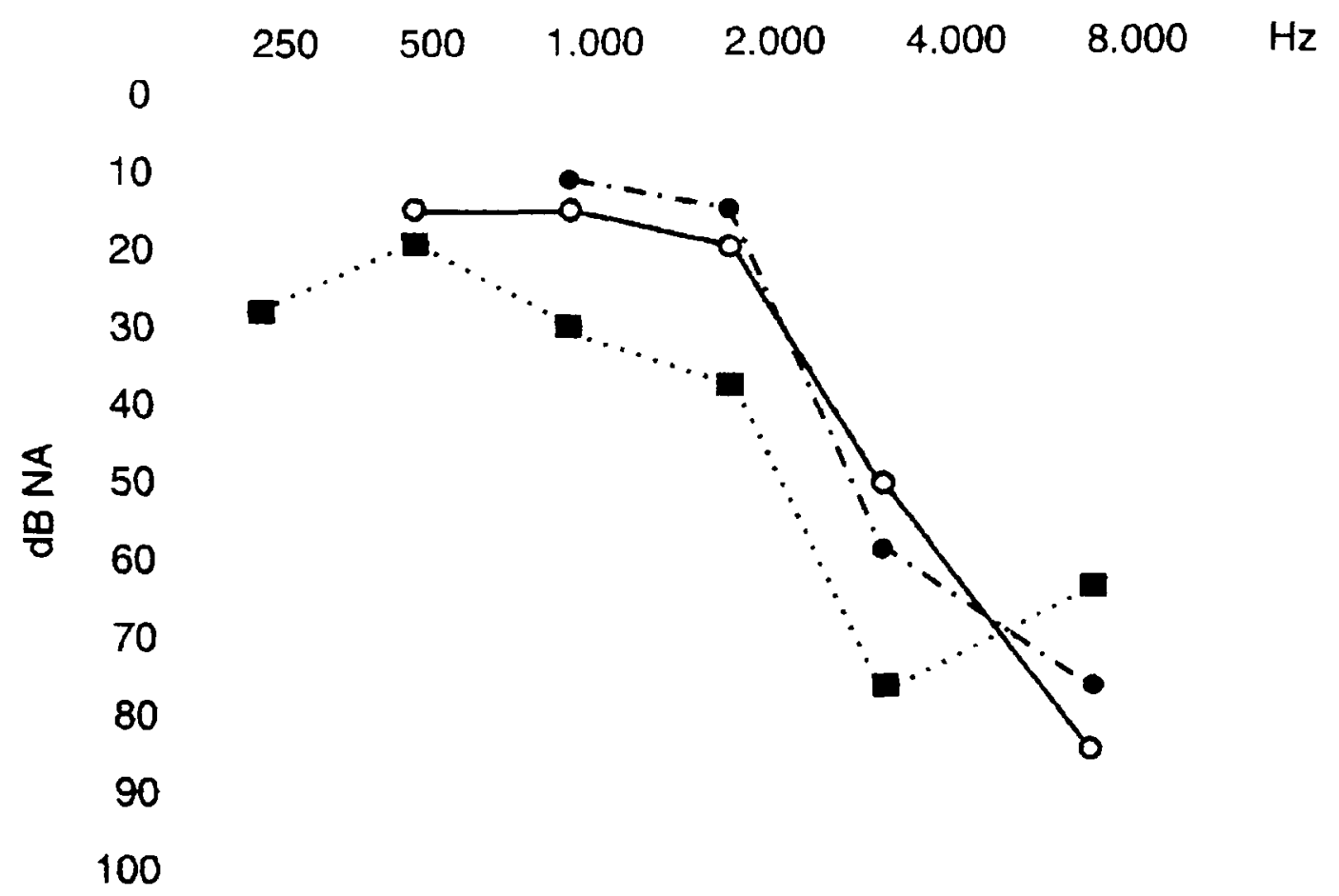

Figura 1. Presbiacusia sensorial segundo Schuknecht. Fonte: RUSSO, I.C.P. Intervenção fonoaudiológica na terceira idade. Rio de Janeiro: Revinter, 1999. 
A presbiacusia neural, caracterizada pela diminuição do reconhecimento de fala e da discriminação auditiva, é decorrente da perda de neurônios cocleares. Nas freqüências baixas, a perda auditiva manifestase de forma leve. As freqüências mais altas apresentam prejuízo auditivo maior, variando de grau severo a profundo.

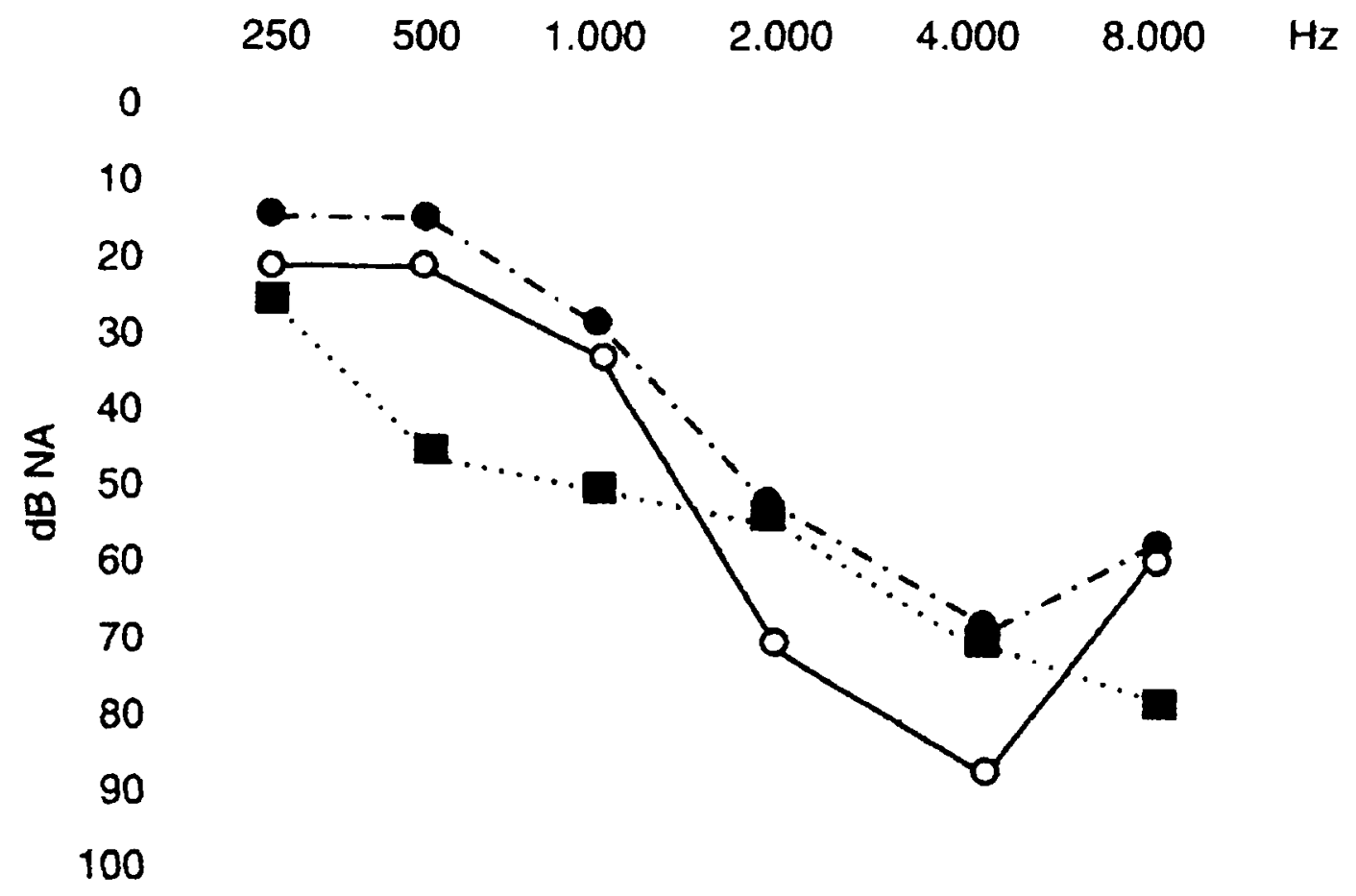

Figura 2. Presbiacusia neural segundo Schuknecht. Fonte: RUSSO, I.C.P. Intervenção fonoaudiológica na terceira idade. Rio de Janeiro: Revinter, 1999. 
A presbiacusia metabólica é marcada pela curva plana na audiometria tonal com boa discriminação auditiva. A perda auditiva nas frequêencias baixas varia de leve a severa e nas freqüências altas a variação é de moderada a profunda. Essas alterações decorrem da degeneração da estria vascular, responsável pela manutenção da função celular na orelha interna.

$\begin{array}{lllllll}250 & 500 & 1.000 & 2.000 & 4.000 & 8.000 & \mathrm{~Hz}\end{array}$

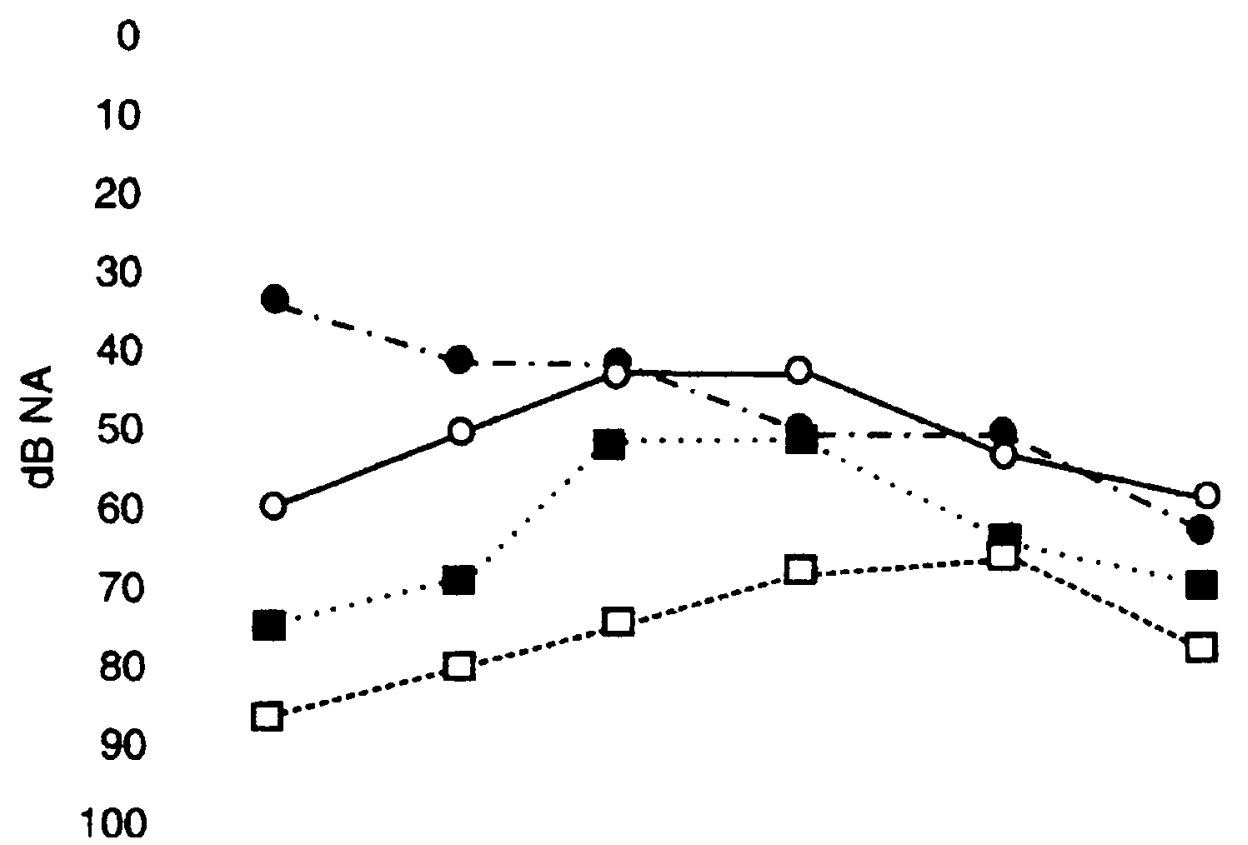

Figura 3. Presbiacusia metabólica segundo Schuknecht. Fonte: RUSSO, I.C.P. Intervenção fonoaudiológica na terceira idade. Rio de Janeiro: Revinter, 1999. 
A presbiacusia mecânica é caracterizada pela configuração audiométrica descendente devido à rigidez da membrana basilar.

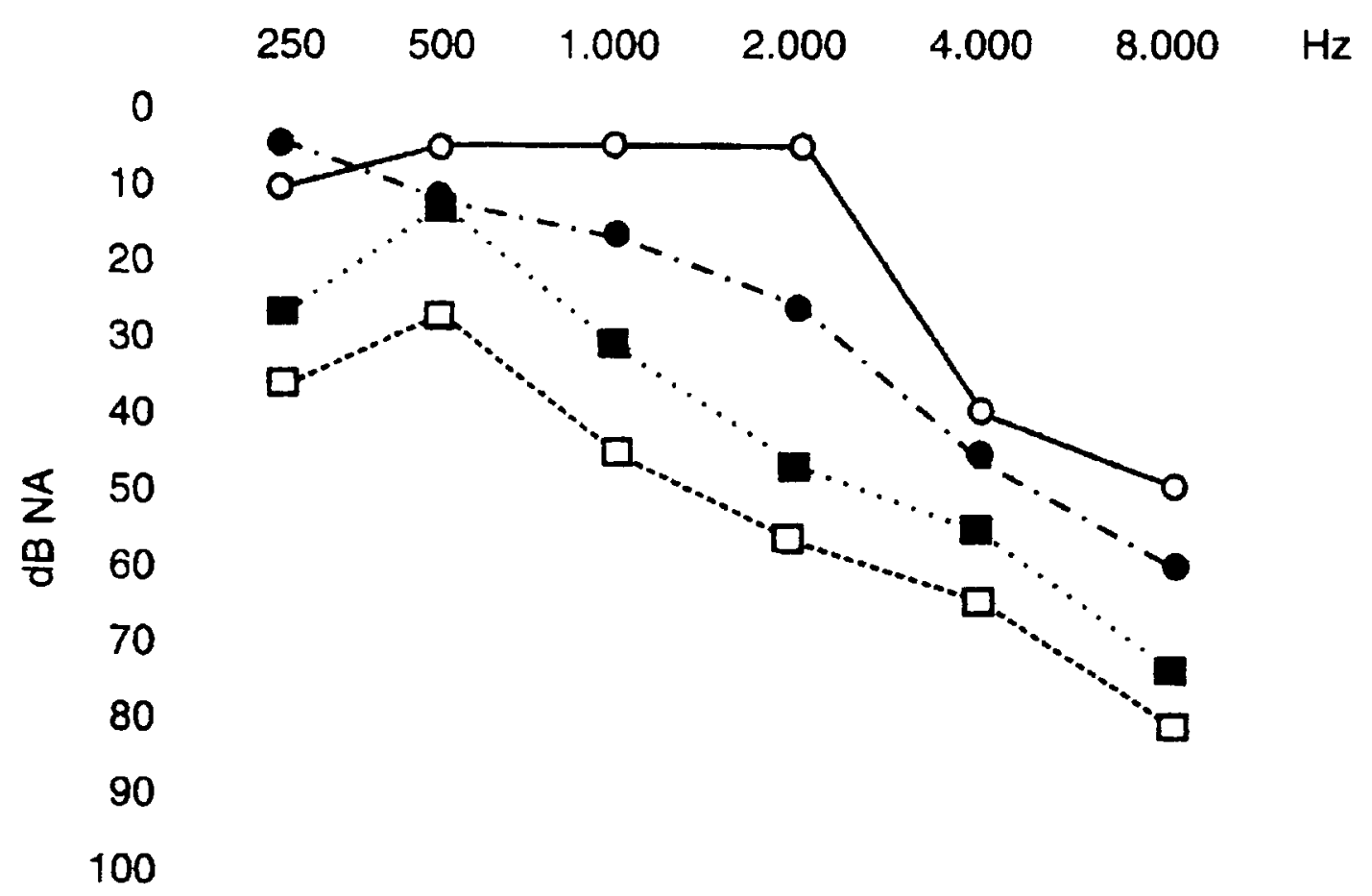

Figura 4. Presbiacusia mecânica segundo Schuknecht. Fonte: RUSSO, I.C.P. Intervenção fonoaudiológica na terceira idade. Rio de Janeiro: Revinter, 1999. 


\section{Diagnóstico}

O início da presbiacusia ocorre na quarta década de vida (SCHUKNECHT ${ }^{87}$ 1955, NICOLA ${ }^{73} 1986$ ) quando o indivíduo está sob o efeito ou ação de uma série de fatores que podem prejudicar a audição ao longo de toda a sua vida. Um desses fatores seria a constante exposição ao ruído que, em alguns casos, pode ser tão prejudicial ao indivíduo que pode levá-lo a um quadro audiológico denominado perda auditiva induzida por ruído (PAIR) (ROP, RABER e FISCHER ${ }^{81} 1979$ ) que pode interferir no diagnóstico de presbiacusia nas idades mais avançadas (WILLOT, CHILSOM e LISTER ${ }^{100}$ 2001).

Para a detecção da presbiacusia faz-se necessária a aplicação de uma anamnese que contemple os fatores associados às diferentes perdas auditivas para que, conjuntamente com o exame audiológico, seja possível chegar à conclusão de presença ou ausência de presbiacusia (HINCHCLIFFE ${ }^{38}$ 1991).

Com o avanço de novas tecnologias em audiologia, o diagnóstico da presbiacusia poderá contar com estudo genético, investigação mais acurada de células, estudos histopatológicos mais precisos, que irão contribuir para elucidar a sua etiologia e conhecer a epidemiologia (HINCHCLIFFE $^{38}$ 1991). 
Muitos fatores têm sido relacionados como contribuidores para a presença de presbiacusia. Entretanto, a maioria dos estudos apresenta problemas na metodologia quanto ao reduzido número de variáveis ou pouco controle das mesmas (JENNINGS e JONES ${ }^{48} 2001$ ).

Atualmente, os estudos epidemiológicos nem sempre diferenciam o tipo de perda auditiva nos adultos e idosos o que pode gerar resultados diferentes quanto à prevalência dessa patologia.

TRATAMENTO

O tratamento da presbiacusia envolve múltiplas ações que, em conjunto, possibilitam a reabilitação auditiva; contudo, não há como recuperar a audição perdida (RUSSO ${ }^{83} 1988$ ).

A reabilitação auditiva significa levar o idoso para a comunicação, tirando-o do isolamento social e funcional (ALBER $\Pi^{2}$ 1977, MADER $\left.^{66} 1984\right)$ e auto imagem negativa gerados pela presbiacusia e, muitas vezes, tirando-o da depressão (KALAYAM ${ }^{53}$ 1995). Cabe ao fonoaudiólogo indicar, programar e aplicar meios e estratégias eficientes para minimizar os efeitos da perda auditiva apresentada pelo idoso (ANDERSON, GREEN e 
MELIN ${ }^{5}$ 1997, LUNDBORG, RISBERG, HOLMQVIST, LINDSTRÖM e SVÄRD ${ }^{63}$ 1982, GOMEZ e MADEY 30 2001).

Uma das estratégias refere-se à indicação e adaptação de aparelhos auditivos conhecidos como Aparelhos de Amplificação Sonora Individual (AASI) (FREDERIKSEN, BLEGVARD e ROJSKAER ${ }^{22}$ 1974). Um dos maiores desafios para o fonoaudiólogo é saber indicar e avaliar o benefício do uso da amplificação para o idoso com presbiacusia, pois o aparelho de amplificação sonora é a base do processo de reabilitação audiológica (BERGER ${ }^{7}$ 1976, RUSSO ${ }^{84}$ 1999).

A adaptação adequada do AASI irá melhorar a função comunicativa do idoso com presbiacusia (HARLESS e MCCONNELL ${ }^{34}$ 1982) e, conseqüentemente, melhorar a sua auto imagem como interlocutor. Contudo, é importante lembrar que esta adaptação dependerá não somente da presbiacusia, mas dos componentes centrais da audição (HAYES e JERGER $^{33}$ 1979) ou seja, dos aspectos cognitivos envolvidos na audição e sua compreensão. Por exemplo, faz-se necessária a presença de atenção para receber o estímulo auditivo e processá-lo corretamente.

Nesse sentido, é importante lembrar em um programa de reabilitação audiológica que tratamento de presbiacusia não significa indicar 
e adaptar o AASI somente. Será necessário para o sucesso do programa envolver os aspectos centrais da audição (BERGMAN ${ }^{8} 1971$, HERBST $^{36}$ 1986).

Ainda nessa linha, enfatiza-se a participação familiar do processo de adaptação do aparelho auditivo (ILER, DANHAUER e MULAC ${ }^{43}$ 1982). Cabe ao fonoaudiólogo que cuida da reabilitação do idoso com presbiacusia trabalhar também a atitude dos idosos e demais profissionais de saúde frente à perda auditiva. Dificilmente o idoso irá procurar ajuda no aspecto auditivo enquanto as atitudes pessoais e profissionais forem negativas em relação à deficiência auditiva (HUMPHREY, HERBST e FAURQI ${ }^{42}$ 1981, JOHNSON E DANHAUER ${ }^{50}$ 1982). O abandono do AASI também tem sido relacionado a essas atitudes negativas, principalmente por parte dos familiares (KAPTEYN ${ }^{54,55} 1977$, ANDERSSON ${ }^{4}$ 1978, ILER, DANHAUER e MULAC $^{43} 1982$, JOHNSON $^{51} 1982$, COHN $\left.^{16} 1999\right)$. 


\section{EPIDEMIOLOGIA}

\section{Prevalência}

Estudo conduzido em Toronto, Canadá, avaliou 563 indivíduos participantes de um programa oferecido pelo Baycrest Centre for Geriatric Care, conhecido como Baycrest Program. Foram avaliados idosos, entre 60 e 99 anos, do hospital para doentes crônicos (cerca de 150 idosos), da residência (cerca de 200 idosos) e do hospital dia (cerca de 200 idosos). Após avaliações com médico otorrinolaringologista e audiológica, foram identificados 348 idosos com perda auditiva. A perda auditiva foi considerada como uma perda superior a $40 \mathrm{~dB}$ nas freqüências de 500, 1000, 2000 e $4000 \mathrm{~Hz}$. A presbiacusia foi considerada em 283 casos $(50,3 \%)$ a causa primária da perda auditiva (ALBERTI ${ }^{2}$ 1977).

Um estudo epidemiológico norte americano sobre a perda auditiva, em pessoas acima de 57 anos de idade, baseado na audiometria, revelou prevalência de $31 \%$ de presbiacusia (MOSCICKI ${ }^{72}$ 1985). Posteriormente, esse estudo foi ampliado utilizando dados do estudo de Framingham, com pessoas entre 60 e 90 anos e foi encontrada prevalência de $29 \%$ de presbiacusia (GATES, COOPER, KANNEL e MILLER ${ }^{27} 1990$ ).

Foi conduzido em Toronto, Canadá, um estudo para determinar a prevalência de presbiacusia em população institucionalizada. Os sujeitos do 
estudo tinham entre 60 a 99 anos, sendo encontrada prevalência de $69 \%$ de presbiacusia, adotando o limiar de $40 \mathrm{~dB}$ nas freqüências de 1000 e $2000 \mathrm{~Hz}$, como limite para identificar a presença de presbiacusia. Os autores não utilizaram o nivel de $25 \mathrm{~dB}$ por acreditaram que já era esperado uma alta severidade de perda auditiva nessa população (CIURLIA-GUY, CASHMAN e LEWSEN ${ }^{15}$ 1993).

Um estudo tentou isolar somente a presbiacusia como fator determinante da perda auditiva e encontrou prevalência de 3,7\% e 3,3\% em populações urbanas e rurais, respectivamente, em Nova Delhi, Índia (KACKER $^{52}$ 1997). Nesse estudo não houve descrição da metodologia empregada e, portanto, não foi possível saber com exatidão o que estes dados refletem.

Um estudo epidemiológico sobre a perda auditiva em adultos e idosos, com idades entre 48 e 92 anos, revelou prevalência de 45,9\%, sendo que nas pessoas acima de 80 anos esse valor era de $89,5 \%$ (CRUICKSHANKS, KLEIN, KLEIN, WILEY, NONDAHL e TWEED ${ }^{18,19}$ 1998). No entanto, os resultados não esclarecem se houve uma distinção entre deficiência auditiva decorrente do processo de envelhecimento e aquela decorrente de outros fatores, uma vez que não foi explicitado se houve questionamento sobre exposição a ruídos e doenças previamente existentes. 
Na região de Veneto, Itália, foi conduzido um estudo com dados obtidos a partir de um questionário de auto avaliação. Foram envolvidos cinco centros rurais (Conselve, Teolo, Contarina, Chioggia e Villorba) e quatro centros urbanos (Mestre, Verona, Vicenza e Belluno). Foram entrevistadas e avaliadas pessoas acima de 65 anos de idade. Foi encontrada a prevalência de $8,1 \%$ de queixa auditiva em homens e $7,4 \%$ de queixas em mulheres. Quando foram comparadas as queixas auditivas com os dados audiométricos, os autores observaram grande diferença nos resultados, pois a avaliação audiológica mostrou $20 \%$ de alterações auditivas. Os autores concluíram que a audiometria é mais sensível para identificar a presbiacusia do que um questionário de auto avaliação (MAGGI, MINICUCI, MARTINI, LANGLOIS, SIVIERO, PAVAN e ENZI ${ }^{67}$ 1998).

Em estudo realizado nas proximidades de Roterdam, Holanda, a avaliação audiométrica aplicada em pessoas acima de 60 anos identificou perda auditiva em $24,3 \%$ dos avaliados. Nesse trabalho os autores definiram a perda auditiva como a média de $40 \mathrm{~dB}$ ou mais, na melhor orelha, para as freqüências de 1, 2 e 4 kHz (VAN DEN BERG ${ }^{94}$ 1999).

Em outro trabalho realizado região de Veneto (excluindo-se uma área urbana), na Itália, foi conduzido estudo com a descrição das características clínicas e epidemiológicas em pessoas acima de 60 anos de idade de ambos os sexos. Os autores observaram que, com a idade, houve 
um declínio nos limiares auditivos, mais evidentes nas freqüências médias e altas. Quanto ao gênero, as mulheres apresentaram, na análise da curva audiométrica, maior perda auditiva em altas freqüências quando comparadas com homens. Os pesquisadores não encontraram diferenças entre aqueles que viviam no campo e nas cidades, não havendo, assim, influência negativa do desenvolvimento tecnológico, este não especificado pelos autores, na audição (MEGIGHIAN, SAVASTANO, SALVADOR, FRIGO e BOLZAN ${ }^{70} 2000$ ).

Um estudo realizado em Sichuan, China, sobre prejuízo auditivo em geral, identificou o aumento da perda auditiva com o avançar da idade. Ao verificar as causas da perda auditiva, a presbiacusia esteve presente em $37,54 \%$ dos casos. Os autores consideraram como casos de presbiacusia as pessoas acima de 55 anos de idade, perda auditiva bilateral simétrica neurosensorial sem causa conhecida e história familiar negativa para perda auditiva (LIU, XU, HU, NANCE, SISMANIS, ZHANG e XU ${ }^{60} 2001$ ).

\section{Fatores de risco}

Estudo conduzido em Toronto, Canadá, ao avaliar 563 idosos entre 60 e 99 anos verificou que a audição nas mulheres era significativamente melhor que nos homens (ALBERT ${ }^{2} 1977$ ). 
Um estudo realizado no Japão descreveu a audição de 1192 indivíduos com idades entre 65 a 85 anos e mais. Os idosos foram divididos em cinco faixas etárias: 65 a 69 anos, 70 a 74 anos, 75 a 79 anos, 80 a 84 anos e 85 anos e mais. A média de perda auditiva foi aumentando a cada faixa etária, iniciando com $35 \mathrm{~dB}$ para a faixa inicial e terminando com 55, 6 $\mathrm{dB}$ na última faixa. A discriminação nos grupos mais jovem foi de $75,4 \%$ caindo para $52,1 \%$ no mais idoso. Nesse estudo não foi encontrada diferença entre homens e mulheres (YAGI 1996 citado por COHN ${ }^{16}$ 1999, p.152).

Há muito tempo, doenças cardiovasculares e hipertensão têm sido relacionadas à presbiacusia (JENNINGS e JONES ${ }^{48}$ 2001). 0 estudo mais conhecido utilizou o Framingham Heart Study Cohort, no qual foi detectado nessa população $83 \%$ de perda auditiva (MOSCICKI, ELKINS, BAUM e MCNAMARA $^{72}$ 1985). Ao realizar a análise multivariada foi possivel verificar que os fatores significativos foram exposição ao ruído, presença de doenças, história familiar de perda auditiva e doença de Menière; porém, o fator com maior significância foi a idade.

Um estudo epidemiológico que atenta para o histórico médico foi conduzido na Inglaterra e concluiu que a maioria do grupo estudado possuía outros fatores, que não somente a idade, como contribuintes para a perda auditiva e que a metade não possuía dados de história médica que pudessem auxiliar no diagnóstico do tipo de perda auditiva. Os autores 
alertaram para o fato de que sem investigação adequada, por eles considerada como anamnese detalhada, não é possível diagnosticar a presbiacusia com precisão (LIM e STEPHENS ${ }^{59} 1991$ ).

Outro estudo que analisou pessoas acima de 50 anos revelou que somente $50 \%$ das audiometrias podiam revelar a presença de presbiacusia segundo os tipos histopatológicos. Dessa forma, o estudo discutiu que a outra metade das pessoas diagnosticas com presbiacusia possuíam mais de um processo degenerativo associado à perda auditiva, segundo os autores esse fato estaria associado a combinação de processos histopatológicos relacionados ao envelhecimento (KATSARKAS e AYUKAWA ${ }^{56}$ 1986).

Um estudo transversal observacional com adultos entre 48 e 92 anos revelou a associação entre fumantes ativos e perda auditiva, ajustada por idade e sexo. O mesmo estudo revelou que os fumantes passivos apresentavam risco de perda auditiva maior do que os não fumantes, indicando a importância não somente de um hábito de vida, mas também de um fator ambiental envolvido na perda auditiva (CRUICKSHANKS, KLEIN, KLEIN, WILEY, NONDAHL E TWEED ${ }^{18,19} 1998$ ).

Além da presença do hábito de fumar foram estudados fatores como abuso de álcool, traumatismo craniano e uso de medicamentos em 
população acima de 70 anos na Suécia. Houve associação entre perda auditiva e hábito de fumar, abuso de álcool e traumatismo craniano entre os homens. Já entre as mulheres houve a associação da perda auditiva com o uso de medicamentos (ROSENHALL, SIXT, SUNDH e SVANBORG ${ }^{80} 1993$ ).

Fatores sócio-econômicos e estado de saúde foram estudados em duas coortes, uma com pessoas abaixo de 70 anos e outra com pessoas entre 70 e 88 anos, ambas na Suécia. Os resultados apontaram para a presença de perda auditiva maior entre os grupos com baixo poder aquisitivo e baixa escolaridade. A presença de perda auditiva também esteve associada à presença de doença e entre os que morreram nos primeiros anos de estudo encontravam-se as pessoas com maior prejuízo auditivo (SIXT e ROSENHALL ${ }^{89}$ 1997).

Um estudo utilizando-se do Framingham Heart Study avaliou a audição em 1475 indivíduos, entre 58 a 95 anos, procurando a relação entre perda auditiva e história familiar. A história familiar de perda auditiva esteve mais associada às mulheres do que aos homens (GATES, COBB, D'AGOSTINO e WOLF ${ }^{26}$ 1993). Mais tarde esse estudo foi ampliado para 2293 participantes do Framingham Heart Study e foi verificado que fatores genéticos têm mais efeito na presbiacusia em mulheres do que em homens (GATES, COUROPMITREE E MYERS ${ }^{28} 1999$ ). 
Em estudo conduzido em Wisconsin, EUA, foi verificada a associação entre diabetes e perda auditiva. Foi considerada a perda auditiva acima de $25 \mathrm{~dB}$ e foi utilizado um grupo de estudo populacional, 3571 indivíduos com idade entre 48 a 92 anos. A perda auditiva foi mais freqüente nos diabéticos do que nos não diabéticos. Porém, quando ajustado pela idade esse dado perdeu a significância estatística (DALTON, CRUICKSHANKS, KLEIN, KLEIN e WILEY20 1998).

A hipercolesterolemia foi estudada e associada a presbiacusia, assim como a arterosclerose há algum tempo (DEL GUIDICE ${ }^{21} 1960$ ). Mais recentemente um estudo com 217 idosos, com idade entre 60 a 82 anos, analisou 27 medidas obtidas de exame hematológico. Foram analisados cálcio, potássio, cloro, sódio, creatinina, hematócritos, colesterol total e fracionado, entre outros exames. Foi verificado que os exames não eram preditivos de alteração em média de tons puros no exame audiológico, com exceção no exame de colesterol para mulheres, no qual a diferença entre mulheres com a razão entre LDL/HDL alta apresentou $5 \mathrm{~dB}$ acima das que possuíam essa razão baixa. Nos homens essa diferença foi de $1 \mathrm{~dB}$. Os autores concluíram que esses exames, quando dentro do limite de normalidade, podem ter pouco valor preditivo de limiares auditivos em idosos (LEE, MATHEWS, MILLS, DUBNO e ADKINS ${ }^{58}$ 1998). 
Conhecendo-se os fatores de risco para a presbiacusia podem ser elaboradas estratégias de promoção de saúde auditiva e aplicá-las junto à população que está envelhecendo, ou seja, oferecer a toda a comunidade medidas de prevenção.

Após leitura de alguns estudos epidemiológicos pode-se verificar que nem sempre há diferenciação quanto ao tipo de perda auditiva nos adultos e idosos o que pode gerar resultados diferentes quanto à prevalência da doença.

O conhecimento da prevalência poderá auxiliar a alocação de recursos quanto à reabilitação audiológica.

A presbiacusia não possui tratamento específico que reverta a perda auditiva; no entanto, existem programas de reabilitação (RUSSO ${ }^{83}$ 1988, RUSSO ${ }^{84}$ 1999) que podem minimizar o impacto dessa perda. A reabilitação poderá ser feita após conhecimento do impacto da presbiacusia na vida do indivíduo. Pode ser indicado o uso de aparelho de amplificação sonora individual (RUSSO ${ }^{83} 1988$ ) que permitirá a melhora na recepção do sinal de fala (ALMEIDA e RUSSO ${ }^{3}$ 1996) propiciando melhor compreensão do que é ouvido e promovendo a integração social. 
A perda auditiva em adultos acarreta alterações na habilidade comunicativa e pode levar a quadros de depressão e isolamento social (KRICOS e LESNER $^{57}$ 1995) A diminuição da acuidade auditiva e a reduzida sensibilidade nos limiares da fala prejudicam a inteligibilidade e criam situações muitas vezes embaraçosas, nas quais a compreensão de fala encontra-se prejudicada. Nesse sentido, pode-se compreender o porquê das frustrações frente aos problemas gerados pela presbiacusia levarem os indivíduos muito além dos problemas auditivos (RUSSO $\left.{ }^{84} 1999\right)$.

A família e os amigos percebem a incapacidade auditiva; porém, muitas vezes não sabem como lidar com ela. Situações de tensão são criadas frente às dificuldades de comunicação e, na medida em que soluções não são vislumbradas, o contato social e o confronto são evitados (BESS, LCHTENSTEIN, LOGAN, BURGER E NELSON ${ }^{9}$ 1989).

Não obstante a isso, o idoso com presbiacusia depara-se com suas dificuldades pessoais ao enfrentar a limitação auditiva. $E$, na ignorância do que está ocorrendo, acaba voltando-se para si mesmo, facilitando o quadro de isolamento e a conseqüente depressão.

Na medida em que nossa sociedade depara-se com o aumento da expectativa de vida (RAMOS, VERAS e KALACHE ${ }^{78}$ 1987) decorrente tanto da transição demográfica quanto da transição epidemiológica $\left(\operatorname{SEADE}^{88} 1990\right.$, 
SCHOURE JUNIOR, RAMOS e PAPALÉO NETO ${ }^{86} 1994$, PASCHOAL $^{76}$ 1996) passa a viver a possibilidade do aumento de prevalência de presbiacusia, assim como de outras doenças crônico-degenerativas.

Em nosso meio ainda não existem estudos epidemiológicos que contemplem a presbiacusia, não pela ausência de importância do tema, mas possivelmente pelas dificuldades metodológicas envolvidas e infelizmente pelo desconhecimento do que pode ser feito pelo indivíduo com presbiacusia.

Nesse sentido, este estudo epidemiológico pretende analisar a presbiacusia, sendo o primeiro estudo desta natureza realizado no Brasil. 


\section{II . OBJETIVOS}

\section{I. OBJETIVO GERAL}

Determinar a prevalência de presbiacusia, bem como identificar os fatores associados à ela em uma população idosa com atendimento ambulatorial.

\section{II. OBJETIVOS ESPECÍFICOS}

1. Descrever as características da audição, indicação e realização de audiometria, dificuldades, sinais e sintomas relacionados à audição, antecedentes mórbidos e exame físico de uma população idosa com atendimento ambulatorial.

2. Estimar a prevalência de presbiacusia em uma população idosa com atendimento ambulatorial.

3. Verificar a associação entre a presença de presbiacusia e a presença de sinais e sintomas auditivos.

4. Verificar a associação entre a necessidade referida de fazer exame auditivo e a presença de sinais e sintomas auditivos.

5. Verificar se existe associação entre a presença de presbiacusia e variáveis sócio-demográficas (idade, sexo, cor, estado marital, escolaridade, ocupação e renda). 
6. Verificar se existe associação entre a presença de presbiacusia e hábito de beber e tabagismo.

7. Verificar se existe associação entre a presença de presbiacusia e presença de outras doenças (hipertensão, diabete, arterosclerose).

8. Verificar se existe associação entre a presença de presbiacusia e exames laboratoriais ( $\mathrm{Na}, \mathrm{K}$, uréia, colesterol, glicose).

9. Verificar se existe associação entre a presença de presbiacusia e a história familiar de problemas auditivos. 


\section{MATERIAL E MÉTODOS}

Este foi um estudo eminentemente interdisciplinar, realizado por uma fonoaudióloga e envolvendo:

- Departamento de Epidemiologia da Faculdade de Saúde Pública, por intermédio da Coordenadora da pesquisa, Profa. Associada Maria do Rosário Dias de Oliveira Latorre;

- Serviço de Geriatria do Hospital das Clínicas da Faculdade de Medicina da Universidade de São Paulo (HC - FMUSP), sob a direção do Prof. Dr. Wilson Jacob Filho;

- Serviço de Otorrinolaringologia do HC - FMUSP, sob chefia do Prof. Dr. Aroldo Miniti, Professor Titular da Disciplina de Otorrinolaringologia e do Prof. Dr. Ricardo Ferreira Bento, Prof. Associado da Disciplina de Otorrinolaringologia da FMUSP e Coordenador de pós-graduação da área de Otorrinolaringologia. 0 responsável pela área de otorrinolaringologia neste estudo foi o $\mathrm{Dr}$. Sérgio Garbi, Diretor Técnico de Serviço de Saúde HC-FMUSP e Médico Chefe do Ambulatório da Clínica de Otorrinolaringologia do HC - FMUSP. 


\section{III.I. Delineamento do estudo}

Este é um estudo transversal observacional.

\section{III.II População de estudo}

Foram convidados a participar deste estudo todos os clientes do Grupo de Atendimento ao Idoso Ambulatorial (GAMIA) localizados por telefone.

O GAMIA é um programa de atendimento implantado em 1984 no Ambulatório de Geriatria do HC - FMUSP. Com o objetivo de "otimizar o período em que o cliente fica dentro da instituição" (JACOB FILHO ${ }^{45}$ 1991) o GAMIA oferece ao idoso atendimento centralizado em tempo e espaço, enquanto propicia aos profissionais maior integração, gerando uniformização de conhecimento sobre o idoso. 
Os critérios de inclusão para os participantes ingressarem no GAMIA são (JACOB FILHO ${ }^{45}$ 1991):

- idade igual ou superior a 60 anos;

- capacidade de locomoção independente de outrem;

- capacidade de comunicação que permita atividade em grupo e

- interesse em participar deste trabalho.

A cada início de ano é formado um grupo de 30 idosos e as atividades oferecidas ao grupo ocorrem ao longo de um dia na semana e envolvem as seguintes especialidades: serviço social, enfermagem, medicina, fisioterapia, psicologia, fonoaudiologia, terapia ocupacional, odontologia e nutrição. Ao final de um ano de atividades, o idoso passa a ser acompanhado pela equipe médica, de forma sistemática e participa de atividades semanais compostas por palestras informativas com duração de duas horas, sem necessidade de participação obrigatória. Esse acompanhamento denomina-se pós GAMIA.

Das 378 fichas do arquivo do GAMIA referente ao período de 1994 a 2001, foram localizados por telefone 110 participantes, entre 20 de outubro de 2000 a 10 de dezembro de 2001. A não localização ocorreu por conta de números de telefones que foram alterados (22 casos confirmados), 
telefones que não eram atendidos (10 casos, foram feitas três tentativas de contato telefônico em diferentes dias), telefones fora de serviço ou inexistentes (236 casos).

Entre os 110 idosos localizados por telefone foi verificado que: três mudaram de estado federativo, oito encontravam-se doentes e/ou impossibilitados de saírem de casa segundo seus filhos, três morreram e um não aceitou participar referindo não acompanhar mais as atividades do pós GAMIA. Desse modo foram identificados 95 idosos que aceitaram iniciar a pesquisa, sendo que completaram-na 85 idosos $(77,3 \%$ dos idosos localizados). 


\section{III.III Metodologia}

Os participantes foram convocados, por telefone, para uma consulta no Ambulatório de Geriatria e consultados sobre 0 interesse em participarem do estudo. Os idosos que aceitaram participar, ao comparecerem para a consulta agendada, assinaram o Termo de Consentimento Livre e Esclarecido (Anexo 1). Após esta assinatura foi preenchido o Protocolo Sócio Demográfico e Auditivo (Anexo 2). Tal protocolo foi aplicado por uma única fonoaudióloga, autora deste estudo, no Ambulatório de Geriatria.

\section{- O Protocolo Sócio Demográfico e Auditivo}

Este protocolo foi baseado no tipo de perguntas apresentadas no The Hearing Handicap Inventory for the Elderly (VENTRY e WEINSTEIN ${ }^{95}$ 1982). O uso desse protocolo é recomendado pela American Speech and Hearing Association (ASHA) por ser considerado um instrumento específico para a população idosa (RUSSO ${ }^{83} 1998$ ). As perguntas formuladas visam situar a condição auditiva do idoso frente a diferentes situações no dia-a-dia bem como acessar sua opinião sobre sua audição. 
Terminada a aplicação do Protocolo Sócio-demográfico e auditivo foram preenchidas as questões 6,7 e 8 do Protocolo de Avaliação Clínica em Geriatria e de Saúde (Anexo 3), com a apresentação referente a hábitos de vida do entrevistado.

\section{- Protocolo de Avaliação Clínica em Geriatria e de Saúde}

As questões referentes a exames laboratoriais e histórico de saúde (questões 1 a 5) foram preenchidas ao final do dia dessa consulta, com dados levantados a partir do prontuário médico do entrevistado.

Após a consulta no Ambulatório de Geriatria, cada participante foi encaminhado ao Ambulatório de Otorrinolaringologia, por meio de Pedido de Consulta e Encaminhamento (Anexo 4), para agendar uma avaliação com o médico otorrinolaringologista. 


\section{- Protocolo de pedido de consulta e encaminhamento HC-FMUSP}

O pedido de consulta é um protocolo de rotina do HC - FMUSP e compõe-se de dados acerca da história diagnóstica do paciente e da justificativa do pedido de consulta. Para ser encaminhado à consulta otorrinolaringológica, no item paciente, foi colada a etiqueta de identificação do paciente. No item tipo de atendimento, foi assinalado o pedido de consulta. Em diagnósticos atuais, foi anotada a história clínica do paciente e na justificativa, foi assinalada a presença do paciente no projeto de pesquisa do GAMIA. Após ser datado e assinado, o pedido foi entregue ao entrevistado, que era orientado a se dirigir ao Ambulatório de Otorrinolaringologia do HC - FMUSP e apresentar tal pedido para agendar sua consulta com o médico otorrinolaringologista.

A consulta no Ambulatório de Otorrinolaringologia foi realizada por dois médicos otorrinolaringologistas que possuem vasta experiência na clínica otorrinolaringológica. Um médico foi o responsável pela área de otorrinolaringologia neste estudo, Dr. Sérgio Garbi, Diretor Técnico de Serviço de Saúde HC - FMUSP e Médico Chefe do Ambulatório da Clínica de Otorrinolaringologia do HC - FMUSP e a outra médica foi a Dra Sulene Pirana, Médica Assistente da Disciplina de Otorrinolaringologia do Departamento de Otorrinolaringologia e Oftalmologia da FMUSP. 
Os dois médicos trabalham juntos no Ambulatório de Otorrinolaringologia e, semanalmente, participam de reuniões técnico científicas de atualização para adequação de condutas e procedimentos no referido ambulatório.

A avaliação consistiu da aplicação do protocolo de avaliação otorrinolaringológica (Anexo 5) e da realização da otoscopia em ambas as orelhas.

\section{- Protocolo de avaliação otorrinolaringológica}

Foi preenchido no momento da consulta com 0 otorrinolaringologista, exceto a questão referente ao resultado de audiometria que foi preenchida após a realização deste exame. Durante a aplicação desse protocolo foi realizado o exame físico.

A otoscopia é um procedimento que consiste no uso de um otoscópio que permite a visualização do meato acústico externo e da membrana timpânica em ambas as orelhas. Esse exame físico permite detectar a presença de corpo estranho, infecção ou crescimento de tecido ou 
osso. Caso o participante apresentasse presença de cerume, que prejudicasse ou impossibilitasse a realização da audiometria, foi procedida a lavagem do meato acústico externo pelo próprio otorrinolaringologista. Somente então, foi agendada a audiometria. Nesse dia, foi também agendada a data de retorno do participante ao Ambulatório de Otorrinolaringologia para a devolutiva dos resultados.

\section{- Protocolo de Avaliação Audiológica}

A audiometria tonal foi realizada na empresa de aparelhos auditivos Audibel e seguiu o Protocolo de Avaliação Audiológica (Anexo 6). Foi utilizado o audiômetro Qualitone, modelo WBR, um canal, que foi manipulado por duas fonoaudiólogas treinadas para a aplicação de audiometria e uso do equipamento. O treinamento das fonoaudiólogas consistiu em revisões periódicas de procedimentos de rotina da empresa para aplicação de audiometria e foi feito pela própria empresa. 
O protocolo de avaliação audiológica utilizado nesse estudo foi o mesmo utilizado na empresa de Aparelhos Auditivos Audibel e compõe-se dos itens:

- nome do paciente;

- data de nascimento;

- nome da avaliadora;

- audiômetro utilizado para avaliação;

- data de realização da avaliação;

- audiometria: foram registradas na forma gráfica por meio de audiograma. A representação simbólica da audição foi registrada para cada orelha e seguiu a orientação da American Speech and Hearing Association (ASHA) (YANTIS ${ }^{97}$ 1999).

O protocolo de avaliação audiológica foi utilizado neste estudo da forma como se apresenta, por tratar-se da folha de registro utilizada no local onde os exames audiométricos foram realizados. Convém salientar que foram efetuadas algumas modificações, em relação à apresentação gráfica do audiograma, bem como quanto à nomenclatura anatômica. No audiograma, a abreviatura "hz" deve ser lida como Hz. Onde se lê "ouvido direito" leia-se orelha direita, onde se lê "ouvido esquerdo" leia-se orelha esquerda. Onde se observa a abreviatura "DV" deve-se ler IRF. Os responsáveis pela confecção dessa folha de registro foram comunicados sobre as mudanças necessárias. 
Após a realização da audiometria, o resultado foi encaminhado ao médico otorrinolaringologista responsável por essa área no presente estudo. Após a análise dos resultados foi emitido o diagnóstico médico, confirmando a presença ou ausência de presbiacusia. Para determinar a presença de presbiacusia foram adotados os seguintes critérios: perda auditiva acima de $25 \mathrm{~dB}$ em pelo menos uma orelha, nas freqüências de 500, 1000 e $2000 \mathrm{~Hz}$, ausência de doenças que justifiquem outros tipos de perda auditiva, como, por exemplo, trauma acústico e traumatismo craniano .

Após a realização da audiometria tonal cada participante retornou, em dia e hora agendados, ao ambulatório de otorrinolaringologia, onde recebeu a devolutiva, pelo otorrinolaringologista responsável por este estudo, das avaliações realizadas. Os participantes diagnosticados com presbiacusia foram orientados e receberam, quando indicado, o encaminhamento para uso de aparelho auditivo, conforme procedimento do ambulatório de otorrinolaringologia, se assim o desejassem. Participantes com outros tipos de perda auditiva que necessitassem de encaminhamento receberam-no da mesma forma. 


\section{III.IV. Variáveis de estudo}

- presença de presbiacusia: perda auditiva acima de $25 \mathrm{~dB}$ em pelo menos uma orelha, nas freqüências de 500,1000 e $2000 \mathrm{~Hz}$, ausência de doenças que justifiquem outros tipos de perda auditiva, como, por exemplo, trauma acústico e traumatismo craniano .

- variáveis sócio-demográficas: idade (em anos), sexo (masculino ou feminino), escolaridade (em anos), cor (observada pela entrevistadora), estado marital (situação em relação a presença de companheiro (a)) e renda (em salário mínimo).

- presença de sintomas:

- ouvir bem na conversa frente a frente.

- ouvir bem em ambientes ruidosos.

- ouvir bem quando a pessoa não está na sua frente.

- ouvir bem em ambientes silenciosos.

- precisar ver a face com quem está conversando.

- pedir para os outros repetirem o que falaram.

- família achar que ouve bem.

- ter dificuldades para ouvir quando estão sussurrando.

- ouvir bem a televisão.

- ouve bem ao telefone. 
- ouve bem o rádio.

- alguém ter reclamado do volume alto da televisão.

- amigos acharem que ouve bem.

- mudança da audição com a idade.

- terem dito para fazer exame da audição.

- dificuldade para entender o que falam.

- já ter pensado em fazer exame da audição.

- ter deixado de fazer atividade em função da audição.

- já ter feito exame da audição.

- uso de medicamentos: número total de medicações por idoso.

- tabagismo, tabagismo anterior e fumante passivo.

- hábito de beber.

- índice de massa corporal (IMC), sendo esta calculada segundo a fórmula $I M C=P / A^{2}$, onde $P$ refere-se ao peso e $A$ refere-se $a$ altura. Foram considerados os seguintes valores de referência recomendados pela Organização Mundial de Saúde para idosos (WHO'101 1995): adequado: <26 sobrepeso: $>=26$ 
- exames laboratoriais: foram considerados os valores de referência adotados pelo HC-FMUSP para cada um dos exames:

$\mathrm{Na}$ (sódio): normal entre $135-145 \mathrm{mEq} / \mathrm{L}$,

$\mathrm{K}$ (potássio): normal entre 3,5-5, $0 \mathrm{mEq} / \mathrm{L}$,

Uréia: normal entre $10-45 \mathrm{mg} / \mathrm{dL}$,

Glicose: normal entre $70-110 \mathrm{mg} / \mathrm{dL}$,

Creatinina: normal entre $0,6-1,4 \mathrm{mg} / \mathrm{dL}$,

Eritrócitos: normal entre: $\mathrm{H}=4,4-5,9 ; M=4,0-5,4 \mathrm{milhões} / \mathrm{mm}^{3}$,

Triglicérides: valores em mg/dL e válidos para maiores de 20 anos:

$<150=$ ótimo $; 150-200=$ limítrofe $; 200-499=$ alto $>500=$ muito alto,

Hematócritos: normal entre: $\mathrm{H}=40-52 \% ; M=35-47 \%$,

Hemoglobinas: normal entre: $H=13-18 ; M=12-16 \mathrm{~g} / \mathrm{dL}$,

Plaquetas: normal entre 150.000 a $350.000 / \mathrm{mm}^{3}$,

Colesterol total: valores em mg/dL para maiores de 20 anos:

$<200=$ ótimo, $200-239=$ limítrofe e $>240=$ alto,

LDL: até $130 \mathrm{mg} / \mathrm{dL}, \mathrm{HDL}:>40 \mathrm{mg} / \mathrm{dL}$ e VLDL:38 até $40 \mathrm{mg} / \mathrm{dL}$.

- alquém na família tem problema no ouvido (foi perguntado ao idoso se alguém na sua família tem problema de audição) 
- tem ou teve: otorréia, zumbido, otalgia, traumatismo do ouvido, mal cheiro no ouvido, trauma acústico, cirurgia do ouvido, tonturas, náuseas, irritabilidade, cefaléia, traumatismo de crânio, traumatismo de coluna cervical.

- antecedentes mórbidos: diabetes, hipertensão arterial

- exposição à ruído no trabalho (foi considerado exposição superior a dois anos).

- alteração do humor.

- alteracão do sono.

- mudança de comportamento.

- diminuição da concentração. 


\section{III.V. Análise estatística}

Primeiro as variáveis foram analisadas por meio de proporções e apresentadas de forma descritiva. Foi feito o teste de diferença de médias das variáveis idade, renda e escolaridade pela distribuição t-student ou teste de Mann-Whitney. Foi feito teste de aderência para a curva normal através do teste de Komolgorov-Smirnov e o teste de Levene para homogeneidade das variâncias.

Foi feito o teste de associação pelo Qui-quadrado para avaliar a relação entre necessidade relatada de fazer exame da audição e características da audição, dificuldades auditivas, alteração de humor e de sono, mudança de comportamento, diminuição da concentração e se alguém falou para fazer exame da audição.

Foi feito o teste de associação pelo Qui-quadrado para avaliar a relação entre a presença de presbiacusia e possíveis fatores associados. Após esta fase foi feita a análise conjunta dos fatores de risco por meio da regressão logística múltipla. Para a análise múltipla foram selecionadas todas as variáveis com $p<0,20$ no teste de associação pelo qui-quadrado.

O processo de modelagem foi o stepwise forward selection, no qual a partir da variável mais significativa, isto é, menor valor de $p$, foram 
acrescentadas as outras, uma a uma. A variável permaneceu no modelo quando $p<0,05$. Foi utilizado o teste de Homer-Lemeshow para avaliar a significância do modelo final múltiplo. A medida de risco estimada foi a razão de chances (odds ratio - OR). Foi utilizado o pacote estatístico SPSS para Windows versão 10.0

Em todas as análises foi utilizado o nível de significância de 5\%. 


\section{VI. Questões éticas}

Todos os participantes do estudo receberam orientação sobre a pesquisa realizada bem como foram informados sobre seus objetivos e os procedimentos a que foram submetidos. Após a informação da pesquisa foi apresentado o termo de consentimento livre e esclarecido (Anexo 1). Cada participante recebeu uma cópia do termo.

O projeto deste estudo foi encaminhado ao Comitê de Ética em Pesquisa da Faculdade de Saúde Pública e por ele aprovado (Anexo 7).

Os participantes da pesquisa foram submetidos a dois exames não invasivos e sem riscos de danos à saúde física. Em primeiro lugar a otoscopia realizada pelo otorrinolaringologista e o exame audiológico realizado por fonoaudiólogo.

Todos os participantes fizeram retorno médico para orientações e encaminhamentos bem como receberam cópia do resultado da audiometria. Os participantes com resultado positivo de presbiacusia foram esclarecidos quanto ao diagnóstico e encaminhados ao Serviço de Otorrinolaringologia do HC-FMUSP para orientação e indicação de uso de AASI. Os participantes com outros tipos de perda auditiva receberam 0 mesmo encaminhamento. 


\section{RESULTADOS}

\section{IV.I. Caracterização da população de estudo}

No período deste estudo foram avaliados 85 idosos e as variáveis auditivas e os fatores associados a presbiacusia serão descritos a partir deste momento. As características sócio-demográficas da população deste estudo, bem como a informação sobre ruído ocupacional podem ser observadas na Tabela 1.

As mulheres são em maior número que homens, correspondendo a $83,5 \%$ do total de entrevistados. Em relação à faixa etária a mais comum foi a compreendida entre 70 a 74 anos. A média de idade foi de 71,7 anos, sendo a idade mínima de 61 anos e a máxima de 89 anos.

A cor branca predominou em $87,1 \%$ dos participantes. O estado marital mais freqüente foi o viúvo $(47,1 \%)$ seguido do casado ou amigado (31,8\%). Entre os participantes, a renda média foi de 4,5 salários

mínimos, sendo a renda mínima de 1 e a máxima de 22 salários mínimos. A faixa de renda mais freqüente foi a de um a dois salários mínimos englobando $44,7 \%$ dos participantes. 
Quanto ao ruído ocupacional foi possivel verificar a sua presença em $31,8 \%$ dos participantes. 0 uso de equipamento de proteção intra auricular (EPI) foi referido por apenas um participante.

Tabela 1. Número e porcentagem de idosos segundo características sóciodemográficas e exposição a ruído ocupacional. GAMIA, HC-FMUSP, São Paulo, 2002.

\begin{tabular}{|c|c|c|c|}
\hline Variável & Categoria & No. & $\%$ \\
\hline \multirow[t]{2}{*}{ sexo } & masculino & 14 & 16,5 \\
\hline & feminino & 71 & 83,5 \\
\hline \multirow[t]{6}{*}{ faixa etária } & $60-64$ & 11 & 12,9 \\
\hline & $65-69$ & 20 & 23,6 \\
\hline & $70-74$ & 27 & 31,7 \\
\hline & $75-79$ & 19 & 22,4 \\
\hline & $80-84$ & 6 & 7,1 \\
\hline & 85 e mais & 2 & 2,3 \\
\hline \multirow{4}{*}{ cor } & branca & 74 & 87,1 \\
\hline & mulata/parda & 4 & 4,7 \\
\hline & preta & 2 & 2,4 \\
\hline & amarela & 5 & 5,8 \\
\hline \multirow{4}{*}{ estado marital } & casado ou amigado & 27 & 31,8 \\
\hline & viúvo & 40 & 47,1 \\
\hline & solteiro & 15 & 17,6 \\
\hline & sep., div. ou desquit. & 3 & 3,5 \\
\hline \multirow{4}{*}{ renda } & $1-2$ & 38 & 44,7 \\
\hline & $3-5$ & 30 & 35,3 \\
\hline & $6-8$ & 6 & 7,1 \\
\hline & 9 e mais & 11 & 12,9 \\
\hline \multirow{4}{*}{ anos de escolaridade } & $1-4$ & 56 & 65,8 \\
\hline & $5-8$ & 19 & 22,4 \\
\hline & $9-11$ & 8 & 9,4 \\
\hline & 12 e mais & 2 & 2,4 \\
\hline exposição a ruído & $\operatorname{sim}$ & 27 & 31,8 \\
\hline ocupacional & não & 58 & 68,2 \\
\hline \multicolumn{2}{|l|}{ Total } & 85 & 100,0 \\
\hline
\end{tabular}


Dentre os idosos que relataram exposição a ruído ocupacional, o tempo mínimo de exposição foi de três anos e o máximo foi de 40 anos, a média foi de 19, 3 anos. Apenas um idoso relatou o uso de protetor auricular no período de trabalho. Os locais de trabalho relatados foram: tecelagem, gráfica, metalúrgica, comércio, laboratório, oficina mecânica e indústria.

No momento do estudo apenas um idoso relatou ainda trabalhar, no caso como massagista. Os demais relataram não mais trabalharem ou nunca terem trabalhado fora de casa.

Os hábitos de beber e de fumar podem ser visualizados na Tabela 2. Apresentaram o hábito de fumar apenas 2,4\% dos idosos, $20 \%$ já fumaram e hoje não têm mais esse hábito. Convivem atualmente com fumantes $23,5 \%$ e já conviveram com fumantes $54,1 \%$ dos idosos. Quanto à bebida alcoólica $16,5 \%$ têm o hábito de beber sendo que a maioria não ultrapassa uma cerveja no final de semana. Em apenas uma entrevista apareceu o alcoolismo como característica. 
Tabela 2. Número e porcentagem de idosos segundo o hábito de fumar e de beber. GAMIA, HC-FMUSP, São Paulo, 2002.

\begin{tabular}{l|c|cc}
\hline \multicolumn{1}{c|}{ Variável } & Categoria & No. & $\%$ \\
\hline Fuma? & não & 83 & 97,6 \\
& sim & 2 & 2,4 \\
\hline Já fumou? & não & 68 & 80,0 \\
& sim & 17 & 20,0 \\
\hline Convive com quem & não & 20 & 76,5 \\
fuma? & sim & 39 & 23,5 \\
\hline Conviveu com quem & não & 46 & 45,9 \\
fumava? & sim & 71 & 54,1 \\
\hline Faz uso de bebida & não & 14 & 83,5 \\
alcoólica? & sim & 85 & 16,5 \\
\hline \multicolumn{2}{|c|}{ Total } & &
\end{tabular}

Quanto à audição pode-se verificar, na Tabela 3, que a maioria dos idosos se beneficiam da conversa frente a frente visto que $89,4 \%$ relatam ouvir bem nessa situação. Tal fato é corroborado quando se pergunta se ele ouve bem sem o interlocutor à sua frente; nessa situação, $48,2 \%$ relatam ouvir bem, enquanto $37,6 \%$ referem não ouvir bem sem visualizar a face de seu interlocutor. Quando a pergunta diz respeito à necessidade de ver a face do interlocutor, o mesmo não se observa; $60 \%$ dos participantes referiram não precisar desse auxilio. Isso indica que visualizar a face do interlocutor pode ser um facilitador não interiorizado pelos idosos. Eles percebem que isto é importante para melhorar a 
compreensão; contudo, não interpretam como algo necessário à melhora da audição.

Tabela 3. Número e porcentagem de idosos segundo características da audição. GAMIA, HC-FMUSP, São Paulo, 2002.

\begin{tabular}{|c|c|c|c|}
\hline Variável & Categorias & No. & $\%$ \\
\hline $\begin{array}{l}\text { Ouve bem na conversa frente } \\
\text { a frente? }\end{array}$ & $\begin{array}{c}\text { não } \\
\text { às vezes } \\
\text { sim }\end{array}$ & $\begin{array}{c}5 \\
4 \\
76\end{array}$ & $\begin{array}{c}5,9 \\
4,7 \\
89,4\end{array}$ \\
\hline Ouve bem em amb. ruidosos? & $\begin{array}{c}\text { não } \\
\text { às vezes } \\
\text { sim }\end{array}$ & $\begin{array}{l}34 \\
11 \\
40\end{array}$ & $\begin{array}{c}40 \\
12,9 \\
47,1\end{array}$ \\
\hline $\begin{array}{l}\text { Ouve ber sem a pessoa na } \\
\text { frente? }\end{array}$ & $\begin{array}{c}\text { não } \\
\text { às vezes } \\
\text { sim }\end{array}$ & $\begin{array}{l}32 \\
12 \\
41\end{array}$ & $\begin{array}{l}37,7 \\
14,1 \\
48,2\end{array}$ \\
\hline $\begin{array}{l}\text { Ouve bem em amb. } \\
\text { silenciosos? }\end{array}$ & $\begin{array}{c}\text { não } \\
\text { às vezes } \\
\text { sim }\end{array}$ & $\begin{array}{c}5 \\
1 \\
79 \\
\end{array}$ & $\begin{array}{r}5,9 \\
1,2 \\
92,9\end{array}$ \\
\hline $\begin{array}{l}\text { Precisa ver a face de quem } \\
\text { conversa? }\end{array}$ & $\begin{array}{c}\text { não } \\
\text { às vezes } \\
\text { sim }\end{array}$ & $\begin{array}{l}51 \\
.9 \\
25\end{array}$ & $\begin{array}{l}60,0 \\
10,6 \\
29,4\end{array}$ \\
\hline $\begin{array}{c}\text { Precisa pedir para repetir? } \\
\text {. }\end{array}$ & $\begin{array}{l}\text { não } \\
\text { às vezes } \\
\text { sim }\end{array}$ & $\begin{array}{l}23 \\
25 \\
37\end{array}$ & $\begin{array}{l}27,1 \\
29,4 \\
43,5\end{array}$ \\
\hline Familia acha que ouve bem? & $\begin{array}{l}\text { não } \\
\text { sim } \\
\end{array}$ & $\begin{array}{l}44 \\
41 \\
\end{array}$ & $\begin{array}{l}51,8 \\
48,2 \\
\end{array}$ \\
\hline $\begin{array}{l}\text { Difícil ouvir alguém } \\
\text { sussurrando? }\end{array}$ & $\begin{array}{c}\text { não } \\
\text { às vezes } \\
\text { sim }\end{array}$ & $\begin{array}{c}34 \\
7 \\
44\end{array}$ & $\begin{array}{c}40,0 \\
8,2 \\
51,8\end{array}$ \\
\hline Duve bem televisão? & $\begin{array}{l}\text { não } \\
\text { sim }\end{array}$ & $\begin{array}{l}16 \\
69 \\
\end{array}$ & $\begin{array}{l}18,8 \\
81,2\end{array}$ \\
\hline Ouve bem ao telefone? & $\begin{array}{l}\text { não } \\
\text { sim }\end{array}$ & $\begin{array}{l}12 \\
73\end{array}$ & $\begin{array}{l}14,1 \\
85,9\end{array}$ \\
\hline Ouve bem $b$ rádio? & $\begin{array}{l}\text { não } \\
\text { sim }\end{array}$ & $\begin{array}{l}11 \\
74 \\
\end{array}$ & $\begin{array}{l}12,9 \\
87,1\end{array}$ \\
\hline Reclama do volume da tv? & $\begin{array}{l}\text { não } \\
\text { sim }\end{array}$ & $\begin{array}{l}44 \\
41\end{array}$ & $\begin{array}{l}51,8 \\
48,2\end{array}$ \\
\hline $\begin{array}{l}\text { Amigos acham que ouve } \\
\text { bem? }\end{array}$ & $\begin{array}{l}\text { não } \\
\text { sim }\end{array}$ & $\begin{array}{l}15 \\
70\end{array}$ & $\begin{array}{l}17,6 \\
82,4\end{array}$ \\
\hline Audição mudou? & $\begin{array}{c}\text { não } \\
\text { pior } \\
\text { melhor }\end{array}$ & $\begin{array}{c}34 \\
49 \\
2 \\
\end{array}$ & $\begin{array}{c}40,0 \\
57,6 \\
2,4 \\
\end{array}$ \\
\hline Dificil entender as pessoas? & $\begin{array}{c}\text { não } \\
\text { às vezes } \\
\text { sim }\end{array}$ & $\begin{array}{l}39 \\
17 \\
29\end{array}$ & $\begin{array}{l}45,9 \\
20,0 \\
34,1\end{array}$ \\
\hline $\begin{array}{l}\text { Deixou atividades pela } \\
\text { audicăo? }\end{array}$ & $\begin{array}{l}\text { não } \\
\text { sim }\end{array}$ & $\begin{array}{c}82 \\
3 \\
\end{array}$ & $\begin{array}{c}96,5 \\
3,5 \\
\end{array}$ \\
\hline Total & & 85 & 100,0 \\
\hline
\end{tabular}


Em ambientes ruidosos apenas $47,1 \%$ referem ouvir. Já em ambientes silenciosos, volta-se a observar melhora na audição visto que 92,9\% revelam ouvir bem nessa situação, indicando que ruídos ambientais interferem no desempenho da audição dessa população.

Quando indagados sobre a audição frente a alguns meios de comunicação, as respostas obtidas foram que ouvem bem a televisão $81,2 \%$ dos idosos, porém na pergunta se alguém já reclamou do volume da televisão $51,8 \%$ referem que não, enquanto porcentagem semelhante $(48,2 \%)$ refere que sim.

Em relação ao uso de telefone, $85,9 \%$ relataram ouvir bem nessa situação. Em relação ao rádio foi observado que $87,1 \%$ dos idosos referiram ouvir bem nessa situação.

Quando o assunto refere-se à percepção que as pessoas de seu ambiente possuem em relação a sua audição, os idosos mostram diferenças interessantes entre as observações de familiares e de amigos. Quando a pergunta refere-se ao que os familiares acham da audição do idoso, 51,8\% deles referem que a família acha que eles não ouvem bem. Por outro lado, $82,4 \%$ referem que seus amigos acham que eles ouvem bem. 
Quando perguntado ao idoso se ele acha que sua audição mudou com a idade, $57,6 \%$ referem que sim e que essa mudança foi para pior. Quando perguntado se é difícil ouvir alguém sussurrando, a resposta se equilibra, ou seja, $51,8 \%$ dizendo que sim. Quando a pergunta é se sente dificuldade para entender o que as pessoas falam, 45,9\% referem que não. Eles são unânimes em dizer que não deixaram de fazer nenhuma atividade em função da perda da audição.

A maioria dos idosos $(68,2 \%)$ declarou que alguém nunca falou para fazer exame de audição (Tabela 4), embora $64,7 \%$ tivessem pensado em fazê-lo e $54,1 \%$ já o tenham realizado em algum momento.

Tabela 4. Número e porcentagem de idosos segundo a indicação de audiometria e sua realização. GAMIA, HC-FMUSP, São Paulo, 2002.

\begin{tabular}{l|c|cc}
\hline \multicolumn{1}{c|}{ Variável } & Categoria & No. & $\%$ \\
\hline Alguém falou para fazer & não & 58 & 68,2 \\
exame da audição? & sim & 27 & 31,8 \\
\hline Já pensou em fazer & não & 30 & 35,3 \\
exame da audição? & sim & 55 & 64,7 \\
\hline Já fez exame da & não & 39 & 45,9 \\
audição? & sim & 46 & 54,1 \\
\hline \multicolumn{2}{c|}{ Total } & 85 & 100,0 \\
\hline
\end{tabular}


As dificuldades auditivas mais relatadas foram: dificuldade para perceber sinais $(83,5 \%)$, dificuldade para entender o que ouve $(76,5 \%)$, dificuldade para localizar sons $(45,9 \%)$ (Tabela 5).

Tabela 5. Número e porcentagem de idosos segundo dificuldades auditivas. GAMIA, HC-FMUSP, São Paulo, 2002.

\begin{tabular}{l|c|cc}
\hline \multicolumn{1}{c|}{ Variável } & Categoria & No. & $\%$ \\
\hline Flutuação auditiva & não & 83 & 97,6 \\
& sim & 2 & 2,4 \\
\hline Escuta & não & 6 & 7,1 \\
& sim & 79 & 92,9 \\
\hline Entende & não & 37 & 76,5 \\
& sim & 20 & 23,5 \\
\hline Localiza sons & não & 39 & 45,9 \\
& sim & 46 & 54,1 \\
\hline Percebe sinais & não & 71 & 83,5 \\
& sim & 14 & 16,5 \\
\hline Total & & 85 & 100,0 \\
\hline
\end{tabular}

Os sinais e sintomas relacionados à audição podem ser observados na Tabela 6 , sendo os mais relatados zumbido $(25,9 \%)$, otalgia $(20 \%)$ e a otorréia $(11,8 \%)$ em ambas as orelhas. Apresentaram odor na orelha direita $8,2 \%$ dos idosos e na orelha esquerda $5,9 \%$. O trauma acústico foi encontrado apenas em orelha direita em um dos idosos. Foi realizada cirurgia na orelha direita em apenas um idoso e em outro idoso na orelha esquerda. 
Tabela 6. Número e porcentagem de idosos segundo sinais e sintomas relacionados à audição. GAMIA, HC-FMUSP, São Paulo, 2002.

\begin{tabular}{|c|c|c|c|}
\hline Variável & Categoria & No. & $\%$ \\
\hline \multirow[t]{2}{*}{ Otorréia OD } & não & 75 & 88,2 \\
\hline & $\operatorname{sim}$ & 10 & 11,8 \\
\hline \multirow[t]{2}{*}{ Otorréia OE } & não & 76 & 89,4 \\
\hline & $\operatorname{sim}$ & 9 & 10,6 \\
\hline \multirow[t]{2}{*}{ Zumbido OD } & กão & 63 & 74,1 \\
\hline & $\operatorname{sim}$ & 22 & 25,9 \\
\hline \multirow[t]{2}{*}{ Zumbido $\mathrm{OE}$} & กão & 60 & 70,6 \\
\hline & $\operatorname{sim}$ & 25 & 29,4 \\
\hline \multirow[t]{2}{*}{ Otalgia OD } & กล̃o & 68 & 80,0 \\
\hline & $\operatorname{sim}$ & 17 & 20,0 \\
\hline \multirow[t]{2}{*}{ Otalgia OE } & กão & 72 & 84,7 \\
\hline & $\operatorname{sim}$ & 13 & 15,3 \\
\hline \multirow[t]{2}{*}{ Trauma OD } & กล̃o & 84 & 98,8 \\
\hline & $\operatorname{sim}$ & 1 & 1,2 \\
\hline \multirow[t]{2}{*}{ Trauma OE } & กว̃o & 83 & 97,6 \\
\hline & sim & 2 & 2,4 \\
\hline \multirow[t]{2}{*}{ Odor OD } & กล̃o & 78 & 91,8 \\
\hline & $\operatorname{sim}$ & 8 & 8,2 \\
\hline \multirow[t]{2}{*}{ Odor OE } & กล̃o & 80 & 94,1 \\
\hline & $\operatorname{sim}$ & 5 & 5,9 \\
\hline \multirow[t]{2}{*}{ Trauma acústico OD } & กว̃o & 84 & 98,8 \\
\hline & $\operatorname{sim}$ & 1 & 1,2 \\
\hline \multirow[t]{2}{*}{ Trauma acústico OE } & não & 85 & 100,0 \\
\hline & sim & - & . \\
\hline \multirow[t]{2}{*}{ Cirurgia OD } & กล̃o & 84 & 98,8 \\
\hline & $\operatorname{sim}$ & 1 & 1,2 \\
\hline \multirow[t]{2}{*}{ Cirurgia OE } & กว̃o & 84 & 98,8 \\
\hline & $\operatorname{sim}$ & 1 & 1,2 \\
\hline \multicolumn{2}{|l|}{ Total } & 85 & 100,0 \\
\hline
\end{tabular}


Quanto aos antecedentes relacionados à audição (Tabela 7) a tontura esteve presente em 38,8\% dos idosos, a náusea em 20\%, a irritabilidade em $15,3 \%$ e a cefaléia em $20 \%$.

Tabela 7. Número e porcentagem de idosos segundo antecedentes mórbidos. GAMIA, HC-FMUSP, São Paulo, 2002.

\begin{tabular}{|c|c|c|c|}
\hline Variável & Categoria & $N^{0}$. & $\%$ \\
\hline \multirow[t]{2}{*}{ Tontura } & não & 52 & 61,2 \\
\hline & sim & 33 & 38,8 \\
\hline \multirow[t]{2}{*}{ Náusea } & não & 68 & 80,0 \\
\hline & $\operatorname{sim}$ & 17 & 20,0 \\
\hline \multirow[t]{2}{*}{ Irritabilidade } & não & 72 & 84,7 \\
\hline & sim & 13 & 15,3 \\
\hline \multirow[t]{2}{*}{ Cefaléia } & não & 68 & 80,0 \\
\hline & sim & 17 & 20,0 \\
\hline \multirow[t]{2}{*}{ Traumatismo de crânio } & não & 82 & 96,5 \\
\hline & sim & 3 & 3,5 \\
\hline \multirow{2}{*}{$\begin{array}{l}\text { Trauma de coluna } \\
\text { cervical }\end{array}$} & กão & 85 & 100,0 \\
\hline & $\operatorname{sim}$ & - & - \\
\hline \multirow[t]{2}{*}{ Diabetes } & กão & 71 & 83,5 \\
\hline & $\operatorname{sim}$ & 14 & 16,5 \\
\hline \multirow[t]{2}{*}{ Hipertensão arterial } & กี̃o & 40 & 47,1 \\
\hline & $\operatorname{sim}$ & 45 & 52,9 \\
\hline \multirow[t]{2}{*}{ Tuberculose } & não & 83 & 97,6 \\
\hline & sim & 2 & 2,4 \\
\hline \multirow[t]{2}{*}{ Caxumba } & não & 29 & 34,1 \\
\hline & $\operatorname{sim}$ & 56 & 65,9 \\
\hline \multirow[t]{2}{*}{ Sarampo } & não & 21 & 24,7 \\
\hline & $\operatorname{sim}$ & 64 & 75,3 \\
\hline \multirow[t]{2}{*}{ Meningite } & กão & 83 & 97,6 \\
\hline & $\operatorname{sim}$ & 2 & 2,4 \\
\hline \multirow[t]{2}{*}{ Sifilis } & não & 82 & 96,5 \\
\hline & sim & 3 & 3,5 \\
\hline \multirow[t]{2}{*}{ Problemas de tireóide } & não & 74 & 87,1 \\
\hline & $\operatorname{sim}$ & 11 & 12,9 \\
\hline \multirow[t]{2}{*}{ Problemias renais } & não & 74 & 87,1 \\
\hline & $\operatorname{sim}$ & 11 & 12,9 \\
\hline Tota! & & 85 & 100,0 \\
\hline
\end{tabular}


Em relação aos antecedentes mórbidos, foi verificado que os mais freqüentes foram: sarampo $(75,3 \%)$, hipertensão arterial $(52,9 \%)$ e diabetes $(16,5 \%)$.

$\mathrm{Na}$ consulta com o médico especialista em otorrinolaringologia foi realizado o exame físico, cujos resultados encontram-se na Tabela 8.

O meato acústico da orelha direita encontrou-se normal em $83,5 \%$ dos idosos, encontrando-se rolha de cera em $12,9 \%$, otite externa em $1,2 \%$ e hiperemia em $2,4 \%$. O meato acústico da orelha esquerda apresentou-se normal em $80 \%$ dos idosos, encontrando-se rolha de cera em $15,3 \%$, descamação em $1,2 \%$, otite externa em $2,4 \%$ e hiperemia em $1,2 \%$.

A membrana timpânica na orelha direita encontrou-se normal em $91,8 \%$ dos idosos, opaca em 3,5\%, retraída em 3,5\% e com calcificação em 1,2\%. A membrana timpânica na orelha esquerda estava normal em $91,8 \%$ dos idosos, opaca em $3,5 \%$ e retraída em $4,7 \%$.

A rinoscopia mostrou-se normal em $97,6 \%$ dos idosos, com mucosa descorada em $1,2 \%$ e desvio de septo nasal anterior em $1,2 \%$. A oroscopia encontrou-se normal em $92,9 \%$ e as alterações encontradas referiram-se a alterações em articulação têmporo-mandibular, hiperemia de palato e hiperemia de faringe. 
Tabela 8. Número e porcentagem de idosos segundo o exame físico otorrinolaringológico. GAMIA, HC-FMUSP, São Paulo, 2002.

\begin{tabular}{|c|c|c|c|}
\hline Variável & Categoria & $\mathrm{N}^{\circ}$. & $\%$ \\
\hline \multirow[t]{5}{*}{ Meato acústico OD } & normal & 71 & 83,5 \\
\hline & rolha de cera & 11 & 12,9 \\
\hline & descamação & - & - \\
\hline & otite extema & 1 & 1,2 \\
\hline & hiperemia & 2 & 2,4 \\
\hline \multirow[t]{5}{*}{ Meato acústico $\mathrm{OE}$} & normal & 68 & 80,0 \\
\hline & rolha de cera & 13 & 15,2 \\
\hline & descamação & 1 & 1,2 \\
\hline & otite extema & 2 & 2,4 \\
\hline & hiperemia & 1 & 1,2 \\
\hline \multirow[t]{4}{*}{ Membrana timpánica OD } & normal & 78 & 91,8 \\
\hline & opaca & 3 & 3,5 \\
\hline & retraida & 3 & 3,5 \\
\hline & cakcificação & 1 & 1,2 \\
\hline \multirow[t]{4}{*}{ Membrana timpânica OE } & normal & 78 & 91,8 \\
\hline & opaca & 3 & 3,5 \\
\hline & retraída & 4 & 4,7 \\
\hline & cakificaçãa & - & \\
\hline \multirow[t]{4}{*}{ Rinoscopia } & normal & 83 & 97,6 \\
\hline & mucosa descorada & 1 & 1,2 \\
\hline & hipertrofia cometos & - & - \\
\hline & desv. septo nasal ant. & 1 & 1,2 \\
\hline \multirow[t]{2}{*}{ Oroscopia } & normal & 79 & 92,9 \\
\hline & alterada & 6 & 7,1 \\
\hline \multicolumn{2}{|l|}{ Total } & 85 & 100,0 \\
\hline
\end{tabular}




\section{II. A presença de presbiacusia}

Entre os 85 idosos avaliados, a presbiacusia esteve presente em $71,8 \%$ e a indicação de aparelho de amplificação sonora e individual (AASI) foi feita em $27,1 \%$ dos casos avaliados (Tabela 9).

Tabela 9. Número e porcentagem de idosos segundo presença de presbiacusia e indicação de aparelho de amplificação sonora individual (AASI). GAMIA, HC-FMUSP, São Paulo, 2002.

\begin{tabular}{l|c|cc}
\hline \multicolumn{1}{c|}{ Variável } & Categoria & $\mathrm{N}^{\circ}$. & $\%$ \\
\hline Presbiacusia & presente & 61 & 71,8 \\
& ausente & 24 & 28,2 \\
\hline Indicação de AASI & sim & 23 & 27,1 \\
& não & 62 & 72,9 \\
\hline & Total & 85 & 100,0 \\
\hline
\end{tabular}




\section{III. Associação entre a presença de sinais e sintomas auditivos e a presença de presbiacusia.}

Os dados referentes às características da audição podem ser visualizados na Tabela 10. Foi observada associação estatisticamente significativa entre necessidade de ver a face daquele com quem conversa e presbiacusia $(p=0,044)$. Observa-se a não associação entre presbiacusia e ouvir bem em ambientes ruidosos $(p=0,560)$, ouvir bem sem a pessoa na frente $(p=0,159)$, necessidade de repetição $(p=0,103)$, família acha que ouve bem $(1,000)$, dificuldade para ouvir alguém sussurrando $(p=0,154)$, ouvir bem televisão $(p=0,991)$, ouvir bem ao telefone $(0,191)$, ouvir bem 0 rádio $(p=0,249)$, reclamaram do volume da televisão $(p=0,971)$, amigos acham que ouve bem $(p=1,000)$, audição mudou com idade $(p=0,055)$ e dificuldade para entender as pessoas $(p=0,092)$. 
TABELA 10. Número e porcentagem de idosos segundo características da audição e presença de presbiacusia. GAMIA, HC-FMUSP, São Paulo, 2002.

\begin{tabular}{|c|c|c|c|c|c|}
\hline \multirow[b]{2}{*}{ VARIÁVEL } & \multirow[b]{2}{*}{ categoria } & \multicolumn{2}{|c|}{ Presença de presbiacusia } & \multirow[b]{2}{*}{ TOTAL } & \multirow[b]{2}{*}{$p^{1}$} \\
\hline & & $\begin{array}{c}\text { Não } \\
N .^{\circ}(\%)\end{array}$ & $\frac{\operatorname{Sim}}{\text { N.० }}$ & & \\
\hline $\begin{array}{l}\text { Ouve bern na conversa } \\
\text { frente a frente? }\end{array}$ & $\begin{array}{l}\text { não } \\
\text { sim }\end{array}$ & $\begin{array}{c}1(25,0) \\
23(30,3)\end{array}$ & $\begin{array}{c}8(75,0) \\
53(69,7)\end{array}$ & $\begin{array}{l}9(100,0) \\
76(100,0)\end{array}$ & 0,415 \\
\hline $\begin{array}{l}\text { Ouve bem em ambientes } \\
\text { ruidosos? }\end{array}$ & $\begin{array}{l}\text { não } \\
\text { sim }\end{array}$ & $\begin{array}{l}11(29,4) \\
13(32,5)\end{array}$ & $\begin{array}{l}34(70,6) \\
27(67,5)\end{array}$ & $\begin{array}{l}45(100,0) \\
40(100,0)\end{array}$ & 0,560 \\
\hline $\begin{array}{l}\text { Ouve bem sem a pessoa na } \\
\text { frente? }\end{array}$ & $\begin{array}{l}\text { não } \\
\text { sim }\end{array}$ & $\begin{array}{c}9(21,9) \\
15(36,6)\end{array}$ & $\begin{array}{l}35(78,1) \\
26(63,4)\end{array}$ & $\begin{array}{l}44(100,0) \\
41(100,0)\end{array}$ & 0,159 \\
\hline $\begin{array}{l}\text { Ouve bem em ambiente } \\
\text { silencioso? }\end{array}$ & $\begin{array}{l}\text { não } \\
\text { sim }\end{array}$ & $\begin{array}{c}1(20,0) \\
23(29,1)\end{array}$ & $\begin{array}{c}5(80,0) \\
56(70,9)\end{array}$ & $\begin{array}{l}6(100,0) \\
79(100,0)\end{array}$ & 0,850 \\
\hline $\begin{array}{l}\text { Precisa ver a face com } \\
\text { quem conversa? }\end{array}$ & $\begin{array}{l}\text { não } \\
\text { sim }\end{array}$ & $\begin{array}{l}19(37,3) \\
5(14,7)\end{array}$ & $\begin{array}{l}32(62,7) \\
29(85,3)\end{array}$ & $\begin{array}{l}51(100,0) \\
34(100,0)\end{array}$ & 0,044 \\
\hline Precisa pedir para repetir? & $\begin{array}{l}\text { não } \\
\text { sim }\end{array}$ & $\begin{array}{l}10(43,5) \\
14(24,3)\end{array}$ & $\begin{array}{l}13(56,5) \\
48(75,7)\end{array}$ & $\begin{array}{l}23(100,0) \\
37(100,0)\end{array}$ & 0,103 \\
\hline Familia acha que ouve bem? & $\begin{array}{l}\text { não } \\
\text { sim }\end{array}$ & $\begin{array}{l}12(27,3) \\
12(29,3)\end{array}$ & $\begin{array}{l}32(72,7) \\
29(70,7)\end{array}$ & $\begin{array}{l}44(100,0) \\
41(100,0)\end{array}$ & 1,000 \\
\hline $\begin{array}{l}\text { Dificil ouvir alguém } \\
\text { sussurrando? }\end{array}$ & $\begin{array}{l}\text { não } \\
\text { sim }\end{array}$ & $\begin{array}{l}13(38,2) \\
11(21,6)\end{array}$ & $\begin{array}{l}21(61,8) \\
40(78,4)\end{array}$ & $\begin{array}{l}34(100,0) \\
51(100,0)\end{array}$ & 0,154 \\
\hline Ouve bem televisão? & $\begin{array}{l}\text { năo } \\
\text { sim }\end{array}$ & $\begin{array}{c}4(25,0) \\
20(29,0)\end{array}$ & $\begin{array}{l}12(75,0) \\
49(71,0)\end{array}$ & $\begin{array}{l}16(100,0) \\
69(100,0)\end{array}$ & 0,991 \\
\hline Ouve bem ao telefone? & $\begin{array}{l}\text { não } \\
\text { sim }\end{array}$ & $\begin{array}{c}1(8,3) \\
23(31,5)\end{array}$ & $\begin{array}{l}11(91,7) \\
50(68,5)\end{array}$ & $\begin{array}{l}12(100,0) \\
73(100,0)\end{array}$ & 0,191 \\
\hline Ouve bem o rádio? & $\begin{array}{l}\text { não } \\
\text { sim }\end{array}$ & $\begin{array}{c}1(9,1) \\
23(31,1)\end{array}$ & $\begin{array}{l}10(90,9) \\
51(68,9)\end{array}$ & $\begin{array}{l}11(100,0) \\
74(100,0)\end{array}$ & 0,249 \\
\hline $\begin{array}{l}\text { Reclamaram do volume da } \\
\text { televisão? }\end{array}$ & $\begin{array}{l}\text { não } \\
\text { sim }\end{array}$ & $\begin{array}{l}13(29,5) \\
11(26,8)\end{array}$ & $\begin{array}{l}31(70,5) \\
30(73,2)\end{array}$ & $\begin{array}{l}44(100,0) \\
41(100,0)\end{array}$ & 0,971 \\
\hline $\begin{array}{l}\text { Amigos acham que ouve } \\
\text { bem? }\end{array}$ & $\begin{array}{l}\text { não } \\
\text { sim }\end{array}$ & $\begin{array}{c}4(26,7) \\
20(28,6)\end{array}$ & $\begin{array}{l}11(73,3) \\
50(71,4)\end{array}$ & $\begin{array}{l}15(100,0) \\
70(100,0)\end{array}$ & 1,000 \\
\hline Audição mudou? & $\begin{array}{l}\text { não } \\
\text { sim }\end{array}$ & $\begin{array}{l}14(41,2) \\
10(19,6)\end{array}$ & $\begin{array}{l}20(58,8) \\
41(80,4)\end{array}$ & $\begin{array}{l}34(100,0) \\
51(100,0)\end{array}$ & 0,055 \\
\hline Dificil entender as pessoas? & $\begin{array}{l}\text { não } \\
\text { sim }\end{array}$ & $\begin{array}{l}15(38,5) \\
9(24,1)\end{array}$ & $\begin{array}{l}24(61,5) \\
37(75,9)\end{array}$ & $\begin{array}{l}39(100,0) \\
46(100,0)\end{array}$ & 0,092 \\
\hline \multirow{2}{*}{$\begin{array}{l}\begin{array}{l}\text { Deixou atividades } \\
\text { audição? }\end{array} \\
\text { TOTAL }\end{array}$} & $\begin{array}{l}\text { não } \\
\text { sim } \\
\end{array}$ & $\begin{array}{c}24(29,3) \\
- \\
\end{array}$ & $\begin{array}{l}58(70,7) \\
3(100,0) \\
\end{array}$ & $\begin{array}{c}82(100,0) \\
3(100,0) \\
\end{array}$ & 0,650 \\
\hline & & $24(28,2)$ & $61(71,8)$ & $85(100,0)$ & \\
\hline
\end{tabular}

pi nivel descritivo do teste de qui-quadrado. 
Os dados sobre a indicação de audiometria, pensar em fazer o exame e a realização da audiometria encontram-se na tabela 11. Observa-se associação estatisticamente significativa entre o idoso ter pensado alguma vez em fazer o exame da audição e presbiacusia $(p=0,042)$. Observa-se a não associação estatisticamente significativa com alguém ter falado para fazer o exame $(p=0,561)$ e já ter feito o exame da audição $(p=0,813)$.

TABELA 11. Número e porcentagem de idosos segundo a indicação de audiometria, sua realização e a presença de presbiacusia. GAMIA, HC-FMUSP, São Paulo, 2002.

\begin{tabular}{|c|c|c|c|c|c|}
\hline \multirow{3}{*}{ VARIÁVEL } & \multirow{3}{*}{ categoria } & \multicolumn{2}{|c|}{ Presença de presbiacusia } & \multirow{3}{*}{ TOTAL } & \multirow{3}{*}{$p^{1}$} \\
\hline & & Não & $\operatorname{Sim}$ & & \\
\hline & & N. ${ }^{\circ}(\%)$ & N. ${ }^{\circ}(\%)$ & & \\
\hline Alguém falou para fazer & กão & $18(31,0)$ & $40(69,0)$ & $58(100,0)$ & 0,561 \\
\hline exame da audição? & $\operatorname{sim}$ & $6(22,2)$ & $21(77,8)$ & $27(100,0)$ & \\
\hline Já pensou em fazer exame & não & $13(43,3)$ & $17(56,7)$ & $30(100,0)$ & 0,042 \\
\hline da audição? & $\operatorname{sim}$ & $11(20,0)$ & $44(80,0)$ & $55(100,0)$ & \\
\hline Já fez exame da audição? & não & $12(30,8)$ & $27(69,2)$ & $39(100,0)$ & 0,813 \\
\hline & $\operatorname{sim}$ & $12(26,1)$ & $34(73,9)$ & $46(100,0)$ & \\
\hline TOTAL & & $24(28,2)$ & $61(71,8)$ & $85(100,0)$ & \\
\hline
\end{tabular}

${ }^{1} \mathrm{p}$ : nivel descritivo do teste de qui-quadrado.

As dificuldades auditivas e outros fatores de estudo podem ser observados na Tabela 12 , onde se verifica que todas as variáveis não apresentaram associação estatisticamente significativa com presbiacusia. 
TABELA 12. Número e porcentagem de idosos segundo dificuldades auditivas, alteração de humor e de sono, mudança de comportamento e diminuição da concentração e a presença de presbiacusia. GAMIA, HC-FMUSP, São Paulo, 2002.

\begin{tabular}{|c|c|c|c|c|c|}
\hline \multirow{3}{*}{ VARIÁVEL } & \multirow{3}{*}{ categoria } & \multicolumn{2}{|c|}{ Presença de presbiacusia } & \multirow{3}{*}{ TOTAL } & \multirow{3}{*}{$p^{1}$} \\
\hline & & Não & Sim & & \\
\hline & & N. ${ }^{\circ}(\%)$ & $N .{ }^{\circ}(\%)$ & & \\
\hline \multirow[t]{2}{*}{ Flutuação da audição } & não & $23(27,7)$ & $60(72,3)$ & $83(100,0)$ & 1,000 \\
\hline & $\operatorname{sim}$ & $1(50,0)$ & $1(50,0)$ & $2(100,0)$ & \\
\hline \multirow[t]{2}{*}{ Escuta } & não & $2(33,3)$ & $4(66,7)$ & $6(100,0)$ & 1,000 \\
\hline & $\operatorname{sim}$ & $22(27,8)$ & $57(72,2)$ & $79(100,0)$ & \\
\hline \multirow[t]{2}{*}{ Entende } & não & $10(27,0)$ & $27(73,0)$ & $37(100,0)$ & 1,000 \\
\hline & $\operatorname{sim}$ & $14(29,2)$ & $34(70,8)$ & $48(100,0)$ & \\
\hline \multirow[t]{2}{*}{ Localiza sons } & não & $2(15,4)$ & $11(84,6)$ & $13(100,0)$ & 0,433 \\
\hline & $\operatorname{sim}$ & $22(30,5)$ & $50(69,5)$ & $72(100,0)$ & \\
\hline \multirow[t]{2}{*}{ Percebe sinais } & não & $2(25,0)$ & $6(75,0)$ & $8(100,0)$ & 1,000 \\
\hline & $\operatorname{sim}$ & $22(28,6)$ & $55(71,4)$ & $77(100,0)$ & \\
\hline \multirow[t]{2}{*}{ Alteração do humor } & não & $22(28,2)$ & $56(71,8)$ & $78(100,0)$ & 1,000 \\
\hline & $\operatorname{sim}$ & $2(28,6)$ & $5(71,4)$ & $7(100,0)$ & \\
\hline \multirow[t]{2}{*}{ Alteração do sono } & não & $17(34,7)$ & $32(65,3)$ & $49(100,0)$ & 0,194 \\
\hline & sim & $7(19,4)$ & $29(80,6)$ & $36(100,0)$ & \\
\hline Mudança de & กão & $23(28,4)$ & $58(71,6)$ & $81(100,0)$ & 1,000 \\
\hline comportamento & $\operatorname{sim}$ & $1(25,0)$ & $3(75,0)$ & $4(100,0)$ & \\
\hline Diminuição da & กão & $22(31,9)$ & $47(68,1)$ & $69(100,0)$ & 0,214 \\
\hline concentração & sim & $2(12,5)$ & $14(87,5)$ & $16(100,0)$ & \\
\hline TOTAL & & $24(28,2)$ & $61(71,8)$ & $85(100,0)$ & \\
\hline
\end{tabular}

${ }^{1}$ p: nivel descritivo do teste de associação pelo qui-quadrado. 
Para melhor entender quais os possiveis sinais e sintomas auditivos que estariam levando o indivíduo a referir a necessidade de fazer o exame auditivo, foi feito o teste de associação entre pensou em fazer o exame e estas variáveis (Tabelas 13 e 14). 
TABELA 13. TABELA 10. Número e porcentagem de idosos segundo características da audição e pensou em fazer exame da audição. GAMIA, HC-FMUSP, São Paulo, 2002.

\begin{tabular}{|c|c|c|c|c|c|}
\hline \multirow{2}{*}{ VARIÁVEL } & \multirow{2}{*}{ categoria } & $\begin{array}{c}\begin{array}{c}\text { Pensou em } \\
\text { da }\end{array} \\
\text { Não }\end{array}$ & $\begin{array}{l}\text { fazer exame } \\
\text { audição } \\
\text { Sim }\end{array}$ & \multirow{2}{*}{ TOTAL } & \multirow{2}{*}{$p^{1}$} \\
\hline & & N. ${ }^{\circ}(\%)$ & N. ${ }^{\circ}(\%)$ & & \\
\hline $\begin{array}{l}\text { Ouve bem na conversa } \\
\text { frente a frente? }\end{array}$ & $\begin{array}{l}\text { não } \\
\text { sim }\end{array}$ & $\begin{array}{c}1(11,1) \\
29(38,2)\end{array}$ & $\begin{array}{l}8(88,9) \\
47(61,8)\end{array}$ & $\begin{array}{l}9(100,0) \\
76(100,0)\end{array}$ & 0,216 \\
\hline $\begin{array}{l}\text { Ouve bem em ambientes } \\
\text { ruidosos? }\end{array}$ & $\begin{array}{l}\text { não } \\
\text { sim }\end{array}$ & $\begin{array}{l}11(24,4) \\
19(47,5)\end{array}$ & $\begin{array}{l}34(75,6) \\
21(52,5)\end{array}$ & $\begin{array}{l}45(100,0) \\
40(100,0)\end{array}$ & 0,046 \\
\hline $\begin{array}{l}\text { Ouve bem sem a pessoa na } \\
\text { frente? }\end{array}$ & $\begin{array}{l}\text { não } \\
\text { sim }\end{array}$ & $\begin{array}{c}7(15,9) \\
23(56,1)\end{array}$ & $\begin{array}{l}37(84,1) \\
18(43,9)\end{array}$ & $\begin{array}{l}44(100,0) \\
41(100,0)\end{array}$ & $<0,001$ \\
\hline $\begin{array}{l}\text { Ouve bem em ambiente } \\
\text { silencioso? }\end{array}$ & $\begin{array}{l}\text { não } \\
\text { sim }\end{array}$ & $30(38,0)$ & $\begin{array}{l}6(100,0) \\
49(62,0)\end{array}$ & $\begin{array}{c}6(100,0) \\
79(100,0)\end{array}$ & 0,152 \\
\hline $\begin{array}{l}\text { Precisa ver a face com } \\
\text { quem conversa? }\end{array}$ & $\begin{array}{l}\text { não } \\
\text { sim }\end{array}$ & $\begin{array}{l}24(47,1) \\
6(17,6)\end{array}$ & $\begin{array}{l}27(52,9) \\
28(82,4)\end{array}$ & $\begin{array}{l}51(100,0) \\
34(100,0)\end{array}$ & 0,011 \\
\hline Precisa pedir para repetir? & $\begin{array}{l}\text { não } \\
\text { sim }\end{array}$ & $\begin{array}{l}14(60,9) \\
16(25,8)\end{array}$ & $\begin{array}{c}9(39,1) \\
46(74,2)\end{array}$ & $\begin{array}{l}23(100,0) \\
62(100,0)\end{array}$ & 0,006 \\
\hline Familia acha que ouve bem? & $\begin{array}{l}\text { não } \\
\text { sim }\end{array}$ & $\begin{array}{c}9(20,5) \\
21(51,2)\end{array}$ & $\begin{array}{l}35(79,5) \\
20(48,8)\end{array}$ & $\begin{array}{l}44(100,0) \\
41(100,0)\end{array}$ & 0,006 \\
\hline $\begin{array}{l}\text { Dificil ouvir alguém } \\
\text { sussurrando? }\end{array}$ & $\begin{array}{l}\text { não } \\
\text { sim }\end{array}$ & $\begin{array}{l}18(52,9) \\
12(23,5)\end{array}$ & $\begin{array}{l}16(47,1) \\
39(76,5)\end{array}$ & $\begin{array}{l}34(100,0) \\
51(100,0)\end{array}$ & 0,011 \\
\hline Ouve bem televisão? & $\begin{array}{l}\text { não } \\
\text { sim }\end{array}$ & $\begin{array}{c}1(6,3) \\
29(42,0)\end{array}$ & $\begin{array}{l}15(93,8) \\
40(58,0)\end{array}$ & $\begin{array}{l}16(100,0) \\
69(100,0)\end{array}$ & 0,016 \\
\hline Ouve bem o telefone? & $\begin{array}{l}\text { não } \\
\text { sim }\end{array}$ & $30(41,1)$ & $\begin{array}{c}12(100,0) \\
43(58,9)\end{array}$ & $\begin{array}{l}12(100,0) \\
73(100,0)\end{array}$ & 0,015 \\
\hline Ouve bem o rádio? & $\begin{array}{l}\text { não } \\
\text { sim }\end{array}$ & $\begin{array}{c}1(9,1) \\
29(39,2)\end{array}$ & $\begin{array}{l}10(90,9) \\
45(60,8)\end{array}$ & $\begin{array}{l}11(100,0) \\
74(100,0)\end{array}$ & 0,107 \\
\hline $\begin{array}{l}\text { Reclamaram do volume da } \\
\text { televisão? }\end{array}$ & $\begin{array}{l}\text { não } \\
\text { sim }\end{array}$ & $\begin{array}{l}19(43,2) \\
11(26,8)\end{array}$ & $\begin{array}{l}25(56,8) \\
30(73,2)\end{array}$ & $\begin{array}{l}44(100,0) \\
41(100,0)\end{array}$ & 0,177 \\
\hline $\begin{array}{l}\text { Amigos acham que ouve } \\
\text { bem? }\end{array}$ & $\begin{array}{l}\text { não } \\
\text { sim }\end{array}$ & $\begin{array}{c}2(13,3) \\
28(40,0)\end{array}$ & $\begin{array}{l}13(86,7) \\
42(60,0)\end{array}$ & $\begin{array}{l}15(100,0) \\
70(100,0)\end{array}$ & 0,096 \\
\hline Audição mudou? & $\begin{array}{l}\text { não } \\
\text { sim }\end{array}$ & $\begin{array}{l}17(50,0) \\
13(25,5)\end{array}$ & $\begin{array}{l}17(50,0) \\
38(74,5)\end{array}$ & $\begin{array}{l}34(100,0) \\
51(100,0)\end{array}$ & 0,037 \\
\hline Difícil entender as pessoas? & $\begin{array}{l}\text { não } \\
\text { sim }\end{array}$ & $\begin{array}{l}20(51,3) \\
10(21,7)\end{array}$ & $\begin{array}{l}19(48,7) \\
36(78,3)\end{array}$ & $\begin{array}{l}39(100,0) \\
46(100,0)\end{array}$ & 0,009 \\
\hline $\begin{array}{l}\text { Deixou atividades pela } \\
\text { audicão? }\end{array}$ & $\begin{array}{l}\text { não } \\
\text { sim }\end{array}$ & $\begin{array}{c}29(35,4) \\
1(33,3) \\
\end{array}$ & $\begin{array}{l}53(64,6) \\
2(66,7) \\
\end{array}$ & $\begin{array}{c}82(100,0) \\
3(100,0) \\
\end{array}$ & 1,000 \\
\hline TOTA! & & $30(35,3)$ & $55(64,7)$ & $85(100,0)$ & \\
\hline
\end{tabular}

p. nuvel descritio dio leste de qui-quadrado. 
TABELA 14. Número e porcentagem de idosos segundo dificuldades auditivas, alteração de humor e de sono, mudança de comportamento, diminuição da concentração e alguém falou para fazer exame da audição e pensou em fazer exame da audição. GAMIA, HCFMUSP, São Paulo, 2002.

\begin{tabular}{|c|c|c|c|c|c|}
\hline \multirow{3}{*}{ VARIÁVEL } & \multirow{3}{*}{ categoria } & \multicolumn{2}{|c|}{ Presença de presbiacusia } & \multirow{3}{*}{ TOTAL } & \multirow{3}{*}{$p^{1}$} \\
\hline & & Não & Sim & & \\
\hline & & N.O(\%) & N.O $(\%)$ & & \\
\hline \multirow[t]{2}{*}{ Flutuação da audição } & não & $29(34,9)$ & $54(65,1)$ & $83(100,0)$ & 1,000 \\
\hline & $\operatorname{sim}$ & $1(50,0)$ & $1(50,0)$ & $2(100,0)$ & \\
\hline \multirow[t]{2}{*}{ Escuta } & não & $1(16,7)$ & $5(83,3)$ & $6(100,0)$ & 0,584 \\
\hline & $\operatorname{sim}$ & $29(36,7)$ & $50(63,3)$ & $79(100,0)$ & \\
\hline \multirow[t]{2}{*}{ Entende } & não & $9(24,3)$ & $28(75,7)$ & $37(100,0)$ & 0,103 \\
\hline & $\operatorname{sim}$ & $21(43,8)$ & $27(56,3)$ & $48(100,0)$ & \\
\hline \multirow[t]{2}{*}{ Localiza sons } & não & $2(15,4)$ & $11(84,6)$ & $13(100,0)$ & 0,188 \\
\hline & $\operatorname{sim}$ & $28(38,9)$ & $44(61,1)$ & $72(100,0)$ & \\
\hline \multirow[t]{2}{*}{ Percebe sinais } & não & $1(12,5)$ & $7(87,5)$ & $8(100,0)$ & 0,304 \\
\hline & $\operatorname{sim}$ & $29(37,7)$ & $48(62,3)$ & $77(100,0)$ & \\
\hline \multirow[t]{2}{*}{ Alteração do humor } & não & $28(35,9)$ & $50(64,1)$ & $78(100,0)$ & 1,000 \\
\hline & $\operatorname{sim}$ & $2(28,6)$ & $5(71,4)$ & $7(100,0)$ & \\
\hline \multirow[t]{2}{*}{ Alteração do sono } & não & $19(38,8)$ & $30(61,2)$ & $49(100,0)$ & 0,580 \\
\hline & $\operatorname{sim}$ & $11(30,6)$ & $25(69,4)$ & $36(100,0)$ & \\
\hline Mudança de & não & $29(35,8)$ & $52(64,2)$ & $81(100,0)$ & 1,000 \\
\hline comportamento & $\operatorname{sim}$ & $1(25,0)$ & $3(75,0)$ & $4(100,0)$ & \\
\hline \multirow[t]{2}{*}{ Diminuição da concentração } & não & $28(40,6)$ & $41(59,4)$ & $69(100,0)$ & 0,068 \\
\hline & $\operatorname{sim}$ & $2(12,5)$ & $14(87,5)$ & $16(100,0)$ & \\
\hline Alguém já falou para fazer & não & $27(46,6)$ & $31(53,4)$ & $58(100,0)$ & 0,003 \\
\hline exame da audição? & $\operatorname{sim}$ & $3(11,1)$ & $24(88,9)$ & $27(100,0)$ & \\
\hline TOTAL & & $30(35,3)$ & $55(64,7)$ & $95(100,0)$ & \\
\hline
\end{tabular}

\footnotetext{
'p: nivel descritivo do teste de associação pelo qui-quadrado.
} 
Nove variáveis foram estatisticamente associadas à pensar em fazer o exame da audição. Dos idosos que relataram ouvir bem sem precisar ver a face com quem conversam, $82,4 \%$ já pensaram em fazer o exame de audição, diminuindo para $52,9 \%$ entre aqueles que não precisam ver a face $(p=0,011)$.

Entre os idosos que disseram que a audição mudou com a idade, $74,5 \%$ pensaram em fazer o exame enquanto $50 \%$ dos que não perceberam mudança na audição com a idade pensaram em fazer o exame $(p=0,037)$. Quando referiram ter dificuldade para entender as pessoas $78,3 \%$ pensaram em fazer o exame, enquanto que $48,7 \%$ dos que não referem dificuldade pensaram em fazer o exame $(p=0,009)$. Entre os idosos que precisam pedir para repetir $74,2 \%$ já pensaram em fazer o exame de audição, reduzindo para $39,1 \%$ entre os que não precisam pedir $(p=0,006)$. Entre os idosos que referem dificuldade para ouvir alguém sussurrando, $76,5 \%$ pensaram em fazer o exame e entre os sem dificuldade, esse valor diminui para $47,1 \%(p=0,011)$. Quando indagados se ouvem bem sem a pessoa na frente, $84,1 \%$ relataram que não e pensaram em fazer o exame enquanto $43,9 \%$ relataram que sim e pensaram em fazer o exame $(p<0,001)$. Entre os idosos que relatam que não ouvem bem ao telefone todos $(100 \%)$ pensaram em fazer o exame enquanto os que ouvem bem, $58,9 \%$ pensaram em fazer o exame da audição $(p=0,015)$.

Quando a pergunta é se a família acha que ouve bem, $79,5 \%$ relatam que não e pensaram em fazer o exame enquanto, $48,8 \%$ dos que 
relatam que sim pensaram em fazer 0 exame. Na resposta afirmativa para alguém já ter falado para faze o exame da audição, $88,9 \%$ dos idosos já pensaram em fazer o exame enquanto, $53,4 \%$ que pensaram em fazer 0 exame não relataram que alguém já tivesse falado para que fizessem o exame de audição.

\section{IV. Fatores associados a presbiacusia}

Das características sócio demográficas, presença de ruído ocupacional e possuir familiar com história de problema auditivo (Tabela 15), observa-se a associação estatisticamente significativa entre idade e presbiacusia $(p=0,032)$ e entre possuir familiar com história de problema auditivo e presbiacusia $(p=0,047)$. Observa-se a não associação estatisticamente significativa entre presbiacusia e sexo $(p=0,769)$, cor $(p=0,317)$, estado marital $(p=0,949)$, renda $(p=0,068)$, anos de escolaridade $(p=0,915)$ e ruído ocupacional $(p=0,650)$. 
TABELA 15. Número e porcentagem de idosos segundo sexo, faixa etária, cor, estado marital, renda, anos de escolaridade, ruído ocupacional e possui familiar com história de problema auditivo e presença de presbiacusia. GAMIA, HC-FMUSP, São Paulo, 2002.

\begin{tabular}{|c|c|c|c|c|c|}
\hline \multirow{3}{*}{ VARIÁVEL } & \multirow{3}{*}{ categoria } & \multicolumn{2}{|c|}{ Presença de presbiacusia } & \multirow{3}{*}{ TOTAL } & \multirow{3}{*}{$p^{1}$} \\
\hline & & Não & Sim & & \\
\hline & & $N .{ }^{\circ}(\%)$ & N.O $(\%)$ & & \\
\hline \multirow[t]{2}{*}{ sexo } & masculino & $3(21,4)$ & $11(78,6)$ & $14(100,0)$ & 0,769 \\
\hline & feminino & $21(29,6)$ & $50(70,4)$ & $71(100,0)$ & \\
\hline \multirow[t]{3}{*}{ faixa etária } & $60-64$ & $5(45,5)$ & $6(54,5)$ & $11(100,0)$ & 0,032 \\
\hline & $65-69$ & $9(45,0)$ & $11(55,0)$ & $20(100,0)$ & \\
\hline & 70 e mais & $10(18,5)$ & $44(81,5)$ & $54(100,0)$ & \\
\hline \multirow[t]{2}{*}{ cor } & branca & $19(25,7)$ & $55(74,3)$ & $74(100,0)$ & 0,317 \\
\hline & não branca & $5(45,5)$ & $6(54,5)$ & $11(100,0)$ & \\
\hline \multirow[t]{2}{*}{ estado marital } & casado & $7(25,9)$ & $20(74,1)$ & $27(100,0)$ & 0,949 \\
\hline & não casado & $17(29,3)$ & $41(70,7)$ & $58(100,0)$ & \\
\hline \multirow[t]{2}{*}{ renda } & $1-5$ & $17(34,2)$ & $51(65,8)$ & $68(100,0)$ & 0,068 \\
\hline & 6 e mais & $7(41,2)$ & $10(58,8)$ & $17(100,0)$ & \\
\hline \multirow[t]{3}{*}{ anos escolaridade } & $1-4$ & $15(26,8)$ & $41(73,2)$ & $56(100,0)$ & 0,915 \\
\hline & $5-8$ & $6(31,6)$ & $13(68,4)$ & $19(100,0)$ & \\
\hline & 9 e mais & $3(30,0)$ & $7(70,0)$ & $10(100,00)$ & \\
\hline \multirow[t]{2}{*}{ ruído ocupacional } & não & $15(25,9)$ & $43(74,1)$ & $58(68,2)$ & 0,650 \\
\hline & sim & $9(33,3)$ & $18(66,7)$ & $27(100,0)$ & \\
\hline Possui familiar com & กão & $23(33,8)$ & $45(66,2)$ & $68(100,0)$ & 0,047 \\
\hline problema auditivo? & $\operatorname{sim}$ & $1(5,9)$ & $16(94,1)$ & $17(100,0)$ & \\
\hline TOTAL & & $24(28,2)$ & $61(71,8)$ & $85(100,0)$ & \\
\hline
\end{tabular}

p: nivel descritivo do teste de associação pelo qui-quadrado. 
A média de idade de quem tem presbiacusia é superior à daqueles que não têm $(p=0,014)$, porém não houve diferença estatisticamente significativa entre as médias de renda $(p=0,742)$ e escolaridade $(p=0,832)$ (Tabela 16).

Tabela 16. Comparação de médias de idade, renda e escolaridade segundo presença de presbiacusia. GAMIA, HC-FMUSP, São Paulo, 2002.

\begin{tabular}{|c|c|c|c|}
\hline \multirow{3}{*}{ Variável } & \multicolumn{2}{|c|}{ Presença de presbiacusia } & \multirow{3}{*}{$p$} \\
\hline & Não & $\operatorname{Sim}$ & \\
\hline & média (DP) ${ }^{(1)}$ & média (DP) & \\
\hline Idade (anos) & $69,7(6,23)$ & $72,75(5,79)$ & $0,014^{t(2)}$ \\
\hline Renda (salário min.) & $5,0(2,9)$ & $4,9(2,9)$ & $0,832^{\mathrm{mw}(3)}$ \\
\hline Escolaridade (anos) & $5,1(5,0)$ & $4,3(3,7)$ & $0,742^{\mathrm{mw}(3)}$ \\
\hline
\end{tabular}

(1) $\mathrm{DP}=$ desvio padrão.

(2) t: teste t-student.

(3) mw: teste de Mann-Whitney.

Não se observou associação estatisticamente significativa entre presbiacusia e fumar $(p=0,487)$, ter fumado $(p=0,277)$, conviver com quem fuma $(p=1,000)$, conviveu com quem fumava $(p=1,000)$ e uso de bebida alcoólica $(p=0,748)$ (Tabela 17). 
TABELA 17. Número e porcentagem de idosos segundo os hábitos de beber e de fumar e a presença de presbiacusia. GAMIA, HC-FMUSP, São Paulo, 2002.

\begin{tabular}{|c|c|c|c|c|c|}
\hline \multirow{3}{*}{ VARIÁVEL } & \multirow{3}{*}{ categoria } & Presença de & presbiacusia & \multirow{3}{*}{ TOTAL } & \multirow{3}{*}{$p^{1}$} \\
\hline & & Não & Sim & & \\
\hline & & N.O $(\%)$ & N.O $(\%)$ & & \\
\hline \multirow[t]{2}{*}{ Fuma? } & não & $23(27,7)$ & $60(72,3)$ & $83(100,0)$ & 0,487 \\
\hline & $\operatorname{sim}$ & $1(50,0)$ & $1(50,0)$ & $2(100,0)$ & \\
\hline \multirow[t]{2}{*}{ Já fumou? } & não & $17(25,0)$ & $51(75,0)$ & $68(100,0)$ & 0,277 \\
\hline & $\operatorname{sim}$ & $7(41,2)$ & $10(58,8)$ & $17(100,0)$ & \\
\hline \multirow[t]{2}{*}{ Convive com quem fuma? } & não & $18(27,7)$ & $47(72,3)$ & $65(100,0)$ & 1,000 \\
\hline & $\operatorname{sim}$ & $6(30,0)$ & $14(70,0)$ & $20(100,0)$ & \\
\hline \multirow[t]{2}{*}{ Conviveu com quem fumava? } & กão & $11(28,2)$ & $28(71,8)$ & $39(100,0)$ & 1,000 \\
\hline & $\operatorname{sim}$ & $13(28,3)$ & $33(71,7)$ & $46(100,0)$ & \\
\hline \multirow[t]{2}{*}{ Faz uso de bebida alcoólica? } & não & $21(29,6)$ & $50(70,4)$ & $71(100,0)$ & 0,748 \\
\hline & $\operatorname{sim}$ & $3(21,4)$ & $11(78,6)$ & $14(100,0)$ & \\
\hline TOTAL & & $24(28,2)$ & $61(71,8)$ & $85(100,0)$ & \\
\hline
\end{tabular}

\footnotetext{
${ }^{1}$ p: nivel descritivo do teste de associação pelo qui-quadrado.
}

Os dados referentes a número de diagnósticos médicos, número de medicações prescritas e índice de massa corporal (IMC) podem ser visualizados na Tabela 18, verificando-se a inexistência de associação estatística entre elas e a presença de presbiacusia. 
TABELA 18. Número e porcentagem de idosos segundo número de diagnósticos médicos, número de medicações prescritas, índice de massa corporal (IMC) e a presença de presbiacusia. GAMIA, HC-FMUSP, São Paulo, 2002.

\begin{tabular}{|c|c|c|c|c|c|}
\hline \multirow{3}{*}{ VARIÁVEL } & \multirow{3}{*}{ categoria } & Presença de & presbiacusia & \multirow{3}{*}{ TOTAL } & \multirow{3}{*}{$p^{1}$} \\
\hline & & Não & Sim & & \\
\hline & & $N .0(\%)$ & N.O $(\%)$ & & \\
\hline \multirow[t]{2}{*}{ Número de diagnósticos ${ }^{2}$} & $0-5$ & $18(25,0)$ & $43(75,0)$ & $61(100,0)$ & 0,937 \\
\hline & 6 e mais & $6(27,3)$ & $16(72,7)$ & $22(100,0)$ & \\
\hline \multirow[t]{2}{*}{ Número de medicamentos ${ }^{2}$} & $0-5$ & $20(24,2)$ & $52(75,8)$ & $72(100,0)$ & 0,890 \\
\hline & 6 e mais & $4(30,8)$ & $9(69,2)$ & $13(100,0)$ & \\
\hline \multirow[t]{2}{*}{$\operatorname{IMC}^{3}$} & $\begin{array}{l}\text { adequado e } \\
\text { desnutrido }\end{array}$ & $11(32,4)$ & $23(67,6)$ & $34(100,0)$ & 1,000 \\
\hline & sobrepeso & $12(30,0)$ & $28(70,0)$ & $40(100,0)$ & \\
\hline TOTAL & & $24(28,2)$ & $61(71,8)$ & $85(100,0)$ & \\
\hline
\end{tabular}

\footnotetext{
${ }^{1}$ p: nível descritivo do teste de associação pelo qui-quadrado.

2 excluídos 2 casos sem a informação

${ }^{3}$ excluídos 10 casos sem a informação.
}

Os resultados de exames laboratoriais podem ser visualizados na Tabela 19 e nela observa-se a não associação estatisticamente significativa entre estas variáveis e presbiacusia. 
TABELA 19. Número e porcentagem de idosos segundo exames laboratoriais e a presença de presbiacusia. GAMIA, HC-FMUSP, São Paulo, 2002.

\begin{tabular}{|c|c|c|c|c|c|}
\hline \multirow{3}{*}{ VARIÁVEL } & \multirow{3}{*}{ categoria } & Presença de & presbiacusia & \multirow{3}{*}{ TOTAL } & \multirow{3}{*}{$p^{1}$} \\
\hline & & Não & Sim & & \\
\hline & & $N .{ }^{\circ}(\%)$ & N. ${ }^{\circ}(\%)$ & & \\
\hline $\mathrm{Na}(\mathrm{mEq} / \mathrm{L})^{2}$ & $\begin{array}{c}<135 \\
135-145\end{array}$ & $\begin{array}{c}3(25,0) \\
20(27,8)\end{array}$ & $\begin{array}{c}9(75,0) \\
52(72,2)\end{array}$ & $\begin{array}{l}12(100,0) \\
72(100,0)\end{array}$ & 1,000 \\
\hline$K(m E q / L)^{2}$ & $\begin{array}{c}\mathbf{3 , 5}-\mathbf{5 , 0} \\
>5\end{array}$ & $\begin{array}{l}22(28,9) \\
1(14,3)\end{array}$ & $\begin{array}{l}54(71,1) \\
6(85,7)\end{array}$ & $\begin{array}{l}76(100,0) \\
7(100,0)\end{array}$ & 0,698 \\
\hline Uréia (mg/dL) & $\begin{array}{c}10-45 \\
>45\end{array}$ & $\begin{array}{c}19(26,4) \\
5(41,7)\end{array}$ & $\begin{array}{l}53(73,6) \\
7(58,3)\end{array}$ & $\begin{array}{l}72(100,0) \\
12(100,0)\end{array}$ & 0,460 \\
\hline Glicose (mg/dL) & $\begin{array}{c}70-110 \\
>110\end{array}$ & $\begin{array}{c}19(27,1) \\
5(33,3)\end{array}$ & $\begin{array}{l}51(72,9) \\
10(66,7)\end{array}$ & $\begin{array}{l}70(100,0) \\
15(100,0)\end{array}$ & 0,867 \\
\hline $\begin{array}{l}\text { Creatinina } \\
(\mathrm{mg} / \mathrm{dL})^{2}\end{array}$ & $\begin{array}{c}0,6-1,4 \\
>1,4\end{array}$ & $\begin{array}{c}23(28,0) \\
1(50,0)\end{array}$ & $\begin{array}{l}59(72,0) \\
1(50,0)\end{array}$ & $\begin{array}{l}82(100,0) \\
2(100,0)\end{array}$ & 1,000 \\
\hline $\begin{array}{l}\text { Eritrócitos } \\
\text { (milhões/mm3) }^{2}\end{array}$ & $\begin{array}{l}\text { normal } \\
\text { atterado }\end{array}$ & $\begin{array}{c}2(16,7) \\
20(29,8)\end{array}$ & $\begin{array}{l}10(83,3) \\
48(70,6)\end{array}$ & $\begin{array}{l}12(100,0) \\
68(100,0)\end{array}$ & 0,575 \\
\hline $\mathrm{HgB}(\mathrm{g} / \mathrm{dL})$ & $\begin{array}{l}\text { normal } \\
\text { alterado }\end{array}$ & $\begin{array}{c}2(15,4) \\
1(100,0)\end{array}$ & $11(84,6)$ & $\begin{array}{l}13(100,0) \\
1(100,0)\end{array}$ & 0,470 \\
\hline Hematócritos (\%) & $\begin{array}{l}\text { normal } \\
\text { alterado }\end{array}$ & $\begin{array}{l}18(27,7) \\
3(50,0)\end{array}$ & $\begin{array}{l}47(72,3) \\
3(50,0)\end{array}$ & $\begin{array}{l}65(100,0) \\
6(100,0)\end{array}$ & 0,498 \\
\hline Plaquetas $\left(\mathrm{mm}^{3}\right)^{2}$ & $\begin{array}{c}150.000-350.000 \\
>350.000\end{array}$ & $\begin{array}{l}21(28,0) \\
3(33,3)\end{array}$ & $\begin{array}{l}54(72,0) \\
6(66,7)\end{array}$ & $\begin{array}{l}75(100,0) \\
9(100,0)\end{array}$ & 1,000 \\
\hline $\begin{array}{l}\text { Colesterol total } \\
(\mathrm{mg} / \mathrm{dL})>20 \text { anos }^{2}\end{array}$ & $\begin{array}{l}<239 \\
>240\end{array}$ & $\begin{array}{l}15(25,4) \\
9(36,0)\end{array}$ & $\begin{array}{l}44(74,6) \\
16(64,0)\end{array}$ & $\begin{array}{l}59(100,0) \\
25(100,0)\end{array}$ & 0,473 \\
\hline $\mathrm{HDL}(\mathrm{mg} / \mathrm{dL}) 2$ & $\begin{array}{l}<40 \\
>=40\end{array}$ & $\begin{array}{l}22(29,3) \\
2(22,2)\end{array}$ & $\begin{array}{l}53(70,7) \\
7(77,8)\end{array}$ & $\begin{array}{l}75(100,0) \\
9(100,0)\end{array}$ & 0,956 \\
\hline$L D L(m g / d L)$ & $\begin{array}{l}\text { Até } 130 \\
>130\end{array}$ & $\begin{array}{c}6(22,2) \\
18(31,6)\end{array}$ & $\begin{array}{l}21(77,8) \\
39(68,4)\end{array}$ & $\begin{array}{l}27(100,0) \\
57(100,0)\end{array}$ & 0,530 \\
\hline VLDL (mg/dL) & $\begin{array}{c}<38 \\
38 \text { e mais }\end{array}$ & $\begin{array}{c}4(30,8) \\
20(28,2)\end{array}$ & $\begin{array}{c}9(69,2) \\
51(71,8)\end{array}$ & $\begin{array}{l}13(100,0) \\
71(100,0)\end{array}$ & 1,000 \\
\hline $\begin{array}{l}\text { Triglicérides } \\
\text { (mg/dL) }\end{array}$ & $\begin{array}{c}<150 \\
150 \text { e mais } \\
\end{array}$ & $\begin{array}{c}16(26,7) \\
8(33,3) \\
\end{array}$ & $\begin{array}{l}44(73,3) \\
16(66,7) \\
\end{array}$ & $\begin{array}{l}60(100,0) \\
24(100,0) \\
\end{array}$ & 0,731 \\
\hline TOTA & & $24(28,2)$ & $61(71,8)$ & $85(100,0)$ & \\
\hline
\end{tabular}

\footnotetext{
${ }^{1} \mathrm{p}$ : nivel descritivo do teste de associação pelo qui-quadrado.
} 
A Tabela 20 apresenta os dados referentes aos sintomas relacionados à audição e sua associação com a presbiacusia. Foram analisados apenas aqueles sintomas com prevalência superior a $10 \%$ dos casos, para evitar a presença de caselas vazias. Observa-se a não associação estatisticamente significativa entre essas variáveis e a presença de presbiacusia.

TABELA 20. Número e porcentagem de idosos segundo sintomas relacionados à audição e a presença de presbiacusia. GAMIA, HC-FMUSP, São Paulo, Zi,J2.

\begin{tabular}{|c|c|c|c|c|c|}
\hline \multirow{3}{*}{ VARIÁVEL } & \multirow{3}{*}{ categoria } & \multicolumn{2}{|c|}{ Presença de presbiacusia } & \multirow{3}{*}{ TOTAL } & \multirow{3}{*}{$p^{1}$} \\
\hline & & Não & Sim & & \\
\hline & & $N .{ }^{\circ}(\%)$ & N. ${ }^{\circ}(\%)$ & & \\
\hline \multirow[t]{2}{*}{ Otoméia OD } & กão & $19(25,3)$ & $56(74,7)$ & $75(100,0)$ & $\overline{0,210}$ \\
\hline & $\operatorname{sim}$ & $5(50,0)$ & $5(50,0)$ & $10(100,0)$ & \\
\hline \multirow[t]{2}{*}{ Otorréia OE } & não & $19(25,0)$ & $57(75,0)$ & $76(100,0)$ & 0,125 \\
\hline & $\operatorname{sim}$ & $5(55,5)$ & $4(44,5)$ & $9(100,0)$ & \\
\hline \multirow[t]{2}{*}{ Zumbido OD } & não & $21(33,3)$ & $42(66,7)$ & $63(100,0)$ & 0,136 \\
\hline & $\operatorname{sim}$ & $3(13,6)$ & $19(86,4)$ & $22(100,0)$ & \\
\hline \multirow[t]{2}{*}{ Zumbido CE } & não & $17(28,3)$ & $43(71,7)$ & $60(100,0)$ & 1,000 \\
\hline & $\operatorname{sim}$ & $7(28,0)$ & $18(72,0)$ & $25(100,0)$ & \\
\hline \multirow[t]{2}{*}{ Otalgia OD } & não & $20(29,4)$ & $48(70,5)$ & $68(100,0)$ & 0,857 \\
\hline & $\operatorname{sim}$ & $4(23,5)$ & $13(76,5)$ & $17(100,0)$ & \\
\hline \multirow[t]{2}{*}{ Otalgia OE } & não & $21(29,2)$ & $51(70,8)$ & $72(100,0)$ & 0,909 \\
\hline & $\operatorname{sim}$ & $3(23,0)$ & $10(77,0)$ & $13(100,0)$ & \\
\hline TOTAL & & $24(28,2)$ & $61(71,8)$ & $85(100,0)$ & \\
\hline
\end{tabular}

'p: nível descritivo do teste de associação pelo qui-quadrado. 
As variáveis sobre diabetes e hipertensão arterial podem ser visualizados na Tabela 21 onde se observa a não existência de associação estatisticamente significativa entre quaisquer desses fatores à presença de presbiacusia.

TABELA 21. Número e porcentagem de idosos segundo diabetes e hipertensão arterial e a presença de presbiacusia. GAMIA, HCFMUSP, São Paulo, 2002.

\begin{tabular}{|c|c|c|c|c|c|}
\hline \multirow{3}{*}{ VARIÁVEL } & \multirow{3}{*}{ categoria } & \multicolumn{2}{|c|}{ Presença de presbiacusia } & \multirow{3}{*}{ TOTAL } & \multirow{3}{*}{$p^{1}$} \\
\hline & & Não & Sim & & \\
\hline & & N. ${ }^{\circ}(\%)$ & N. $(\%)$ & & \\
\hline \multirow[t]{2}{*}{ Diabetes } & não & $18(25,4)$ & $53(74,6)$ & $71(100,0)$ & 0,315 \\
\hline & $\operatorname{sim}$ & $6(42,9)$ & $8(57,1)$ & $14(100,0)$ & \\
\hline \multirow[t]{2}{*}{ Hipertensão arterial } & não & $8(20,0)$ & $32(80,0)$ & $40(100,0)$ & 0,177 \\
\hline & $\operatorname{sim}$ & $16(35,6)$ & $29(64,4)$ & $45(100,0)$ & \\
\hline \multicolumn{2}{|c|}{ TOTAL } & $24(28,2)$ & $61(71,8)$ & $85(100,0)$ & \\
\hline
\end{tabular}

${ }^{1}$ p: nivel descritivo do teste de associação pelo qui-quadrado.

Os achados no exame físico realizado pelo médico especialista em otorrinolaringologia podem ser observados na Tabela 22. Houve associação estatisticamente significativa entre alteração em membrana timpânica em orelha direita $(p=0,027)$ e em orelha esquerda $(p=0,027)$, mas 
não foi observada associação estatística significativa com a presença de alterações de meato acústico em orelha direita $(p=0,769)$ e em orelha esquerda $(p=0,434)$ e em oroscopia $(p=0,855)$.

TABELA 22. Número e porcentagem de idosos segundo exame físico otorrinolaringológico e a presença de presbiacusia. GAMIA, HCFMUSP, São Paulo, 2002.

\begin{tabular}{|c|c|c|c|c|c|}
\hline \multirow[b]{2}{*}{ VARIÁVEL } & \multirow[b]{2}{*}{ categoria } & \multicolumn{2}{|c|}{ Presença de presbiacusia } & \multirow[b]{2}{*}{ TOTAL } & \multirow[b]{2}{*}{$p^{1}$} \\
\hline & & \begin{tabular}{|c|} 
Não \\
N.o $(\%)$ \\
\end{tabular} & $\frac{\operatorname{sim}}{\text { N. }{ }^{\circ}(\%)}$ & & \\
\hline Meato acústico OD & $\begin{array}{l}\text { normal } \\
\text { alterada }\end{array}$ & $\begin{array}{c}21(29,6) \\
3(21,4)\end{array}$ & $\begin{array}{l}50(70,4) \\
11(78,6)\end{array}$ & $\begin{array}{l}71(100,0) \\
14(100,0)\end{array}$ & 0,764 \\
\hline Meato acústico $\mathrm{OE}$ & $\begin{array}{l}\text { normal } \\
\text { alterada }\end{array}$ & $\begin{array}{c}21(30,9) \\
3(17,6)\end{array}$ & $\begin{array}{l}47(69,1) \\
14(82,4)\end{array}$ & $\begin{array}{l}68(100,0) \\
17(100,0)\end{array}$ & 0,434 \\
\hline Membrana timpânica $O D$ & $\begin{array}{l}\text { normal } \\
\text { alterada }\end{array}$ & $\begin{array}{c}19(24,4) \\
5(71,4)\end{array}$ & $\begin{array}{c}59(75,6) \\
2(28,6)\end{array}$ & $\begin{array}{c}78(100,0) \\
7(100,0)\end{array}$ & 0,027 \\
\hline Membrana timpânica $\mathrm{OE}$ & $\begin{array}{l}\text { normal } \\
\text { alterada }\end{array}$ & $\begin{array}{c}19(24,4) \\
5(71,4)\end{array}$ & $\begin{array}{c}59(76,6) \\
2(28,6)\end{array}$ & $\begin{array}{c}78(100,0) \\
7(100,0)\end{array}$ & 0,027 \\
\hline Oroscopia & $\begin{array}{l}\text { normal } \\
\text { alterada }\end{array}$ & $\begin{array}{c}23(29,1) \\
1(16,7)\end{array}$ & $\begin{array}{c}56(70,9) \\
5(83,3)\end{array}$ & $\begin{array}{c}79(100,0) \\
6(100,0)\end{array}$ & 0,855 \\
\hline TOTAL & & $24(28,2)$ & $61(71,8)$ & $85(100,0)$ & \\
\hline
\end{tabular}

'p: nível descritivo do teste de associação pelo qui-quadrado.

A partir da análise pelo teste de associação pelo qui-quadrado, foram selecionadas, para a análise múltipla todas as variáveis com $p<0,20$ (Tabela 23). 
Tabela 23. Variáveis selecionadas para a análise múltipla. GAMIA, HCFMUSP, São Paulo, 2002.

\begin{tabular}{l|c|c}
\hline \multicolumn{1}{c|}{ VARIAVEL } & categoria & (teste $\mathrm{X}^{2}$ ) \\
\hline Membrana timpânica OD e OE & $\begin{array}{c}\text { Normal } \\
\text { alterada }\end{array}$ & 0,027 \\
\hline Faixa etária & $\begin{array}{c}60-64 \\
65-69 \\
70 \mathrm{e} \text { mais }\end{array}$ & 0,032 \\
\hline Possui familiar com problema & sim & 0,047 \\
\hline auditivo? & não & 0,068 \\
\hline Renda & $\begin{array}{l}1-2 \\
\text { 3-5 }\end{array}$ & \\
\hline Otorréia OE & simais & 0,125 \\
\hline Zumbido OD & não & 0,136 \\
\hline Hipertensão arterial & sim & 0,177 \\
\hline
\end{tabular}

p: nivel descritivo do teste de associação pelo qui-quadrado.

$\mathrm{Na}$ análise múltipla (Tabela 24) apenas a presença de membrana timpânica na orelha direita e na orelha esquerda e idade foram fatores independentes significativos. A presença de membrana timpânica alterada foi fator protetor para a presença de presbiacusia $(O R=0,1)$ e 0 idoso com 70 anos e mais tem 4,4 vezes a chance de ter presbiacusia quando comparado com o idoso entre 60 e 64 anos. A faixa etária entre 65 e 69 anos não foi de risco. 
TABELA 24. Resultado final do modelo de regressão logística múltipla para a presença de presbiacusia. GAMIA,HC-FMUSP, São Paulo, 2002.

\begin{tabular}{lc|c|c|c}
\hline VARIÁVEL & categoria & $n$ & OR bruta $\left[\mathrm{IC}_{95 \%}\left(\mathrm{OR}_{\text {bruta }}\right)\right.$ & OR ajustada $\left[\mathrm{IC}_{95 \%}\left(\mathrm{OR}_{\mathrm{j} j u s t a d a}\right)\right]$ \\
\hline Membrana & normal & 77 & 1,0 & 1,0 \\
Timpânica OD e OE & alterada & 8 & $0,1[0,0 ; 0,5]$ & $0,1[0,01 ; 0,5]$ \\
& & & & 1,0 \\
Faixa etária & $60-64$ & 11 & 1,0 & $1,0[0,2 ; 4,9]$ \\
& $65-69$ & 20 & $1,1[0,2 ; 4,5]$ & $4,4[1,1 ; 19,0]$ \\
& 70 e mais & 54 & $3,7[0,9 ; 14,4]$ & \\
\hline
\end{tabular}

Teste de Hosmer-Lemeshow: $p=0,984$. 


\section{DISCUSSÃO}

Este estudo objetivou a análise da presença de presbiacusia em idosos com atendimento ambulatorial no Serviço de Geriatria do HC - FMUSP, bem como os fatores a ela associados. Para tanto, foi escolhido dentro do Serviço de Geriatria um grupo de idosos chamado GAMIA. Essa escolha foi feita por se tratar de um grupo com acompanhamento médico periódico, com realização de exames e cujo perfil audiológico era desconhecido. Dos 378 idosos que já freqüentaram o GAMIA no período de 1984 a 2001 não se conhece o número total dos que já morreram, quantos mudaram da cidade de São Paulo, nem quantos estão incapacitados para saírem de seu local de residência. Neste estudo foi possível localizar, por telefone, 110 idosos, sendo que foram investigados $77,3 \%$ deles (85 idosos).

Os idosos participantes do GAMIA freqüentam, uma vez por semana, durante o período de um ano, o Serviço de Geriatria do HC- FMUSP. Após esse período, a freqüência ao serviço reduz-se às consultas médicas de acompanhamento e outros serviços de reabilitação, gerando a diminuição da freqüência do idoso no serviço. Dessa forma, a opção de contato telefônico pareceu ser a forma mais indicada no momento de contatar os participantes. 0 que se observou foi a desatualização de diversos números de telefones, gerando dificuldade no contato. 
O uso do telefone para o contato inicial em pesquisa foi utilizado em outros estudos (MANGIONE et al. ${ }^{68} 1993$, WORTH e TIERNEY ${ }^{102}$ 1993, FREEDMAN, AYKAN e MARTIN ${ }^{23} 1998$, , VERBONCOEUR et al. ${ }^{96} 2000$, RAINA, TORRANCE-RYNARD, WONG e WOODWARD ${ }^{77} 2002$, WEIMAR et al. ${ }^{98}$ 2002). A taxa de respostas positivas nesses estudos variou de $67,2 \%$ (WEIMAR et al. ${ }^{98}$ 2002) a $90 \%$ (VERBONCOEUR et al. ${ }^{96}$ 2000), comparativamente, no presente estudo, com a participação atingindo $77,3 \%$ das pessoas acessadas, foi observado que o telefone pode ser uma forma de fazer o contato inicial para participação em pesquisa.

O não acesso aos demais participantes do GAMIA deveu-se ao fato de que o momento deste estudo correspondeu ao período de grandes mudanças nos telefones na cidade, desde a alteração de prefixos até a mudança integral do número de telefone.

As recusas observadas neste estudo ocorreram em maior parte devido a doenças ou incapacidades presentes no idoso, impedindo-o de se locomover de sua residência para realizar as entrevistas e exame audiológico ( 8 casos), sendo que essas recusas foram relatadas pelos filhos dos idosos.

A perda de independência e/ou autonomia nos idosos pode ser fator impeditivo de participação, tal fato tem sido relatado em outros estudos (ADAMS et al. ${ }^{1} 1990$, REUBEN, POSEY, HAYES e LMM ${ }^{79} 1994$, PASCHOAL $^{76}$ 
1996, CHOU, KUO, CHEMN E LIN ${ }^{14}$ 1997, JACOMB, JORM, KORTEN, CHRISTENSEN e HENDERSON ${ }^{46} 2002$ ), visto que a saída de casa fica difícil para esses indivíduos. Mesmo o acompanhamento médico do serviço encontra-se prejudicado nesses casos, o que inviabiliza o acesso a dados de saúde e exames laboratoriais atualizados.

Outro dado foi a observação da dificuldade de localizar os idosos em suas residências (10 casos). Geralmente, quando o contato era feito o idoso relatava possuir vida ativa, com passeios, compromissos e viagens, pouco permanecendo em casa.

O contato inicial com o idoso, foi feito pela fonoaudióloga responsável por este estudo, bem como todo o esclarecimento sobre a dinâmica do estudo. Isso facilitou a adesão do idosos ao estudo visto que para completar todas as etapas da pesquisa era necessário comparecer ao hospital três veźes e uma vez ao local de realização do exame. Dos idosos que aceitaram participar do estudo, dez (10,5\%) não o completaram. Em um caso o motivo foi morte, em dois casos houve internação hospitalar durante a realização das entrevistas e os demais não conseguiram conciliar suas atividades com a realização das entrevistas e do exame.

O exame audiológico foi realizado fora do ambiente hospitalar em função da empresa participante oferecer os exames para esta pesquisa 
sem a obrigatoriedade do idoso adquirir o aparelho auditivo nesse local. A sobrecarga de exames audiométricos dentro do hospital auxiliou na decisão de utilização de serviço externo.

No sentido de garantir a confiabilidade dos resultados dos exames audiométricos, realizados pelo centro auditivo, foram realizadas reuniões de esclarecimentos, bem como apresentação do projeto de pesquisa deste estudo aos profissionais envolvidos no atendimento à essa população. As reuniões foram realizadas na própria empresa para facilitar a participação das fonoaudiólogas envolvidas na realização dos exames audiométricos. A apresentação do projeto facilitou a compreensão da necessidade de comprometimento, das pessoas envolvidas, com o rigor da metodologia.

O treinamento de fonoaudiólogos para a aplicação de procedimentos padronizados em audiologia foi assunto de estudos envolvendo questões metodológicas nessa área (CAMERON ${ }^{12}$ 1997, HELFER ${ }^{35}$ 1999, PANNBACKER, BATCHELOR e BINDERIM ${ }^{75}$ 2000). A utilização de treinamento bem como a calibração dos equipamentos são fundamentais para a segurança da confiabilidade dos resultados obtidos (WILBER ${ }^{99} 1999$ ).

Houve situações em que o idoso precisou comparecer ao hospital não três, mas quatro vezes. Isso porque ao realizarem a avaliação 
com o médico otorrinolaringologista era detectada alteração que impedia o pronto encaminhamento ao exame audiológico. Exemplos dessa situação foram presença de rolha de cera e infecções, situações que necessitaram de retorno para acompanhamento antes da realização da audiometria, visto que a realização do exame nessas condições não resultaria em informação auditiva confiável. $O$ ideal seria que 0 idoso otimizasse sua presença no hospital, realizando todos os procedimentos em um só dia. Contudo, isto não foi possivel por envolver clínicas diferentes, a Geriatria e a Otorrinolaringologia, além de profissionais diferentes, fonoaudiólogas e médicos otorrinolaringologistas, com horários diferentes de trabalho.

\section{A população de estudo}

Em relação à caracterização da população, a maioria era do sexo feminino $(83,5 \%)$. Isso se explica pelo fato dos grupos de terceira idade serem mais freqüentados por idosas SEADE $^{88}$ 1990; ZIMERMAN ${ }^{103}$ 2000). Sendo o GAMIA um grupo com esse perfil, o número maior de mulheres também foi observado. Dados do Censo 2000 (IBGE ${ }^{25} 2000$ ) apontam para o maior número de mulheres idosas na população brasileira em relação ao número de homens idosos, em números absolutos o número de mulheres é de 8.165 .591 (55,4\%), enquanto o número de homens é de 6.577.298 (44,6\%), totalizando 14.742 .889 indivíduos. 
Quanto à idade houve variação entre 60 a 89 anos, sendo que a distribuição concentrou-se entre 65 a 80 anos, coincidindo com vários estudos já realizados (GATES, COOPER, KANNEL E MILLER ${ }^{27}$ 1990, CIURLIAGUY, CASHMAN e LEWSEN ${ }^{15}$ 1993, VAN DEN BERG, PRINS, VERSCHUURE e HOES $^{94}$ 1999). Contudo, é comum em estudos sobre presbiacusia acompanhar pessoas com idade inferior a 65 anos para verificar o efeito idade na prevalência desse agravo à saúde (MOSCICKI, ELKINS, BAUM e MCNAMARA $^{72} 1985$, CRUICKSHANKS et al. ${ }^{19} 1998$, LIU et al. ${ }^{60} 2001$ ).

O censo 2000 identificou que $56,3 \%$ dos idosos encontravamse na faixa etária entre 60 a 69 anos, $31,5 \%$ na faixa entre 70 a 79 anos e $12,2 \%$ dos idosos estão com 80 anos ou mais (IBGE ${ }^{25}$ 2000). 0 grupo de idosos deste estudo apresenta-se com a seguinte distribuição: $36,4 \%$ entre a faixa de 60 a 69 anos, $54,2 \%$ entre 70 a 79 anos e $9,4 \%$ com 80 anos ou mais. Neste estudo a faixa etária com maior número de idosos concentrou-se entre 70 a 79 anos, enquanto a população brasileira concentra-se na faixa dos 60 aos 69 anos.

Os estudos levantados apresentavam também a presença importante de pessoas acima de 90 anos, idade em que a presbiacusia passa a atingir $89 \%$ da população de estudo (CIURLIA-GUY, CASHMAN e LEWSEN ${ }^{15}$ 1993, CRUICKSHANS et al. ${ }^{19}$ 1998). Neste estudo a idade máxima foi de 89 anos não permitindo comparação com os mesmos. 
Quanto à renda, todos os idosos deste estudo possuíam algum tipo de renda, concentrando-se $44,7 \%$ deles entre um a dois salários mínimos, seguidos por $35,3 \%$ com três a cinco salários mínimos. Segundo pesquisa do IPEA realizada em 1998, a renda média per capita de famílias com idosos é $15 \%$ maior que a renda de famílias sem idosos (IPEA ${ }^{44} 1998$ ).

Um estudo que analisou a renda da população e presença de presbiacusia identificou maior presença de perda auditiva nos grupos de indivíduos com menor poder aquisitivo, além de menor grau de escolaridade (SIXT e ROSENHALL ${ }^{89}$ 1997).

A definição de presbiacusia envolve aspectos interdisciplinares e sua detecção não poderia ser diferente (CORSO ${ }^{17} 1977$, BUTLER e GASTEL ${ }^{11}$ 1979, JERGER, CHMIEL, WILSON E LUCHI ${ }^{47}$ 1995, JENNINGS e JONES ${ }^{48}$ 2001). Dessa forma, o envolvimento de outros profissionais neste estudo fezse necessário e o conhecimento da metodologia de trabalho permitiu a adoção de condutas adequadas para a identificação da presença de presbiacusia de forma confiável.

Nos estudos realizados com a população idosa e presença de presbiacusia observa-se presença equilibrada entre homens e mulheres. Apenas um deles concluiu que a perda auditiva é maior entre mulheres (MEGIGHIAN, SAVASTANO, SALVADOR, FRIGO e BOLZAN ${ }^{70} 2000$ ) outros 
estudos concluíram o contrário (MOSCICKI, ELKINS, BAUM e MCNAMARA ${ }^{72}$ 1985, GATES, COOPER, KANNEL e MILLER ${ }^{27}$ 1990, MAGGI et al ${ }^{67}$ 1998) fato que não pode ser verificado neste estudo, que pode ser explicado pelo pequeno número de homens participantes o que dificultaria a comparação entre os gêneros, ou pela mudança no perfil ocupacional que a mulher vem apresentando nas últimas décadas $\left(\mathrm{SEADE}^{88}\right.$ 1990). A maior presença feminina no trabalho fora de casa soma-se a maior exposição a fatores antes mais presentes na vida do homem. Não é impossivel que em futuros estudos a diferença entre homens e mulheres quanto a perda auditiva não seja mais identificada.

Considerando-se ainda o fator ambiental a que um indivíduo que trabalha fora se expõe, neste estudo todos os homens trabalharam e entre as mulheres, sete não trabalharam fora de casa, sendo que quatro delas exerciam a atividade de costureira em casa. No caso desta população a exposição a fatores ambientais pode ser considerado semelhante entre homens e mulheres, pois ambos os grupos trabalharam fora de casa e em geral as mulheres trabalharam em tecelagem, com freqüente exposição ao ruído.

Em relação à cor, predominou a branca em $87,1 \%$ dos participantes não permitindo importante análise sobre a diferença entre prevalência de presbiacusia em diferentes raças. Na população idosa 
brasileira a cor predominante, segundo o censo 2000 também é a cor branca, presente em $60 \%$ nessa população (IBGE ${ }^{25} 2000$ ).

Quanto a escolaridade, todos os idosos freqüentaram a escola, sendo que a maioria, $65,8 \%$ esteve na escola entre 1 a 4 anos. Segundo 0 Censo 2000 , no estado de São Paulo, a alfabetização atinge $82,7 \%$ dos individuos ( IBGE $^{25} 2000$ ).

A exposição ao ruído ocupacional esteve presente em $31,8 \%$ dos participantes, sendo que provavelmente a maioria não fez uso de protetor auditivo visto que na época em que trabalhavam não havia proteção ao trabalhador quanto a esse aspecto.

A importância do conhecimento sobre exposição ao ruído ocupacional na identificação da presbiacusia foi relatada em alguns estudos (BUTLER e GASTEL ${ }^{11}$ 1979, FRISINA e FRISINA ${ }^{24}$ 1997, COHN ${ }^{16}$ 1999,) contudo seu efeito e sua associação com a presença de presbiacusia ainda não foi especificada (LUTMAN e SPENCER ${ }^{65}$ 1991), conhecendo-se apenas que a exposição prolongada ao ruído pode alterar a audição, pela perda auditiva induzida pelo ruído (ROP, RABER e FISCHER ${ }^{81}$ 1979, LUTMAN e SPENCER $^{65}$ 1991,) ou somado a outros fatores ambientais pode estar presente no diagnóstico de presbiacusia (MADER ${ }^{66}$ 1984, ROSENHALL, SIXT, SUNDH e SVANBIRG $\left.{ }^{80} 1993\right)$. 
Quando perguntados sobre situações do dia-a-dia relacionados à audição, foram observadas entre os idosos as situações já conhecidas do fonoaudiólogo como sendo importantes para a qualidade e efetividade da comunicação.

A conversa frente a frente favoreceu a compreensão em $89,4 \%$ dos idosos. Tal situação possibilita o uso de outras fontes de estimulação, que não somente a auditiva, para a compreensão e, muitas vezes, é esquecida pelo interlocutor. Não é incomum encontrar pessoas que conversam realizando diferentes atividades que não permitem 0 posicionamento frente a frente. A conversa frente a frente foi descrita como importante estratégia de comunicação para facilitar a compreensão e sua presença tem sido constante nos programas de reabilitação audiológica (HULL $^{40}$ 1999, HANRATTY E LAWLOR ${ }^{32} 2000$ ).

Quando questionado especificamente sobre a necessidade de ver a face de seu interlocutor, 37,6\% revelaram não ouvir bem sem visualizar a face do outro. Esses idosos reconhecem a dificuldade de entender o que ouvem sem o apoio visual, demonstrando a presença de alteração auditiva prejudicando a comunicação (TOWNSEND e BESS ${ }^{93} 1980$, STRAWBRIDGE, WALLHAGEN, SHEMA e KAPLAN ${ }^{91}$ 2000). 
Quando em ambientes ruidosos, $40 \%$ relataram não ouvir bem, demonstrando nesse momento a importância de orientação quanto à comunicação nesses ambientes. Por outro lado, quando a pergunta é se ouve bem em ambientes silenciosos, 92,9\% dos idosos referiram ouvir bem. Nesse caso a orientação sobre a manutenção de ambientes sem ruído competitivo parece fazer sentido como um facilitador da compreensão da fala (HULL ${ }^{39} 1978$, LUBINSKI $^{62} 1995$, COHN $\left.^{16} 1999\right)$.

Quando indagados sobre a audição frente a alguns meios de comunicação, as respostas obtidas foram que ouvem bem a televisão $81,2 \%$ dos idosos, porém na pergunta se alguém já reclamou do volume da televisão $51,8 \%$ referem que não, enquanto porcentagem semelhante, $48,2 \%$ referem que sim. Pode-se pensar nessa situação que mesmo declarando ouvir bem a televisão, algumas pessoas o fazem aumentando o volume da mesma, sugerindo que esse seria um meio de contornar a dificuldade auditiva. Nesse caso, contudo, esse é um meio contra indicado visto que provocaria piora no desempenho auditivo, após longo período de exposição ao ruído intenso (LUBINSKI ${ }^{62}$ 1995).

No uso do telefone, $85,9 \%$ dos idosos relataram ouvir bem nessa situação. Vale lembrar que as consultas foram agendadas via telefone neste estudo e foram observadas inúmeras situações nas quais as informações precisavam ser repetidas. Neste momento, não é possível 
analisar esse dado, visto que a observação da entrevistadora não foi registrada em protocolo.

Nas características auditivas foi possivel observar que $97,6 \%$ dos idosos não apresentam flutuação da audição. Relataram escutar $92,9 \%$ dos idosos, contudo $76,5 \%$ relataram não entender o que escutam. Tal fato corrobora as observações de outros pesquisadores sobre a característica particular da presbiacusia " eu escuto mas não entendo" (JONES, VICTOR e VETTER ${ }^{49} 1984$ RUSSO $^{83} 1999$ ).

Relataram não localizar o som, $45,9 \%$ dos idosos e não perceber os sinais, $83,5 \%$. Esses dados revelam importante conseqüência da audição em tarefas do dia-a-dia. Localizar o som e perceber sinais significam muitas vezes a condição de segurança, inclusive de vida (STRAWBRIDGE, WALLHAGEN, SHEMA e KAPLAN ${ }^{91}$ 2000).

Com a pergunta a sua audição mudou com a idade, foi possível observar que $57,6 \%$ declararam que sim e para pior. Já quando foi perguntado se os familiares notavam essa diferença, $51,8 \%$ referiram que sim e quando a pergunta se refere a amigos essa porcentagem cai para $17,6 \%$. 
Nessa situação, parece ser semelhante a percepção do idoso e de seus familiares, não tendo relação com a percepção dos amigos. Esse fato pode ser auxiliar em uma anamnese, na qual as perguntas se a audição mudou com a idade e o que sua família acha da sua audição podem indicar a realidade sobre a audição do idoso. A importância do papel do familiar frente a deficiência auditiva do idoso é conhecida e descrita com freqüência (THOMAS, HUNT, GARRY, HOOD, GOODWIN E GOODWIN ${ }^{92}$ 1983, JERGER, CHMIEL, WILSON e $\mathrm{LUCHI}^{47}$ 1995, GOMEZ e MADEY' 2001).

Um fato interessante observado neste estudo foi que, apesar da audição piorar com o avançar da idade, os idosos não deixaram de fazer suas atividades em função disso. Quando perguntados se deixaram de fazer alguma atividade em função da audição $96,5 \%$ relataram que não. Tal fato pode levar a dois caminhos de interpretação; primeiro que, apesar das dificuldades encontradas, a audição não prejudica as atividades dos idosos. O outro caminho seria pensar que os idosos não admitem deixar as atividades frente a uma dificuldade, ou pelo menos não admitem deixar de fazer algo em função da audição. Cabe ressaltar aqui que a existência de apenas uma questão sobre $o$ assunto pode não ter sido suficiente para verificar esse fato discutido na literatura (BERGMAN ${ }^{8}$ 1971, CORSO $^{17}$ 1977, ANDERSSON $^{4}$ 1978, BESS, LTCHTENSTEIN, LOGAN, BURGER e NELSON ${ }^{9}$ 1989, RUSSO ${ }^{84}$ 1999). Observa-se no idoso com deficiência auditiva, especialmente na presbiacusia, na qual a inteligibilidade de fala encontra-se 
prejudicada, o afastamento de atividades sociais que requeiram participação efetiva, visto que a presbiacusia afasta esses indivíduos das situações comunicativas (CORSO ${ }^{17}$ 1977, LUTMAN $^{64}$ 1991, FRISINA e FRISINA ${ }^{24} 1997$, RUSSO $^{84}$ 1999, GOMEZ e MADEY ${ }^{30}$ 2001).

Quando indagados se alguém já falou para fazer exame da audição $68,2 \%$ relataram que não, indicando que as pessoas ao seu redor não se sensibilizaram para a necessidade de avaliação auditiva, incluindo-se os médicos, em especial geriatras, que acompanham a essa população. Quando a pergunta foi se já pensou em fazer o exame da audição, $64,7 \%$ relata que sim e $54,1 \%$ relataram que já fizeram o exame de audição. A sensibilização da comunidade na qual o idoso se insere é fundamental, bem como dos profissionais de saúde que atuam com o idoso, em especial os geriatras. As pessoas em contato com o idoso portador de deficiência auditiva podem e deveriam orientá-lo sobre seu agravo à saúde comunicativa. 


\section{Prevalência}

A presbiacusia esteve presente em $71,8 \%$ dos idosos. Diferente de outros estudos, a presbiacusia mostrou-se bastante freqüente, superando estudos nos quais para idosos não institucionalizados, sua prevalência está em torno de 29 a 45\% (MOSCICKI, ELKINS, BAUM e MCNAMARA ${ }^{72}$ 1985, GATES, COOPER, KANNEL E MILLER ${ }^{27} 1990$, STACH, SPRETNJAK, JERGER ${ }^{90}$ 1990, MAGGI et al. ${ }^{67} 1998$, VAN DEN BERG, PRINS, VERSCHUURE e HOES $^{94}$ 1999, LIU et al. ${ }^{60} 2001$ ) sendo que para idade superior a 89 anos esse valor sobe para $89 \%$ (CRUICKSHANKS et al. ${ }^{19}$ 1998). Os achados deste trabalho condizem com achados em instituições asilares onde a presbiacusia apresenta prevalência em torno de $70 \%$ (CIURLIA-GUY ${ }^{15}$ 1993). Tal fato pode ser explicado por este grupo estar inserido em ambiente hospitalar, o que favoreceria a procura por pessoas com maior número de agravos à saúde do que em grupos fora de ambiente hospitalar. 


\section{Associação entre a presença de sinais e sintomas auditivos e a presença de presbiacusia}

Quando comparados os grupos de quem possuía presbiacusia e quem não a possuía verificou-se que a necessidade de ver a face com quem conversa e ter pensado em fazer exame de audição foram variáveis associadas a presença de presbiacusia. 0 fato de ver a face com quem se conversa parece ser um facilitador de compreensão visto que é comum entre idosos com presbiacusia a queixa de que ouvem mas não entendem (JONES, VICTOR e VETTER ${ }^{49} 1984$, RUSSO $^{83}$ 1988). Já o fato de pensarem em fazer o exame da audição seria um indicativo de que percebem que há um problema auditivo e ele precisaria de atenção.

Ter pensado em fazer o exame da audição pode revelar não apenas a conscientização de um problema como também a influência que outras pessoas, no caso deste estudo, pessoas da família, podem ter sobre essa necessidade, visto que eles já disseram diretamente ao idoso que observaram mudanças na audição do mesmo. Nesse sentido programas de prevenção, mais precisamente de Promoção da Saúde Auditiva poderiam ser fundamentais para o esclarecimento sobre essa doença.

Uma vez verificado que o fato da pessoa pensar em fazer o exame da audição estava associada a presença de presbiacusia foi analisado 
se entre os grupos de quem pensou em fazer o exame e de quem não pensou em fazer o exame da audição havia diferenças quanto às características da audição.

Esse dado pode também revelar que alguns sinais e sintomas auditivos seriam importantes na decisão do idoso pensar em fazer um exame da audição. A análise realizada entre o idoso pensar em fazer o exame da audição revelou associação estatisticamente significativa com a variável ouve bem sem a pessoa na frente? Nesse caso, entre os idosos que não ouvem bem sem a pessoa na frente, $84,1 \%$ pensou em fazer o exame da audição. Quando analisada a variável precisa ver a face com quem conversa? $82,4 \%$ dos idosos que responderam sim já pensaram em fazer o exame da audição. As associações estatisticamente significativas entre as duas variáveis e pensou em fazer o exame revelam a importância da conversa frente a frente como estratégia facilitadora da comunicação (MCCARTNEY, NADLER ${ }^{69} 1979$, LUBINSKI $^{62} 1985$, BESS, LCHTENSTEIN, LOGAN, BURGER e NELSON ${ }^{9} 1989$, JERGER, CHMIEL, WILSON e LUCHI ${ }^{47}$ 1995).

As demais variáveis relacionadas a comunicação e que apresentaram associação estatisticamente significativa com ter pensado em fazer o exame foram: precisa pedir para repetir? Difícil ouvir alguém sussurrando? Ouve bem televisão? Ouve bem ao telefone? Difícil entender as pessoas? Mais uma vez sinais e sintomas auditivos que dificultam a 
comunicação apresentaram-se como fatores que fazem o idoso pensar que algo não está bem com sua saúde auditiva (ALBERT ${ }^{2}$ 1977, TOWNSEND e BESS $^{93}$ 1980， MADER ${ }^{66}$ 1984， KALAYAN ${ }^{53}$ 1995， STRAWBRIDGE, WALLHAGEN, SHEMA E KAPLAN ${ }^{91} 2000$ )

Duas outras variáveis mostraram-se associadas a pensar em fazer o exame da audição e deveriam ser lembradas em uma anamnese: familia acha que ouve bem? E audição mudou com a idade? Como dito anteriormente, o papel da família é fundamental na percepção do problema auditivo bem como na reabilitação audiológica do idoso e o fato da auto percepção de que a perda auditiva está presente também pode auxiliar nessa reabilitação.

Além dessas variáveis, foi encontrada associação entre alguém já ter falado para o idoso fazer o exame e o próprio pensar nessa possibilidade, indicando que se o interlocutor percebe a dificuldade $e$ verbaliza-a ao idosos, este irá preocupar-se e também pensar em fazer o exame. Dessa maneira pensar em fazer o exame da audição pode estar demonstrando que o idoso, seja por meios próprios ou de familiares, é capaz de revelar, pela anamnese, que algo com sua audição não está bem (VENTRY E WEINSTEIN ${ }^{95}$ 1982). 


\section{Fatores associados a presbiacusia}

$\mathrm{Na}$ análise dos fatores associados à presbiacusia foi verificada nessa população a associação estatisticamente significativa entre idade e presbiacusia e possuir familiar com problema na audição e presbiacusia. A idade é um fator associado à presbiacusia já verificado em alguns estudos (CORSO $^{17}$ 1977, ARNESEN ${ }^{6}$ 1982, COHN ${ }^{16}$ 1999, BHATT ${ }^{10}$ 2001), sendo observado inclusive 0 aumento da prevalência de presbiacusia com 0 aumento de idade (MOSCICKI, ELKINS, BAUM e MCNAMARA ${ }^{72}$ 1985, YAGI 1996 citado por $\mathrm{COHN}^{16} 1999$, p. 152). Este fato também foi verificado neste estudo, onde no modelo de regressão logística verificou-se que quando separados por faixa etária, os idosos entre 60 e 64 anos não diferiram dos entre 65 e 69 anos, porém quando a idade sobe para 70 anos e mais a chance desses idosos apresentarem presbiacusia aumenta em 4, 4 vezes em relação aos demais idosos.

A presença de história familiar entre os idosos com presbiacusia pode estar relacionada a fatores genéticos mencionados em outros estudos (MOSCICKI, ELKINS, BAUM e MCNAMARA $^{72} 1985$, GATES, COBB, D'AGOSTINO e WOLF ${ }^{26}$ 1993), porém com resultados conservadores em alguns deles (GATES, COUROPMITRE e MYERS ${ }^{28}$ 1999, CHRISTENSEN, FREDERIKSEN e HOFFMAN ${ }^{13}$ 2001). Assim como neste estudo onde após 
associação na análise univariada não foi encontrada associação na análise múltipla.

Quanto a variável fumo, estudo sobre sua relação com presbiacusia revelou que além do fumante ativo já descrito em um estudo (ROSENHALL, SIXT, SUNDH e SVANBORG ${ }^{80}$ 1993) o passivo também apresentou risco para perda auditiva (CRUICKSHANKS, KLEIN, KLEIN, WILEY, NONDAHL e TWEED ${ }^{19}$ 1998). Neste estudo foram analisadas as variáveis se fuma, se já fumou, se convive com quem fuma e se conviveu com quem fumava. Todas essas variáveis foram codificadas em sim e não. Não foi encontrada associação estatisticamente significativa entre nenhuma dessas variáveis e presença de presbiacusia.

A variável uso de bebida alcoólica também foi codificada em presente ou ausente e não foi encontrada associação com a presença de presbiacusia, assim como relatado, em relação a mulheres, em um estudo (ROSENHALL, SIXT, SUNDH e SVANBORG ${ }^{80} 1993$ ).

Variáveis como hábito de fumar, fumo passivo e hábito de beber apresentam dificuldade metodológica de mensuração. Neste estudo verificou-se apenas a presença ou ausência do evento, não foi possível quantificar o fumo nem a ingestão de bebida. 
O número de diagnósticos médicos nesta população variou de nenhum a nove, com média de 4,5 diagnósticos por idoso. Quanto a presença de presbiacusia existem estudos que encontraram maior prevalência dessa doença em idosos com maior número de diagnósticos médicos do que em idosos com menor número de diagnósticos (MOSCICKI, ELKINS, BAUM E MCNAMARA ${ }^{72}$ 1985, SIXT e ROSENTHALL ${ }^{89}$ 1997, JENNINGS e JONES ${ }^{48}$ 2001). Neste estudo não houve associação entre essa variável e presença de presbiacusia, o que também está de acordo com um estudo (LM e STEPHENS ${ }^{59} 1991$ ).

Quanto ao uso de medicamentos, foi observado na população deste estudo, que a variação quanto ao número foi de zero a dez, com média de 3,5 medicamentos por idoso. Não foi encontrada associação estatisticamente significante entre o número de medicamento e presbiacusia. Estudo com idosos revelou que o uso de medicação nessa população precisa ser estudado não apenas quanto ao número e tipo de medicações mas quanto ao tempo de uso e interações medicamentosas (LIM e STEPHENS ${ }^{59}$ 1991, MILLS, MATTHEUS, LEE, DUBNO, SCHULTE e WEBER ${ }^{71} 1999$ ).

Quanto ao índice de massa corporal (IMC), houve variação entre 17 e 37, com média de 23,2. Não foi encontrada associação entre essa variável e presença de presbiacusia. 
Quanto aos exames laboratoriais analisados neste estudo, não foi encontrada associação entre nenhum exame e presença de presbiacusia, estudos que corroboram esses achados foram conduzidos em países como Itália (DEL GUIDICE ${ }^{21}$ 1960) e EUA (LEE, MATHEWS, MILLS, DUBNO e ADKINS $^{58}$ 1998). Contudo No mesmo estudo norte americano (LEE, MATHEWS, MILLS, DUBNO e ADKINS ${ }^{58}$ 1998) foi encontrada associação entre razão de colesterol e presença de presbiacusia apenas em mulheres.

A associação entre diabetes e presbiacusia já foi descrita em estudo realizado em Wiscosin, EUA,(DALTON, CRUICKSHANKS, KLEIN, KLEIN E WILEY ${ }^{20} 1998$ ), contudo neste estudo não foi encontrada associação entre essa variável e presbiacusia. Quando ajustado por idade o estudo norte americano também não encontrou associação entre diabetes e presbiacusia.

A hipertensão arterial foi estudada nos EUA (MOSCICKI, ELKINS, BAUM e MCNAMARA ${ }^{72}$ 1985, JENNINGS e JONES ${ }^{48}$ 2001) onde verificou-se que presença desse agravo a saúde estaria relacionada a presença de presbiacusia. Neste estudo verificou-se a variável hipertensão arterial, segundo sua presença ou ausência e não foi encontrada associação com presença de presbiacusia.

Do exame físico realizado pelo médico otorrinolaringologista foram analisadas as variáveis meato acústico de orelhas direita e esquerda, 
membrana timpânica de orelhas direita e esquerda e oroscopia. A presença de alteração em membrana timpânica foi fator protetor segundo o modelo de regressão logística neste estudo, fato que não se explica visto que sua importância se faz em alterações auditivas relacionada à orelha média principalmente e não à presença de presbiacusia. Neste momento não há como justificar tal achado, o pequeno número de idosos nessa situação poderia não estar revelando a importância desse achado. Um estudo com 30 idosos, com média de idade de 77anos, verificou que alterações na elasticidade da membrana timpânica eram menos encontradas no grupo com presbiacusia do que no grupo sem presbiacusia. O motivo estaria relacionado ao não efeito do envelhecimento nessa região, contudo os autores foram conservadores em concluir a relação de membrana timpânica e presbiacusia. Mais estudos nessa área precisam ser realizados. Porém lendo esse estudo foi possível pensar que se algo está errado com membrana timpânica poderia ser identificada uma perda auditiva que não a presbiacusia nesse indivíduo. A presbiacusia, associadA ao envelhecimento do indivíduo não seria afetada por alterações na membrana timpânica.

A realização deste estudo buscou contemplar as necessidades de informação e avaliações para se alcançar o diagnóstico de presbiacusia. Outros locais que trabalham com idosos e desejam conhecer seu perfil auditivo necessitarão de exames diagnósticos para identificar a alteração auditiva. Contudo, a deteç̧ão de problemas auditivos pode ser verificada 
antes da audiometria por meio de questionários e/ou inventários auditivos (VENTRY e WEINSTEIN ${ }^{95}$ 1982), como pode ser verificado neste estudo.

Dessa forma, este estudo pretendeu contribuir para que outros estudos possam ser realizados da mesma forma ou seguindo parte do mesmo, dependendo do objetivo proposto. Se o objetivo for identificar a presença de presbiacusia, seguir a metodologia completa seria aconselhável, pois para o fonoaudiólogo identificar a presença de presbiacusia precisará do apoio de outros profissionais, principalmente do médico otorrinolaringologista. Caso o objetivo seja a identificação de problemas relacionados à audição sugere-se utilizar a metodologia até o item de protocolo auditivo.

O fonoaudiólogo é o profissional capaz de orientar e reabilitar a audição em diferentes níveis de atuação, seja na promoção de saúde, a partir de conhecimentos sobre cuidados auditivos e preservação auditiva; seja na reabilitação, com indicação e adaptação de próteses e com exercícios específicos para melhora de desempenho auditivo (RUSSO ${ }^{84} 1999$, WILLOT, CHISOLM E LSTTER ${ }^{100}$ 2001).

Dessa forma, dispondo de conhecimentos objetivos ou subjetivos acerca do perfil auditivo de sua população, o fonoaudiólogo que 
trabalha com a população idosa poderá aprimorar sua atuação, utilizando-se de instrumentos e/ou protocolos auxiliares na detecção do perfil auditivo.

A realização deste estudo permitiu o conhecimento de um perfil antes desconhecido no Serviço de Geriatria do HC - FMUSP e mesmo do departamento de Otorrinolaringologia dessa instituição. A parceria estabelecida por ocasião deste estudo está sendo ampliada para que as áreas de Fonoaudiologia, Geriatria e Otorrinolaringologia possam caminhar juntas quanto ao estudo da presbiacusia. Nesse sentido o perfil audiológico da população atendida no GAMIA terá seu acompanhamento continuado. Os problemas verificados neste estudo referentes ao destino dos idosos estão sendo contemplados com a atuação de uma idosa do próprio GAMIA na atualização de todos os telefones e endereços dos participantes desse grupo.

Os protocolos de estudo serão mantidos, sendo que em algumas questões, como por exemplo a referente a presença de familiar com problemas auditivos, serão propostas reformulações para a correta anotação da informação desejada.

A identificação da presença de presbiacusia demonstrou a necessidade de elaboração de um programa de reabilitação auditiva muito além da indicação do aparetho auditivo. A elaboração desse programa, além 
da continuidade deste estudo, será um dos objetivos da área de Fonoaudiologia dentro do Serviço de Geriatria do HC - FMUSP. 


\section{CONCLUSÕES}

Segundo o objetivo geral deste estudo foi possível determinar a prevalência de presbiacusia na população estudada, bem como identificar os fatores associados à ela em uma população idosa com atendimento ambulatorial, verificando-se que:

Entre os idosos avaliados a maioria refere mudança para pior na audição com o avançar da idade e muitos foram realizar o exame da audição para verificar as alterações observadas. A alteração de audição prejudica a compreensão da fala, apesar do idoso continuar referindo que ouve mas não entende, contudo isso não é fator para que ele evite atividades em função da audição.

Entre os idosos avaliados $71,8 \%$ apresentou presbiacusia.

Houve associação estatisticamente significativa entre a presença de presbiacusia e precisar ver a face do interlocutor e pensar em fazer o exame da audição.

Houve associação estatisticamente significativa entre pensar em fazer o exame da audição e ouvir bem sem a pessoa na frente, precisar ver a face com quem conversa, precisar pedir para repetir, família acha que ouve 
bem, dificil ouvir alguém sussurrando, ouvir bem televisão, ouvir bem ao telefone, audição mudou com a idade, difícil entender as pessoas e alguém já falou para fazer exame da audição.

Houve associação estatisticamente significativa entre idade e presença de presbiacusia. Não houve associação estatística significativa entre as demais variáveis sócio-demográficas e presbiacusia entre os idosos avaliados.

Não houve associação estatisticamente significativa entre hábito de beber e tabagismo e presbiacusia entre os idosos avaliados.

Não houve associação estatisticamente significativa entre presença de doenças e presbiacusia entre os idosos avaliados.

Não houve associação estatisticamente significativa entre exames laboratoriais e presbiacusia entre os idosos avaliados.

Não houve associação estatiscamente significativa entre a presença de presbiacusia e possuir familiar com problemas auditivos entre os idosos avaliados. 


\section{REFERÊNCIAS BIBLIOGRÁFICAS}

1. Adams MM, Scherr PA, Branch LG, Hebert LE, Cook NR, Lane AM et al. A comparison of elderly participants in a community survey with nonparticipants. Public Health Rep 1990; 105 (6): 617-22.

2. Alberti PW. Hearing aids and aural rehabilitation in a geriatric population. $\mathbf{J}$ Otolarygol 1977; 6 (suppl.): 1-49.

3. Almeida K, Russo ICP. Considerações sobre a seleção e adaptação de próteses auditivas para o deficiente auditivo idoso. In: Almeida K, Iorio MCM. Próteses auditivas: fundamentos teóricos e aplicações clínicas. São Paulo: Lovise; 1996. p. 177-190.

4. Andersson G. Adaptation to a hearing aid. A consumer's point of view. Scand. Audiol 1978; 8 (suppl): 42-4.

5. Andersson G, Green M, Melin L. Behavioural hearing tactis: a controlled trial of a short treatment programme. Behav Res Ther 1997; 35 (6): 52330.

6. Arnesen AR. Presbyacusis - loss of neurons in the human cochlear nuclei. J Laryngol Otol 1982; 96: 503-511. 
7. Berger KW. Prescription of hearing aids: a rationale. $\mathbf{J}$ Am Audiol Soc $1976 ; 2(3): 71-78$.

8. Bergman $M$. Hearing and ageing. Implications of recent research findings. Audiology $1971 ; 10: 164-171$.

9. Bess $F H$, Lichtenstein MJ, Logan SA, Burger MC, Nelson E. Hearing impairment as a determinant of function in the elderly. $\mathbf{3}$ Am Geriatr Soc 1989; 37: 123-128.

10. Bhatt KA, Liberman MC, Nadol JB. Morphometric analysis of age-related changes in the human basilar membrane. Ann Otol Rhinol Laryngol 2001; 110: $1147-1153$.

11. Butler RN, Gastel B. Hearing and age. Research challenges and the national institute on aging. Ann Otol 1979; 88: 676-683.

12. Cameron TH. Epidemiological issues in audiology: impact on professional training and service delivery. J Commun Disord 1997; 30 (4): 285-300.

13. Christensen K, Frederiksen H, Hoffman HJ. Genetic and environmental influences on self-reported reduced hearing in the old and oldest old. J Am Geriatr Soc 2001; 49: 1512-1517. 
14. Chou P, Kuo HS, Chen $\mathrm{CH}$, Lin HC. Characteristics of non-participants and reasons for non-participation in a population survey in Kin-Hu, Kinmen. Eur J Epidemiol 1997; 13 (2): 195-200.

15. Ciurlia-Guy $E$, Cashman $M$, Lewsen B. Identifying hearing loss and hearing handicap among chronic care elderly people. Gerontologist 1993; 33 (5): 644-649.

16. Cohn ES. Hearing loss with aging. Presbycusis. Clin Geriatr Med 1999; 15 (1): $145-161$.

17. Corso JF. Presbyacusis, hearing aids and aging. Audiology 1977; 16: 146-163.

18. Cruickshanks KJ, Klein R, Klein BE, Wiley $T L$, Nondahl DM, Tweed TS. Cigarette smoking and hearing loss: the epidemiology of hearing loss study. JAMA 1988; 279 (21): 1715-1719.

19. Cruickshanks KJ, Klein $R$, Klein BE, Wiley $\pi$, Nondahl DM, Tweed TS, Mares-Perlman JA, Nondhal DM. Prevalence of hearing loss in older adults in Beaver Dam, Wisconsin. The epidemiology of hearing loss study. Am J Epidemiol 1998; 148 (9): 879-886. 
20. Dalton DS, Cruickshanks KJ, Klein R, Klein BEK, Wiley TL. Association of NIDDM and hearing loss. Diabets Care 1998; 21 (9): 1540- 1544.

21. Del Guidice M, Amorelli A. Cholesterolemia and presbyacusis. Arch Ital Otolaryngol 1960; 68: 175-179.

22. Frederiksen $E$, Blegvad $B$, Rojskjaer $C$. Binaural hearing and treatment of presbycusis patients aged 70 to 80 years. A follow-up examination. Scand Audiol $1974 ; 3: 83-86$.

23. Freedman VA, Aykan $H$, Martin LG. Aggregate changes in severe cognitive impairment among older Americans: 1993 and 1998. J Gerontol B Psychol Sci Soc Sci 2001; 56(2):S100-11.

24. Frisina DR, Frisina RD. Speech recognition in noise and presbycusis: relations to possible neural mechanisms. Hear Res 1997; 106: 95-104.

25. Fundação IBGE. Censo demográfico - São Paulo; 2000. Disponível em: <URL:http://www.ibge.gov.br/home/estatistica/populacao/censo2000/tabula cao_avancada/tabela_brasil>. 
26. Gates GA, Cobb JL, D'Agostino RB, Wolf PA. The relation of hearing in the elderly to the presence of cardiovascular disease and cardiovascular risk factors. Arch Otolaryngol Head Neck Surg 1993; 119 (2): 156-161.

27. Gates G, Cooper J, Kannel W, Miller N. Hearing in the elderly: the Framingham Cohort, 1983-1985. Part1. Basic audiometric test results. Ear Hear 1990; 11: 247-256.

28. Gates GA, Couropmitree NN, Myers RH. Genetic association in agerelated hearing thresholds. Arch Otolaryngol Head Neck Surg 1999; 125: 654-659.

29. Gilad O, Glorig A. Presbycusis: the aging ear. Part II. J Am Auditory Soc $1979 ; 4$ (6): 207-217.

30. Gomez RG, Madey SF. Coping-with-hearing-loss model for older adults. J Gerontol B Psychol Sci Soc Sci 2001; 56 (4): P223-5.

31. Gulya J. Aging: structural and phisiological changes of the auditory and vestibular mechanisms. In: Cherow, E. (Ed.) Procedings of the Research Symposium on Communication Sciences and Disorders and Ageing. ASHA Reports 1990; 19:126-133. 
32. Hanratty B, Lawlor DA. Effective management of the elderly hearing impaired - a review. J Public Health Med 2000, 22(4): 512-7.

33. Hayes D, Jerger J. Aging and the use of hearing aids. Scand Audiol 1979; 8: 33-40.

34. Harless EL, McConnell F. Effects of hearing aid use on self concept in older persons. J Speech Hear Dis 1982; 47: 305-309.

35. Helfer KS. Continuing education in audiology: what do we want? Am J Audiol 1999; 8 (1): 6-12.

36. Herbst KG. Hearing aids for the elderly: expediency versus felt need. $\mathbf{B r} \mathbf{J}$ Audiol 1986; 20: 91-93.

37. Hinchcliffe R. The anatomical locus of presbycusis. J Speech Hear Dis $1962 ; 27: 301-310$.

38. Hinchcliffe R. The age function of hearing - aspects of the epidemiology. Acta Otolaryngol Suppl. 1991. 476:7-11. 
39. Hull RH. Hearing evaluation of the elderly. In: Katz J., editor. Handbook of Clinical Audiology. $2^{\text {nd }}$ ed. Baltimore: The Williams \& Wilkins Co.; 1978. p. $469-478$.

40. Hull RH. Atendimento ao paciente idoso. IN: Katz J., editor. Tratado de Audiologia Clínica. 1 ed. São Paulo: Manole; 1999. p. 783-791.

41. Humes LE. Considerações psicoacústicas em audiologia clínica. In: Katz J. Tratado de Audiologia Clínica. 1 ed. São Paulo: Manole; 1999. p. 56-72.

42. Humphrey $C$, Herbst KG, Faurqi S. Some characteristics of the hearingimpaired elderly who do not present themselves for rehabilitation. Br J Audiol 1981; 15: 25-30.

43. Iler $\mathrm{KL}$, Danhauer $\mathrm{JL}$, Mulac A. Peer perceptions of geriatrics wearing hearing aids. Am Speech Language-Hear Ass 1982; 47: 433-438.

44. IPEA. Fontes dos rendimentos dos idosos. São Paulo; 1998. Disponível em: <URL: http://www.ipea.gov.br>.

45. Jacob Filho W. Relatório da prática em evolução do Grupo de Assistência ao Idoso Ambulatorial. São Paulo: GAMIA/HC-FMUSP, 1991. 
46. Jacomb PA, Jorm AF, Korten AE, Christensen $H$, Henderson AS. Predictors of refusal to participate: a longitudinal health survey of the elderly in Australia. BMC Public Health 2002; 2 (1): 4.

47. Jerger J, Chmiel R, Wilson N, Luchi R. Hearing impairment in older adults: new concepts. J Am Geriatr Soc 1995; 43: 928-935.

48. Jennings CR, Jones NS. Presbyacusis. J Laryngol Otol 2001; 115 :171178.

49. Jones DA, Victor CR, Vetter NJ. Hearing difficulty and its psychological implications for the elderly. J Epidemiol Community Health 1984; 38: 7578.

50. Johnson $\mathrm{CE}$, Danhauer JL. Attitudes toward severely hearing - impaired geriatrics with and without hearing aids. Aust J Audiol 1982; 4 (2): 41-45.

51. Johnson EW. Hearing prostheses and communication aids for the elderly. Med Instrumentation 1982; 16 (2).

52. Kacker SK. Hearing impairment in the age. Indian J Med Res 1997; 106: 333-9. 
53. Kalayam B, Meyers BS, Kakuma T, Alexopoulos GS, Young RC, Solomon et al. Age onset of geriatric depression and sensorineural hearing deficits. Biol Psychiatry 1995; 38: 649-658.

54. Kapteyn TS. Satisfaction with fitted hearing aids. I. An analyses of technical information. Scand Audiol 1977; 6: 147-156.

55. Kapteyn TS. Satisfaction with fitted hearing aids. II. An investigation into the influence of psycho-social factors. Scand Audiol 1977; 6: 171-177.

56. Katsarkas A, Ayukawa $\mathrm{H}$. Hearing loss due to aging. J Otolaryngol $1986 ; 15$ (4): 239-44.

57. Kricos PB, Lesner SA. Hearing care for older adults audiologic rehabilitation. Boston: Butterworth-Heinemann, 1995.

58. Lee FS, Mathews L, Mills JH, Dubno JR, Adkins WY. Analysis of blood chemestry and hearing levels in a sample of older persons. Ear Hear 1998; 19 (3): $180-190$.

59. Lim DP, Stephens SD. Clinical investigation of hearing loss in the elderly. Clin Otolaringol 1991; $16(3): 288-293$. 
60. Liu $X Z, X u L R$, Hu $Y$, Nance WE, Sismanis $A$, Zhang $S L, X u Y$. Epidemiological studies on hearing impairment with reference to genetic factors in Sichuan, China. Ann Otol Rhinol Laryngol 2001; 110: 356-363.

61. Lowell SH, Paparella MM. Presbycusis: what is it? Laryngoscope 1977; 87: $1710-1717$.

62. Lubinski R. Dementia and communication. California: Singular Publishing Group; 1995. Environmental considerations for elderly patients. p. 257-278.

63. Lundborg T, Risberg A, Holmqvist C, Lindström B, Svärd I. Rehabilitative procedures in sensorineural hearing loss. Studies on the routine used. Sand Audiol 1982; 11: 161-170.

64. Lutman, ME. Hearing disability in the elderly. Acta Otolaryngol Suppl. 1991. 476:239-48.

65. Lutman ME, Spencer HS. Occupational noise and demographic factors in hearing. Acta Otolaryngol Suppl 1991; 476: 74-84. 
66. Mader S. Hearing impairment in elderly persons. J Am Geriatr Soc. $1984 ; 32(7):$ 584-553.

67. Maggi S, Minicuci N, Martini A, Langlois J, Siviero P, Pavan M, Enzi G. Prevalence rates of hearing impairment and comorbid conditions in older people:the Veneto Study. J Am Geriatr Soc 1998; 46: 1069-1074.

68. Mangione CM, Seddon JM, Cook EF, Krug JH, Sahagian CR, Campion EW, Glynn RJ. Correlates of cognitive function scores in elderly outpatients. J Am Geriatr Soc 1993; 41 (5): 491-497.

69. McCartney JH, Nadler G. How to help your patient cope with hearing loss. Geriatrics 1979; March: 69-76.

70. Megighian D, Savastano M, Salvador L, Frigo A, Bolzan M. Audiometric and epidemiological analysis of elderly in the Veneto region. Gerontology 2000; 46: 199-204.

71. Mills JH, Matthews LJ, Lee FS, Dubno JR, Schulte BA, Weber PC. Genderspecific effects of drugs on hearing levels of older persons. Ann $\mathbf{N}$ Y Acad Sci $1999 ; 28$ (884): 381-388. 
72. Moscicki E, Elkins E, Baum H, McNamara P. Hearing loss in the eiderly: in epidemiologic study of the Framingham Heart Study Cohort. Ear Hear 1985; 6:184-190.

73. Nicola P. Geriatria. Porto Alegre: Luzzatto D.C.; 1986.

74. Organización Mundial de La Salud. La salud de las personas de edad. Ginebra; 1989. (Série de Informes Técnicos, 779).

75. Pannbacker M, Batchelor B, Binderim L. Speech and language screening for the audiologists. Am J Audiol 2000; 9 (2): 59-62.

76. Paschoal, SMP. Epidemiologia do envelhecimento. In: Papaléo Netto, M. Gerontologia. São Paulo: Atheneu, 1996.

77. Raina P, Torrance-Rynard V, Wong M, Woodward C. Agreement between self-reported and routinely collected health-care utilization data among seniors. Health Serv Res 2002; 37 (3): 751-74.

78. Ramos LR, Veras RP, Kalache A. Envelhecimento populacional: uma realidade brasileira. Rev Saúde Pública 1987; 21 (3): 211-224. 
79. Reuben DB, Posey E, Hays RD, Lim ME. Predictors of patient refusal to participate in ambulatory-based comprehensive geriatric assessment. J Gerontol 1994; 49 (5): M209-15.

80. Rosenhall U, Sixt $E$, Sundh V, Svanborg A. Correlations between presbyacusis and extrinsic noxious factors. Audiology 1993; 32: 234-243.

81. Rop I, Raber A, Fischer GH. Study of the hearing losses of industrial workers with occupational noise exposure, using statistical methods for the analysis of qualitative data. Audiology 1979; 18: 181-196.

82. Rupp RR. Understanding the problems of presbycusis. Geriatrics 1970; January: 100-107.

83. Russo I.C.P. Uso de próteses auditivas em idosos portadores de presbiacusia: indicação, adaptação e efetividade. São Paulo; 1988. [Tese de Doutorado - Universidade Federal de São Paulo/Escola Paulista de Medicina].

84. Russo ICP. Intervenção fonoaudiológica na terceira idade. Rio de Janeiro: Revinter; 1999. Distúrbios da audição: a presbiacusia; p. 51-82. 
85. Sacia $\mathrm{CF}$, Beck $\mathrm{CJ}$. The power of fundamental speech sounds. Bell System Tech J 1926; 5: 393-403,

86. Schoueri Júnior R, Ramos LR, Papaléo Netto M. Crescimento populacional: aspectos demográficos e sociais. In: Carvalho Filho ET, Papaléo Netto M. editores. Geriatria - Fundamentos, Clínica e Terapêutica. São Paulo: Atheneu, 1994. p. 9-29.

87. Schuknecht HF. Presbycusis. Laryngoscope 1955; 65: 402-419.

88. SEADE, Fundação Sistema Estadual de Análise de Dados. 0 idoso na Grande São Paulo. Coleção Realidade Paulista. São Paulo: SEADE, 1990.

89. Sixt E, Rosenhall U. Presbyacusis related to socioeconomic factors and state of health. Scand Audiol 1997; 26 (3): 133-40.

90. Stach B, Spretnjak M, Jerger J. The prevalence of central presbycusis in clinical population. J Am Acad Audiol 1990; 1:109-115.

91. Strawbridge WJ, Wallhagen MI, Shema SJ, Kaplan GA. Negative Consequences of hearing impairment in old age: a longitudinal analysis. Gerontologist 2000; 40 (3): 320-326. 
92. Thomas PD, Hunt WC, Garry PJ, Hood RB, Goodwin JM, Goodwin JS. Hearing acuity in a health elderly population: effects on emotional, cognitive and social status. Gerontology 1983; 38 (3): 321-325.

93. Townsend $\mathrm{TH}$, Bess FH. Effects of age and sensorineural hearing loss on word recognition. Scand Audiol 1980; 9: 245-248.

94. Van den Berg P, Prins A, Verschuure $H$, Hoes AW. Effectiveness of a single and a repeated screen for hearing loss in the elderly. Audiology 1999; 38: 339-340.

95. Ventry IM, Weinstein BE. The Hearing Handicap Inventory for the elderly: a new tool. Ear Hear 1982; 3: 128-134.

96. Verboncoeur CJ, Stewart AL, King AC, Rush S, McLellan BY, Mills K. The use of refusal postcards in recruiting older adults. Ann Behav Med 2000, 22 (4): $330-333$.

97. Yantis P.A. Avaliação dos limiares auditivos por via aérea. In: Kałz J. Tratado de Audiologia Clínica. São Paulo: Manole, 1999. p. 97-108. 
98. Weimar C, Kurth T, Kraywinkel K, Wagner M, Busse O, Haberl RL, Diener HC. Assessment of functioning and disability after ischemic stroke. Stroke 2002; 33 (8): 2053-2059.

99. Wilber LA. Calibração de tons puros, fala e ruído. In: Katz J. Tratado de Audiologia Clínica. São Paulo: Manole, 1999. p. 73-94.

100. Willott JF, Chisolm TH, Lister JJ. Modulation of presbycusis: current status and future directions. Audiol Neuro-Otol 2001; 6: 231-249.

101. World Health Organization. Physical status: The use and interpretation of anthropometry. Geneva, 1995. (WHO Technical Report Series, 854).

102. Worth A, Tierney AJ. Conducting research interviews with elderly people by telephone. J Adv Nurs 1993; 18 (7): 1077-1084.

103. Zimerman GI. Velhice. Aspectos biopsicossociais. Porto Alegre: Artes Médicas Sul; 2000. 
Anexo 1: Termo de consentimento livre e esclarecido 


\section{TERMO DE CONSENTIMENTO LIVRE E ESCLARECIDO}

Título do estudo: Fatores associados a presbiacusia em adultos e idosos. Pesquisadores responsáveis: Andréa Viude e Prof. Dr. Wilson Jacob Filho.

$\mathrm{Eu}$, serei um dos participantes deste estudo conduzido no Hospital das Clinicas da Faculdade de Medicina da Universidade de São Paulo.

Fui informado que o objetivo deste estudo é avaliar a audiçāo. Para tanto irei responder a perguntas sobre minha audiçāo, sobre alguns hábitos de vida, serei avaliado por um médico especialista em otorrinolaringologia que irá examinar minha orelha e farei um exame para medir minha capacidade auditiva chamado audiometria.

Fui informado que serāo coletados dados de meu prontuário neste hospital para auxiliar na análise dos dados.

Fui informado que nenhum dos procedimentos a serem realizados provocam dor ou são invasivos, ou seja, não sofrerei nenhum prejuízo físico.

Fui informado que a minha participação é voluntária e caso eu não queira participar em nenhum momento sofrerei prejuizos nos atendimentos que realizo neste hospital. Fui informado que posso desistir de participar a qualquer momento sem prejuizo nos atendimentos que realizo neste hospital.

Fui informado que receberei os resultados das avaliações bem como as explicações sobre os mesmos. Caso necessite de indicaçāo de aparelho auditivo serei encaminhado ao serviço competente neste hospital, no caso formado pela mesma equipe que realizará a avaliaçāo de otorrinolaringologia.

Fui informado que se tiver qualquer dúvida sobre este estudo poderei entrar em contato com Andréa Viude através do telefone 9609-4620 ou com Dr. Wilson Jacob Filho através do telefone 3069-6236.

Eu concordo em participar deste estudo,

Data:

Nome do participante:

Assinatura do participante:

Pesquisador:

Assinatura: 
Anexo 2: Protocolo sócio-demográfico e auditivo 
PROTOCOLO SÓCIO-DEMOGRÁFICO E AUDITIVO

I. IDENTIFICAÇÃO DO QUESTIONÁRIO:

1. Número do questionário

2. Entrevistador

3. Data da entrevista

$1+1$

4. Local da entrevista

II. IDENTIFICAÇÃO DO ENTREVISTADO

5. Nome:

6. Endereço atual:

Bairro:

Cidade:

Estado:

CEP:

Telefone:

Observações:

7. Registro Geral - HC:

8. Em que estado brasileiro nasceu?

9. Data de nascimento:

10. Sexo:
1. ( ) M
2. ( ) F 
III. CARACTERIZAÇÃO SÓCIO-DEMOGRÁFICA

III. I. COR

11. Observar a que predomina na aparencia:

1. ( ) branca

2. ( ) mulata/parda

3. ( ) preta/negra

4. ( ) amarela

5. ( ) outra, qual:

III.2. ESTADO MARITAL
12. I. ( ) casado (união livre ou legal)
2.( ) separado, divorciado, desquitado
3. ( ) viúvo
4. ( ) solteiro
9. ( ) não quer responder

\section{III.3. ESCOLARIDADE}
13. Até que série completa você estudou?
0. ( ) não sabe ler nem escrever
0,5. ( ) sabe ler e escrever sem ter ido à escola
1. ( ) $1^{\mathrm{a}}$ série do $1^{\circ}$ grau
2. ( ) $2^{\mathrm{a}}$ série do $1^{\circ}$ grau
3. ( ) $3^{\mathrm{a}}$ série do $1^{\circ}$ grau
4. ( ) $4^{\mathrm{a}}$ série do $1^{\circ}$ grau
5. ( ) $5^{a}$ série do $1^{\circ}$ grau
6. ( ) $6^{\mathrm{a}}$ série do $1^{\mathrm{o}}$ grau
7. ( ) $7^{\mathrm{a}}$ série do $1^{\circ}$ grau
8. ( ) $8^{\mathrm{a}}$ série do $\mathrm{l}^{\mathrm{o}}$ grau
9. ( ) $1^{\mathrm{a}}$ série do $2^{\circ}$ grau
10. ( ) $2^{\mathrm{a}}$ série do $2^{\circ}$ grau
11. ( ) $3^{\mathrm{a}}$ série do $2^{\circ}$ grau
12. ( ) universitário incompleto
13. ( ) universitário completo
98. ( ) não quer informar
99. ( ) não sabe informar 


\section{III.4. RENDA}

14. Renda atual: R\$

15. Quantas pessoas vivem desta renda?

III.5. OCUPAÇĀO

\begin{tabular}{|c|c|}
\hline 16. & Descrever todas as ocupações exercidas(por ordem temporal) e duração (em meses): \\
\hline 16.1. & $1^{a}$ ocupação: \\
\hline & duração em meses: \\
\hline 16.2 . & $2^{a}$ ocupação: _. _ _ _ _ \\
\hline & duração em meses: \\
\hline 16.3. & $3^{\mathrm{a}}$ ocupação: \\
\hline & duração em meses: \\
\hline 16.4. & $4^{\mathrm{a}}$ ocupação: \\
\hline & duração em meses: \\
\hline 16.5. & $5^{\natural}$ ocupação: \\
\hline & duraçăo em meses: \\
\hline
\end{tabular}

\section{AUDIÇÃO}

\begin{tabular}{|c|c|c|c|}
\hline \multirow[t]{2}{*}{17.} & \multicolumn{3}{|c|}{ Ouve bem na conversa frente a frente? } \\
\hline & $0 .($ ) não & 1. ( ) às vezes & 2. ( ) $\operatorname{sim}$ \\
\hline \multirow[t]{2}{*}{18.} & \multicolumn{3}{|c|}{ Ouve bem em ambientes ruidosos? } \\
\hline & 0. ( ) não & 1. ( ) às vezes & 2. ( ) $\operatorname{sim}$ \\
\hline \multirow[t]{2}{*}{19.} & \multicolumn{3}{|c|}{ Ouve bem quando a pessoa com quem está conversando não está a sua frente? } \\
\hline & $0 .($ ) não & 1. ( ) às vezes & 2. ( ) $\operatorname{sim}$ \\
\hline \multirow[t]{2}{*}{20.} & \multicolumn{3}{|c|}{ Ouve bem em ambientes silenciosos? } \\
\hline & $0 .($ ) não & 1. ( ) às vezes & 2. ( ) $\operatorname{sim}$ \\
\hline \multirow[t]{2}{*}{21.} & \multicolumn{3}{|c|}{ Precisa ver a face da pessoa com quem está conversando? } \\
\hline & $0 .($ ) não & 1. ( ) às vezes & 2. ( ) $\operatorname{sim}$ \\
\hline \multirow[t]{2}{*}{22.} & \multicolumn{3}{|c|}{ Precisa pedir para os outros repetirem o que falaram? } \\
\hline & $0 .($ ) não & 1. ( ) às vezes & 2. ( ) $\operatorname{sim}$ \\
\hline \multirow[t]{2}{*}{23.} & \multicolumn{3}{|c|}{ Sua familia acha que o Sr.(a) ouve bem? } \\
\hline & 0. ( ) não & 2. ( ) $\operatorname{sim}$ & \\
\hline \multirow[t]{2}{*}{24.} & \multicolumn{3}{|c|}{ Tem dificuldades para ouvir quando alguém está sussurrando? } \\
\hline & $0 .($ ) não & 1. ( ) às vezes & 2. ( ) $\operatorname{sim}$ \\
\hline
\end{tabular}




\begin{tabular}{|c|c|c|}
\hline \multirow[t]{2}{*}{25.} & \multicolumn{2}{|l|}{ Ouve bem a televisào? } \\
\hline & $0 .($ ) não & 2. ( ) $\operatorname{sim}$ \\
\hline \multirow[t]{2}{*}{26.} & \multicolumn{2}{|l|}{ Ouve bem ao telefone? } \\
\hline & 0. ( ) não & 2. ( ) $\operatorname{sim}$ \\
\hline \multirow[t]{2}{*}{27.} & \multicolumn{2}{|l|}{ Ouve bem o rádio? } \\
\hline & 0. ( ) não & 2. ( ) $\operatorname{sim}$ \\
\hline \multirow[t]{2}{*}{28.} & \multicolumn{2}{|c|}{ Alguém já reclamou que o $\mathrm{Sr}$.(a) estava com o volume da televisão muito alto? } \\
\hline & 0. ( ) não & 2. ( ) $\operatorname{sim}$ \\
\hline \multirow[t]{2}{*}{29.} & \multicolumn{2}{|c|}{ Seus amigos acham que o Sr.(a) ouve bem? } \\
\hline & 0. ( ) não & 2. ( ) $\operatorname{sim}$ \\
\hline \multirow[t]{2}{*}{30.} & \multicolumn{2}{|c|}{ Sua audição mudou com a idade? } \\
\hline & 0. ( ) não & 2. ( ) sim pior ( ) melhor ( ) \\
\hline \multirow[t]{2}{*}{31.} & \multicolumn{2}{|c|}{ Alguém já disse para o senhor fazer um exame da audiçăo? } \\
\hline & $0 .($ ) não & 2. ( ) $\operatorname{sim}$ \\
\hline \multirow[t]{2}{*}{32.} & \multicolumn{2}{|c|}{ Sente dificuldade para entender o que as pessoas falam? } \\
\hline & $0 .($ ) não & 1. ( ) às vezes $\quad 2 .() \operatorname{sim}$ \\
\hline \multirow[t]{2}{*}{33.} & \multicolumn{2}{|c|}{ Já pensou em fazer um exame da audiçăo? } \\
\hline & 0. ( ) não & 2. ( ) $\operatorname{sim}$ \\
\hline \multirow[t]{2}{*}{34.} & \multicolumn{2}{|c|}{ Deixou alguma vez de fazer uma atividade por causa da audição? } \\
\hline & 0. ( ) não & $2 .() \operatorname{sim}$ \\
\hline \multirow[t]{2}{*}{35} & \multicolumn{2}{|c|}{ Já fez exame da audição? } \\
\hline & $0 .($ ) não & 2. ( ) $\operatorname{sim}$ \\
\hline
\end{tabular}


Anexo 3: Protocolo de avaliação clínica em Geriatria e de saúde. 
Protocolo de avaliação médica e de saúde

Nome:

DN:

$\mathrm{RG}-\mathrm{HC}$ :

1. Medicamentos utilizados:

2. Peso:

( Kg)

3. Altura:

$\mathrm{m}$

4. IMC:

5. Exame de sangue:

$\mathrm{Na}$ :

uréia:

creatinina:

eritrócitos:

hematócritos:

colesterol total:

LDL:
$\mathrm{K}$ :

triglicérides:

glicose:

HgB:

plaquetas:

6. Hábito de fumar:

Fuma atualmente: ( ) não ( ) sim

Se sim:

há quanto tempo fuma? anos

Quantos cigarros por dia?

Se não:

Já fumou?

( ) não 
( ) sim, por quanto tempo fumou?

há quanto tempo parou?

Convive com alguém que fuma?

( ) não

( ) sim, quem? por quanto tempo? anos

Conviveu com alguém que fumava?

( ) não

( ) sim, quem? por quanto tempo? anos

\section{Hábito de beber:}

Faz uso de bebida alcoólica? ( ) não ( ) sim, que tipo?

Se sim:

O que bebe?

Quantas vezes por semana:

Quantidade que bebe em um dia:

8. Come carne vermelha?

( ) não

( ) sim 
Anexo 4: Protocolo de pedido de consulta e encaminhamento do HC-FMUSP. 
Hospital das Clínicas da FMUSP

Pedido de consulta

Encaminhamento

À Clinica

Tipo de atendimento solicitado:

\section{- Pedido de consulta}

O relatório é necessário para prosseguir 0 atendimento na clínica de origem.

O paciente deverá retornar com este formulário preenchido na próxima consulta na unidade solicitante.

A marcação da consulta será efetuada na clínica solicitada.
Paciente:

Idade:

RGHC:

\section{Marcação da consulta}

(uso da Clinica ou Registro Geral)

- Encaminhamento

O relatório não é necessário para prosseguir 0 atendimento na clínica de origem.

$O$ atendimento na clinica solicitada será independente do atendimento na clinica de origem.

A marcação da consulta será efetuada no Registro Geral.
Data/Horário

\section{Diagnósticos atuais:}

\section{Justificativa:}

Assinatura

\begin{tabular}{|c|c|}
\hline Clínica/Unidade & Data/Horário \\
\hline \\
Assinatura
\end{tabular}

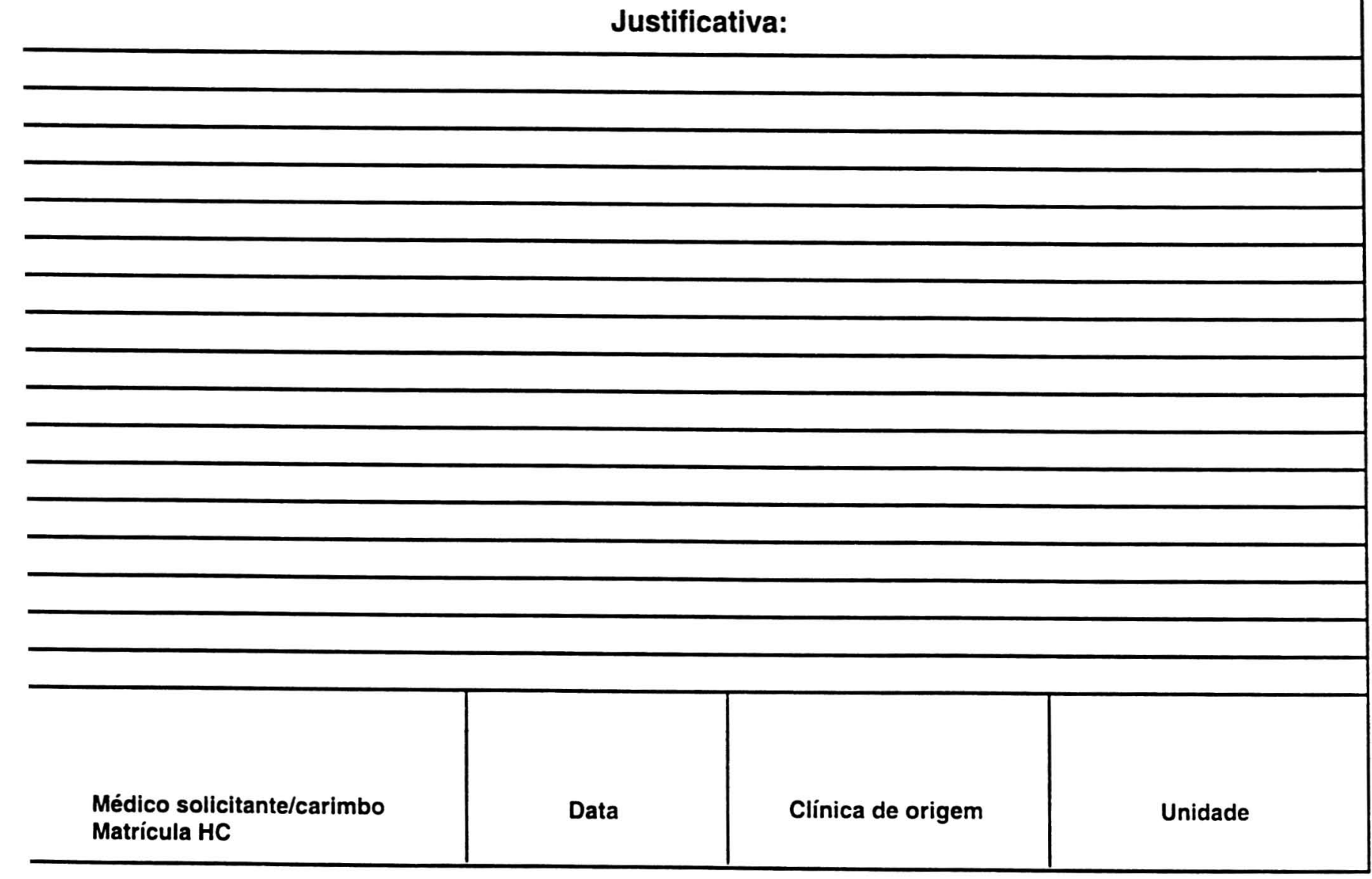

As solicitaçōes deverão estar assinadas, datadas e carimbadas pelo médico assistente. Solicitações não fundamentadas, ilegíveis, incompletas ou inadequadas serão devolvidas. 
Providências adicionais:

$\square$ Agendar na unidade desta clínica.

$\square$ em vaga de consulta de retorno.

$\square$ extra no dia __de __de 199__às__hs.

$\square$ só se houver vaga de consultas novas no Registro Geral.

$\square$ Não agendar. Outras orientações:

Médico consultor/carimbo

\section{Data}

\section{Elaborar nova solicitação:}

$\square$ Dados incompletos.

$\square$ llegivel ou siglas ininteligiveis.

$\square$ Não é caso de pedido de consulta.

Emitir pedido de encaminhamento. 
Anexo 5: Protocolo de avaliação otorrinolaringológica. 


\section{ANAMNESE AUDIOLÓGICA DIRIGIDA}

Empresa

Nome

Idade Data de Nasc.: _L

Data:

RG

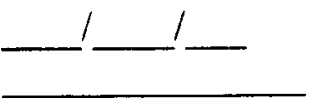

QUEIXA DURAÇÃO anos mese

Início : idade modo : súbito () progressivo ()

Flutuacão da audicão: $\operatorname{sim}($ ) Não ( )

Associacão com outras causas ( traumas, doencas ,etc )

Discriminacão : escuta $\operatorname{sim}($ ) não( ) entende $\operatorname{sim}()$ não ( )

Audição é : Normal

OD OE

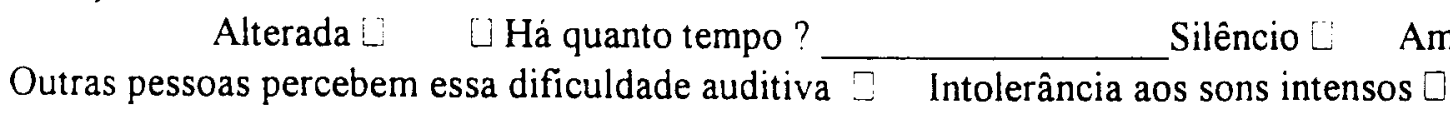

Dificuldade para entende as pessoas $\square$ Quando?

Dificuldade na localização da fonte sonora $\square$ Má percepção de sinais e avisos $\square$

Alguém na familia tem problema no ouvido?

Tem ou teve :

OD OE

Otorréia
Zumbido
Otalgia
Traumatismo de ouvido
Mal cheiro no ouvido
Trauma acústico
Cirurgia de ouvido

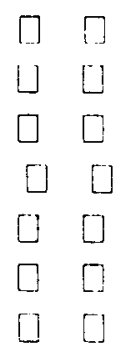

$\square$ Tonturas

[ Náuseas

$\square$ Irritabilidade

[] Cefaléia

[ T Traumatismo de crânio

$\square$ Traumatismo de coluna cervical

Antecedentes Mórbidos

Faz ou fez uso constante dos medicamentos

Diabetes

Hipertensão arterial

Tuberculose

Caxumba

Sarampo

Meningite

$\square$ Sífilis

- Aspirina $\square$ Diuréticos

[] Antibióticos

1] Drogas

$\square$ Etilista Social

Fumante: $\square \mathrm{S} \square \mathrm{N} \square \mathrm{EX}$

Há quanto tempo?

Exposição à ruído no trabalho? $\square \mathrm{S} \square \mathrm{N}$

$\square$ Alteração do humor $\square$ Alteração do sono

$\square$ Mudança de comportamento

Problemas de Tireóide

Problemas Renais

$\square$ Diminuição da concentração

O Outros 


\section{EXAME FÍSICO}

OTOSCOPIA

C. A . E .:Normal

Rolha de cera

Exostose

Descamação

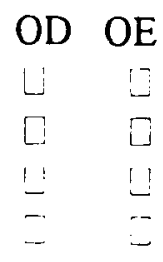

M.T.: Normal

Opaca

Retraída

Calcificação

Perfuração

Exuldato purulenta

RINOSCOPIA

$\square$ Normal

Mucosa descorada

Hipertrofia de cornetos

L Desvio do Septo nasal anterior

OROSCOPIA : $\quad \square$ Normal

? Alterada

EXAME AUDIOMÉTRICO

CONCLUSÕES

TRATAMENTO

MÉDICO 
Anexo 6: Protocolo de avaliação audiológica 


\section{Considerações sobre o protocolo de avaliação audiológica}

O protocolo de avaliação audiológica, disponível na próxima página, foi utilizado neste estudo da forma que se apresenta por tratar-se da folha de registro do local onde os exames audiométricos foram realizados. Convém salientar que algumas modificações quanto a apresentação gráfica do audiograma bem como quanto a nomenclatura anatômica necessitam de correção.

No audiograma a abreviatura "hz" deve ser lida como $\mathbf{H z}$. Onde se lê "ouvido direito" leia-se orelha direita, onde se lê "ouvido esquerdo" leia-se orelha esquerda. Onde se observa a abreviatura "DV" deve-se ler IRF. Os responsáveis pela confecção dessa folha de registro foram comunicados sobre as mudanças necessárias. 
AUDIBEL PHILIPS APARELHOS AUDITIVOS

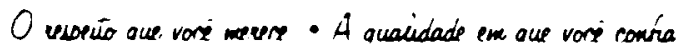

CENTROAUDITIVOAUDIBEL IMP. EXP.

RUA GAHAO OE ITAPETINIVGA ŻZI. I ANDA

ENTRO LEP M:OA2.001 JAOPAULO. S FONE 259.6077 FAX 259.1577

P.UA PAIS DE ARAUJO.293. ANDAR - CEP OA531 ITAIM BIBI-TEL 821.9842

\section{AVALIACAOAODIOLOGICA}

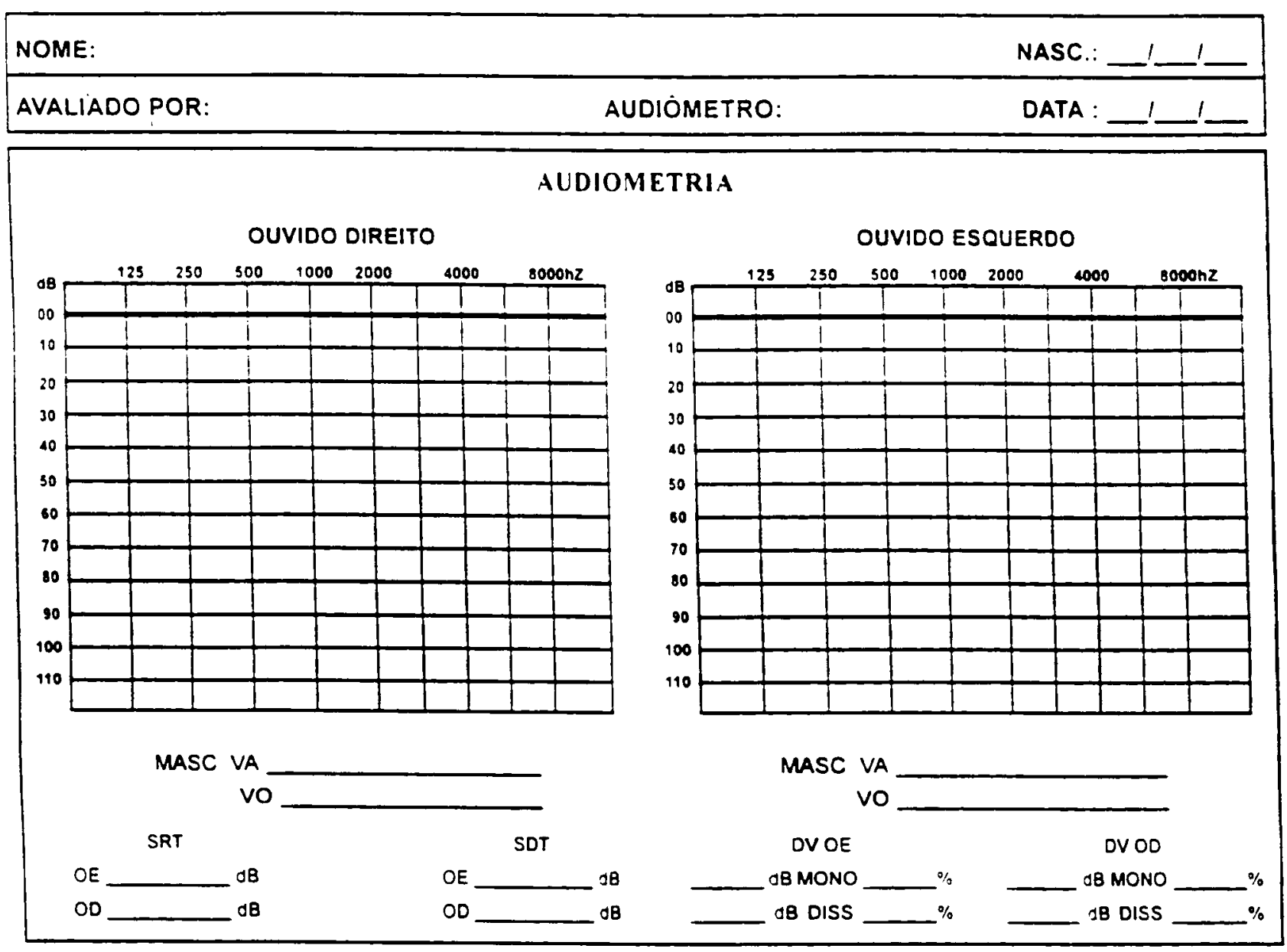


Anexo 7: Termo de aprovação do Comitê de Ética em Pesquisa. 


\section{UNIVERSIDADE DE SÃO PAULO \\ FACULDADE DE SAÚDE PÚBLICA \\ COMITÉ DE ÉTICA EM PESQUISA-COEP \\ Av. Dr. Arnaldo, 715 - sala 18 - sub-solo - Cerquesra cesar \\ Sào Paulo-sP CEP: 01246-904 \\ Telefone (0xx11) 3066-7776 - e-gari: mogracaseusp.br}

Of. $\operatorname{COEP} / 172 / 00$

22 de novembro de 2000

Pelo presente, informo que o Comitê de Ética em Pesquisa da Faculdade de Saúde Pública da Universidade de São Paulo-COEP. analisou e aprovou "adreferendum", de acordo com os requisitos da Resolução CNS/196/96, o protocolo de Pesquisa n. 376, intitulado: "FATORES ASSOCIADOS A PRESBIACUSIA EM ADULTOS E IDOSOS”, apresentado pela pesquisadora Andréa Viude.

Atenciosamente,

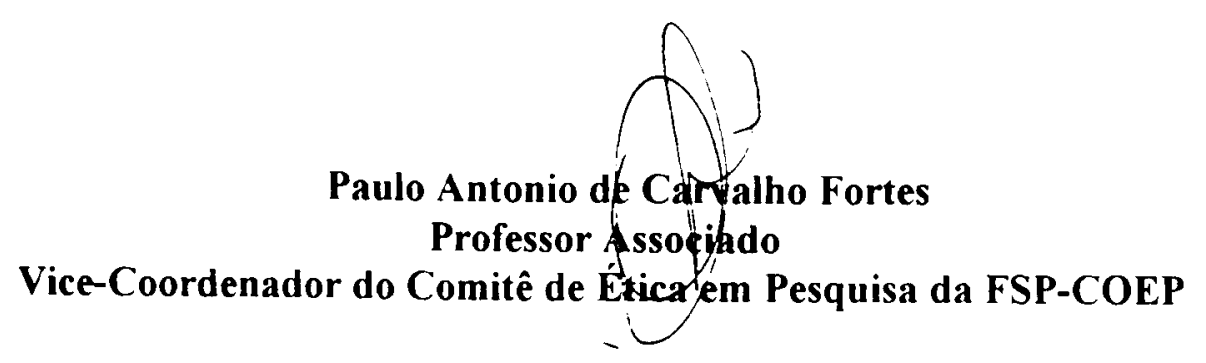

